


\section{Estudios de}

Competitividad 
(c) $\bigoplus_{\mathrm{BY}} \bigoplus_{\mathrm{NC}}$

Esta obra está bajo una Licencia Creative Commons

Reconocimiento-NoComercial 4.0 Internacional.

https://creativecommons.org/licenses/by-nc/4.0/deed.es

Coordinado por los miembros

del Cuerpo Académico de Innovación y Competitividad de la Universidad de Sonora 


\title{
Estudios de \\ Competitividad
}

\author{
Amado Olivares Leal \\ Josefina Ochoa Ruiz \\ José Angel Coronado Quintana
}

(COORDINADORES)

Qartuppi. 
Estudios de Competitividad

1era. edición, noviembre 2015

ISBN 978-607-96359-3-0

DOI 10.29410/QTP.15.02

D.R. @ 2015. Qartuppi, S. de R.L. de C.V. Calle Real 63, Col. Villa Satélite Hermosillo, Son. 83200 México http://www.qartuppi.com

Edición: Qartuppi, S. de R.L. de C.V. Corrección de Estilo: Adriana Colón Martínez Diseño de Portada: León Felipe Irigoyen Morales 


\section{Contenido}

$9 \quad$ Presentación

11 Capítulo 1

Neuromarketing en el consumo de productos masivos

en tiendas de barrio, en Malambo, Atlántico, Colombia

Pabla Peralta Miranda, Viviana Cervantes Atía y Heidy Rico Fontalvo

25 Capítulo 2

Factores determinantes del índice de competitividad empresarial

en el estado de Sonora, México

Amado Olivares Leal, José Ángel Coronado Quintana,

Francisco Espinoza Morales y María Guadalupe Torres Figueroa

42 Capítulo 3

Factores de competitividad de empresas sociales:

La competitividad en las organizaciones

Leonardo Vázquez Rueda, Blanca Isela Ramírez

y Concepción Suástegui Barrera

$57 \quad$ Capítulo 4

Factores estratégicos en la adopción de la gestión del conocimiento en las pequeñas y medianas empresas

Josefina Ochoa Ruiz, Amado Olivares Leal y María Leticia Verdugo Tapia 
73 Capítulo 5

La sucesión de las empresas familiares en las empacadoras

de frutas y derivados en Tecomán, Colima, México

Hugo Martín Moreno Zacarías, Roberto Espíritu Olmos

y Alejandro Rodríguez Vázquez

91 Capítulo 6

La gestión de la cadena de valor del talento humano como ventaja competitiva.

Organización, Administración y Recursos Humanos

Martha Lucía Moya y Juan Carlos Mancilla

111 Capítulo 7

Las bolsas de valores más competitivas en el 2014

José M. Güereña de la Llata, Maria Leticia Verdugo Tapia

y Luis Fernando Güereña de la Llata

123 Capítulo 8

Análisis del consumidor hacia la compra de tortillas de maíz

en Santa Ana, Sonora, México

Brenda Elizabeth Durón González, Elsa Armida Ortega Verdugo

y Josué Castillo Muñoz

133 Capítulo 9

La gestión financiera en las PyMES yucatecas de la industria textil Martha Isabel Bojórquez Zapata y Antonio Emmanuel Pérez Brito 


\section{Presentación}

Este libro es el resultado de los trabajos presentados por los miembros de la Red de Líderes Investigadores de Innovación, Competitividad y Estudios Organizacionales (Red LIICEO), en el marco del V Encuentro Internacional de Cuerpos Académicos.

En esta obra participaron investigadores de universidades nacionales e internacionales, como la Universidad Autónoma de Sinaloa, Universidad de Colima, Universidad Autónoma de Yucatán, Fundación Universitaria para el Desarrollo Humano UNINPAHU (Bogotá, Colombia), Universidad Simón Bolívar (Barranquilla, Colombia) y la Universidad de Sonora, quienes abordaron temas referentes al marco contextual de la empresa, vinculadas con la generación de ventajas competitivas.

En conjunto, Estudios de Competitividad es un esfuerzo para asegurar que los capítulos que la componen impacten positivamente, transmitiendo las ideas y análisis de los académicos participantes. Se espera que esta obra logre entrar con éxito al razonamiento de la Competitividad Empresarial y sobre esta base pueda usted edificar sus conocimientos futuros.

Téngase pues a bien promover y difundir con total apertura esta publicación y sirvan estos comentarios como agradecimiento a los diferentes autores por su confianza y colaboración en este esfuerzo editorial.

Hermosillo, Sonora. Noviembre 2015

Dr. Amado Olivares Leal Líder CA-185-UNISON Representante Red LIICEO 


\title{
Capítulo 1
}

\author{
Neuromarketing en el consumo de productos masivos en tiendas \\ de barrio, en Malambo, Atlántico, Colombia \\ Pabla Peralta Miranda, Viviana Cervantes Atía y Heidy Rico Fontalvo
}

\section{Introducción}

El municipio de Malambo pertenece a la zona metropolitana de Barranquilla, Colombia, el cual cuenta con 119, 289 habitantes, según el censo proyectado por el DANE (2005 - 2020). En los últimos años, ha entrado en etapa de industrialización, ya que cuenta con tres parques industriales de aproximadamente unas 500 empresas. Está ubicado geográficamente sobre el margen oriental del río Magdalena. De acuerdo a la observación directa realizada por los investigadores, se confirma la existencia de supermercados de cadenas, y lógicamente tiendas de barrios, en un promedio de una tienda por cinco cuadras.

El negocio de tienda de barrios es una organización constituida en su mayor parte por propietarios oriundos del interior del país. El espacio ocupado por estos negocios está entre los $5 \mathrm{~m}^{2}$. Estas unidades están encargadas de distribuir productos fraccionados y por unidad de consumo masivo teniendo en cuenta las marcas reconocidas de acuerdo a los intereses del cliente. Entre las características más sobresalientes de este tipo de organizaciones está la facilidad de créditos blandos orientados al consumidor, aspecto que favorece la decisión de compra y satisfacción del mismo, ya que en un mismo lugar logran adquirir las marcas de su preferencia de manera fácil con créditos basados en la confianza y el valor de la palabra.

Los cambios en los nuevos estilos de vida de los consumidores fundamentados en las prácticas modernas ha propiciado la relación entre los productos y el consumidor. Hoy es común encontrarse que las personas, grupos o entidades toman la decisión de compra que satisfagan sus necesidades y expectativas enfatizando como prioridad sus experiencias emocionales, la conciencia y motivaciones internas que impulsan su interés hacia determinados productos y el rechazo hacia otros -sin dejar de lado, naturalmente, los estímulos externos 
producidos por la publicidad y promoción de los productos, la cercanía de los establecimientos, las características del producto ya sea el empaque, la marca y un elemento determinante como es el precio.

Ante estos nuevos retos, relacionados con el comportamiento de compra del consumidor, las diferentes disciplinas de las ciencias económicas, la neurociencia y la biología se han dado a la tarea de explicar las acciones deterministas y los comportamientos impredecibles tanto individuales como colectivos, productos de la interacción de la mente humana con las emociones, de ahí que hoy se mencione el término de neuromarketing, en el cual se enfoca la temática de este artículo.

Es evidente que al igual que en otros sectores de consumo, las tiendas de barrio se ven afectadas por los cambios en los comportamientos del consumidor; un ejemplo es el de los niños que en calidad de consumidores en las tiendas de barrio toman decisiones en productos en cuanto a gustos y preferencias de acuerdo a su edad e intereses. Igualmente ocurre con el consumidor adulto. Cabe señalar que hoy los adultos adquieren los productos teniendo en cuenta aspectos relacionados con la salud, dato que se evidencia en la solicitud de productos life, té helado, nuevos sabores en yogur, bebidas refrescantes, caldo, entre otros; decisiones que se toman por la influencia del entorno, la publicidad, la comunicación y el merchandising, los cuales han permitido que los productos o marcas se posicionen en la mente del consumidor, y por ende ha facilitado su decisión de compra.

\section{Planteamiento del problema}

Uno de los graves problemas sería si el cliente de las tiendas no regresara a comprar, lo cual provocaría que el negocio no fuera competitivo en la distribución de productos masivos. Sin embargo, en la actualidad ocurre todo lo contrario: un consumidor visita la tienda hasta tres veces al día, y lleva en su mente, los productos y las marcas que va adquirir. Esto se debe al gran esfuerzo de marketing que hacen sus proveedores para mantener a los consumidores a través de las estrategias de comunicación y el análisis del comportamientos de las ventas. El modelo de negocio de tiendas de barrios no invierte en campañas publicitarias, mucho menos en marketing relacional -lo afirman el cien por ciento de sus propietarios- pero es un puente como distribuidor, entre sus proveedores y los consumidores, que a través de sus sentidos captan esas campañas publicitarias, con despliegue de productos nuevos, con valores agregados, si el consumidor, afirma Cisneros, (2012) es un ser emocional. Entonces, surge la pregunta: ¿Cómo se aplica el neuromarketing, en el consumo de los productos masivos en las tiendas de barrio, en Malambo, Atlántico, Colombia? 


\section{Revisión teórica}

En el marketing juega un papel importante la investigación y el análisis del comportamiento en el consumidor, para lo cual se utilizan herramientas de alta tecnología, como la cámara Gesell, polígrafo, contadores, software, e incluso laboratorio de neuromarketing, entre otros. Lógicamente se apoya en las ciencias como la neurociencia que permite medir las respuestas de los consumidores producida en cerebro humano al percibir un anuncio de marcas que provoque o impulse la decisión de compra. Este tipo de investigación lo realizan grandes empresas de productos de consumo masivo como: gaseosas, cervezas, cigarrillos, aceites, arroces, caldos, avena, yogur, gelatinas, mecatos, entre otros, los cuales son proveedores de las tiendas de barrios.

Sin embargo, parece contradictorio que siendo los propietarios de los negocios de tienda de barrio de Malambo renuentes a la innovación y a las tecnologías, este sea un punto donde se pueda medir el neuromarketing. Esto se debe a el cerebro del consumidor, tiene acumulada un información previa a la decisión de compra, obtenida a través de la información comercial, como producto del esfuerzo de marketing (inversión), de los proveedores y comercializadores, cuyo índice lo calculan por el volumen de sus ventas de los productos de consumo masivo.

No obstante, en este estudio se refleja cómo influye la comunicación dirigida al mercado de consumo, a través de los diferentes tipos de publicidad: racional, a través de argumentaciones lógicas donde prima la razón; emocional, con una carga de psicología en el uso del producto; la satisfacción del mismo, como la moda y los estilos de vida; por último, la publicidad subliminal, un estímulo débil, que es percibido conscientemente (García, 2011). Por lo tanto estos tipos de mensajes publicitarios son captados por la actividad cerebral de los consumidores, los cuales son medibles a través de técnicas de investigación de mercados como grupos focales, entrevistas, encuestas, pruebas proyectivas, entre otras.

Cabe destacar, que los mensajes publicitarios influyen en los actores involucrados en el estudio. Fue muy común observar que a los consumidores les atraen las promociones como "paga uno y lleva dos", en un envase más líquido por el mismo precio, "la tapa paga" en bebidas refrescantes, obsequios de productos complementarios (en bandejas, vasos, platos), premios sorpresas de productos masivos, entre otros. Esto motiva a los consumidores a comprar, lógicamente a través de conexiones publicitarias.

Asimismo, Andreu-Sánchez, Contreras-Gracia y Martín-Pascual (2014) afirman que en España el neuromarketing es una área de conocimiento reciente en donde se utilizan técnicas y de las neurociencias, y a través de esta ciencia se investiga cómo se puede mejorar el marketing y la comunicación publicitaria (p. 152). En Colombia, exactamente en el departamento Atlántico, 
existen muy pocos estudios en relación a este tema. Los autores (Smidts, 2002; Braidot, 2013; Lee, et al., 2007; Humbert; Kenning, 2008; Randall, 2009 y Pradeep, 2010) citados por AndreuSánchez et al., (2014), coinciden en que el neuromarketing estudia el comportamiento del cerebro utilizando técnicas y métodos de investigación neurocientífica, con el propósito de implementar o mejorar las estrategias de marketing.

De la misma forma, el término de marketing masivo se refiere a la "producción, distribución, y la promoción del mismo producto de la misma manera a todos los consumidores" (Kotler y Armstrong, 2002, p. 237). Y precisamente las tiendas de barrio de alimentos y abarrotes son un canal tradicional para la distribución de productos masivos. En este modelo de negocio el marketing masivo se aplica desde la óptica del propietario del negocio, donde compran a grandes cantidades, para vender al detalle o producto fraccionado, buscando mercados potenciales para aumentar el número de clientes o consumidores, con un enfoque de micro marketing, adaptando los productos a los gustos y preferencias, combinándolos con marketing local. Según Kotler y Armstrong (2002) es la adaptación de las marcas y promociones a las necesidades y deseos de los consumidores involucrados en este artículo, donde también influye el marketing individual en los gustos y preferencias personales.

Existe una contradicción en la aplicación del neuromarketing en las tiendas de barrios de Malambo, específicamente en las marcas posicionadas en la mente del consumidor, en tanto se mantienen los atributos de la marca que le permiten comparar los diferentes productos de consumo masivo, donde influye la variable precio, la cual el consumidor prefiere, pero tiene la limitante del costo, dado que no tiene la capacidad económica para adquirirlo, estando las tiendas ubicadas en los estratos uno y dos, donde los ingresos de los consumidores se les considera en un promedio de hasta dos salarios mínimos legales, en Colombia.

Al mismo tiempo, "la publicidad emocional aporta una carga psicológica en el contenido de su mensaje. Este tipo de publicidad suele hacer hincapié en los resultados del uso del producto y en la satisfacción que el consumidor obtendrá con él" (García-Uceda, 2011, p. 82). Por lo tanto, siempre le gusta estar actualizado e informándose de los cambios en el mercado en cuanto a sus atributos y la comercialización del mismo. Es así como se identifican las características del consumidor, tales como estado de ánimo, experto, experiencias, presión de tiempo, aversión al extremismo, experiencias meta cognitivas, entre otras.

Tubert (2000) señala que Sigmund Freud, planteó que la personalidad se divide en tres fases: inconsciente, preconsciente y el consciente que busca la satisfacción del ego a través de fuerzas internas. El inconsciente reserva impulsos primitivos y sexuales; el preconsciente es un intermedio con poder de decisión si el impulso llega a la zona consciente, mientras que el consciente es capaz de recibir información tanto del mundo externo y el inconsciente. 
Enlazando la teoría del psicoanálisis con el neuromarketing en los consumidores de las tiendas de barrios en Malambo, se observa cómo influyen en la toma de decisión de compra los medios masivos como la televisión, el periódico, la radio, el internet, en los diferentes grupos sociales (niño, jóvenes, adultos, adulto mayor) y los impulsa a comprar las diferentes marcas de productos masivos, incluso con mensajes subliminales que infiltran imágenes de un producto entre los fotogramas en milésimas de segundos, igualmente con publicidad engañosa, al mostrar características positivas del producto de las cuales carecen, o la contra publicidad, donde una marca reconocida afirma que es la mejor del mercado.

La teoría de aprendizaje, expuesta por Petróvich (1849-1936), citado por Schiffman y Lazar (2005), también corresponde a la conducta, la cual sostiene que el consume se repite por los estímulos de la publicidad, fácil de asociar, compras por repeticiones, lugares agradables y memorables, los cuales son el resultado del conocimiento a través de un proceso de información en su memoria, donde se involucra la motivación, señales como la orientación al consumidor, los impulsos de compras, y la respuesta de esas acciones con esfuerzo.

Por esta razón, es pertinente explicar el aprendizaje clásico, condicionado quien Pavlov, citado por Shiffman y Lazar Kanuk (2013), lo identifica con los estímulos y su respuesta el sujeto pasivo y la repetición de las acciones, lo clasificó Observacional, no recibe recompensa, evita acciones negativas para no sufrir castigo. La interactuación de la publicidad y el consumidor, es muy interesante, para aplicar métrica de lo que percibe, ya que es un proceso de aprendizaje que cambia y evoluciona, tanto en conocimiento, como en experiencias, donde se hace necesario una auto retroalimentación.

Teniendo en cuenta la anterior teoría, resulta una contradicción porque los consumidores no compran si no tienen la información de los productos ofertados. Incluso en Colombia, la ley 1480, de octubre del 2011, de Protección al consumidor, en su Art. 23 relacionado con la información mínima y responsabilidad de la información indica que está debe ser veraz, clara, suficiente oportuna, verificable, compresible, precisa e idónea. Por lo tanto, es impredecible este aprendizaje el cual puede ser: accidental o intencional -donde juega un papel importante la motivación- en masa o concentrado, y de observación.

La teoría sociopsicológica, citada por Schiffman y Lazar Kanuk (2005), actúa por los grupos de referencia influencia (moda), satisfacción de las necesidades en forma inconsciente. Destaca la aceptación que logra el consumidor de las tiendas de barrios, a través de procesos cognitivos o mentales del procesamiento de la información recibida a través de la publicidad de los productos de consumo masivos, la cual almacena, retiene y recupera. Un aprendizaje cognitivo cuando se procesa una información y se toma la decisión de compra para resolver un problema, y lo repite en varias oportunidades, hasta llegar a la fidelización. 
Realmente comprender la motivación de los consumidores en los procesos de toma de decisiones, información y comportamiento de compra y consumo se ha convertido en un aspecto estratégico para los responsables de marketing de las empresas, ya que les permite diseñar planes de comunicación de marcas y productos encaminados a posicionar su oferta a los intereses personales del consumidor, teniendo en cuenta aquello con lo cual se involucra mayormente y por lo que se siente emocionalmente vinculado.

\section{Metodología \\ Diseño}

La investigación tuvo un enfoque cuantitativo, debido a la medición de las variables: tiendas de barrios, neuromarketing, clientes y consumidores, marca. En relación a esto, Gómez afirma que este método "utiliza la recolección y el análisis de datos para contestar preguntas de investigación y probar hipótesis establecidas previamente, y confía en la medición numérica [...] para intentar establecer con exactitud patrones en una población" (2006. p. 60). El método utilizado fue el descriptivo, que "busca cuantificar los datos y, en general, aplicar algunas formas de análisis estadístico" (Malhotra, p. 137). De esta manera se describe la realidad que actualmente se presenta en el entorno y la relación con las variables estudiadas, e igualmente la hipótesis, como la define Gómez (2006), son supuestos donde se involucran las variables, para apoyar el conocimiento organizado. En esta investigación se plantea la hipótesis siguiente: Los clientes de este tipo de negocios están informados de las características de los productos, y son conscientes de las sensaciones que les produce en la decisión de compra.

Por lo anteriormente descrito, el estudio enfocado en la praxis busca los significados de las experiencias que tienen los consumidores en las tiendas de barrios para interpretar sus decisiones de compras, y en consecuencias los procesos y la influencia del neuromarketing, identificada también como "Neurobiología del desarrollo, que es la disciplina que analiza las particularidades, experiencias en el aprendizaje de los seres vivos a través de su ciclo de vida" (Braidot, 2013), además en la forma como perciben los mensajes publicitarios de las diferentes marcas de productos masivos, recogidos en testimonios de los consumidores y clientes, segmentado en forma demográfica, para la valoración de los acontecimientos en el escenario de este tipo de estudio, que se van transformando a través de los tiempos.

Se aplicó una encuesta con preguntas cerradas a 90 consumidores que frecuentan las tiendas de barrios, los cuales fueron seleccionados en forma aleatoria, teniendo en cuenta lo expuesto por Yuni y Urbano (2006), con respecto a la confiabilidad de un instrumento donde los datos son objeto de medición y cuyas propiedades son la exactitud, medición y registro; los cuales serán confiables en la medida que los datos sean reales, en relación a las variables 
medidas, en este estudio fundamentado las experiencias. Igualmente se aplicó una lista de cheque, que permitió apreciar la toma de decisión de compra de los consumidores, a través de los números de visitas y los productos masivos comprados en los puntos objetos de estudios.

La población objeto de estudio fueron los negocios de tiendas de barrios del municipio de Malambo. La muestra se tomó en forma aleatoria, que -de acuerdo a Fernández (2004) - consiste en "seleccionar unidades muéstrales, basado en el criterio del investigador [...]" (p. 154). Se enfocó la investigación en 90 consumidores, entre 15 y 60 años de edad, residentes de seis barrios del municipio de Malambo, entre estos San Jorge, Bellavista, Concorde, Centro, la Popa, la Magdalena y el Carmen, en los estratos 1, 2, y 3; con esta muestra se logró estudiar los procesos de conducta y la toma de decisiones, a través del marketing inteligente, enfocados a las comunicaciones comerciales, el branding, post targeting, los canales de distribución y las ventas, partiendo desde los conocimientos previos y las experiencias de los consumidores.

\section{Resultados}

Los resultados se presentan de manera descriptiva y se muestra la aplicación del neuromarketing en el consumo de los productos masivos en las tiendas de barrio, en Malambo, (Atlántico-Colombia). El 98\% de los consumidores seleccionados en forma aleatoria decide la compra de sus productos porque tiene un aprendizaje previo y está informado de las características de los productos, los cuales consume en el día a día. Por su parte, el $99 \%$ identifica las marcas a través de publicidad transmitida en internet, televisión, y radio, y se muestran muy atentos a las promociones, especialmente en aquellos negocios que son aliados estratégicos de las tiendas de barrio, para aprovechar los productos de marca propia.

Del mismo modo, el $86 \%$ de los habitantes de los barrios involucrados en esta investigación visita las tiendas de barrios por lo menos tres veces, al día. Asimismo, los consumidores no seleccionan sus productos a ciegas, debido a que ellos están invirtiendo su presupuesto, identificado como el diario (cálculo de los costos y gastos del consumo diario de una familia), el cual tratan de economizar y maximizar.

Teniendo en cuenta lo anteriormente expuesto, el cerebro humano, de acuerdo a lo planteado por Paul MacLean, citado por Cisneros (2012, p. 4), en su teoría del cerebro triuno:

Divide el cerebro en tres cortezas. córtex; límbico, y el complejo reptiliano, situado por encima de los ojos, el hemisferio Izquierdo (razonar) es la función cognitiva más elevada como el razonamiento abstracto y el lenguaje y el hemisferio derecho para (crear), regula los instintos y las emociones. Con el avance de la tecnología y los estudios realizados al 
cerebro humano, donde el consumidor ejecuta su proceso cognitivo, para posteriormente desarrollar el proceso de compra, el cual se inicia con la necesidad que tiene de los productos masivos.

Por lo tanto, se hace necesario segmentar a los consumidores de acuerdo a su ciclo de vida, ya que de esta forma se puede atender sus gustos y preferencias hacia ciertos productos de consumo masivo que ofertan las tiendas de barrios del municipio de Malambo. Otro aspecto relevante en los resultados es que el $90 \%$ de la población que acude a las tiendas son jóvenes y adultos, los cuales toman sus decisiones de compra, porque tienen capacidad de pago para adquirir el producto masivo ofertado en ellas. A continuación se presenta una gráfica relacionada con la decisión de compra del consumidor:

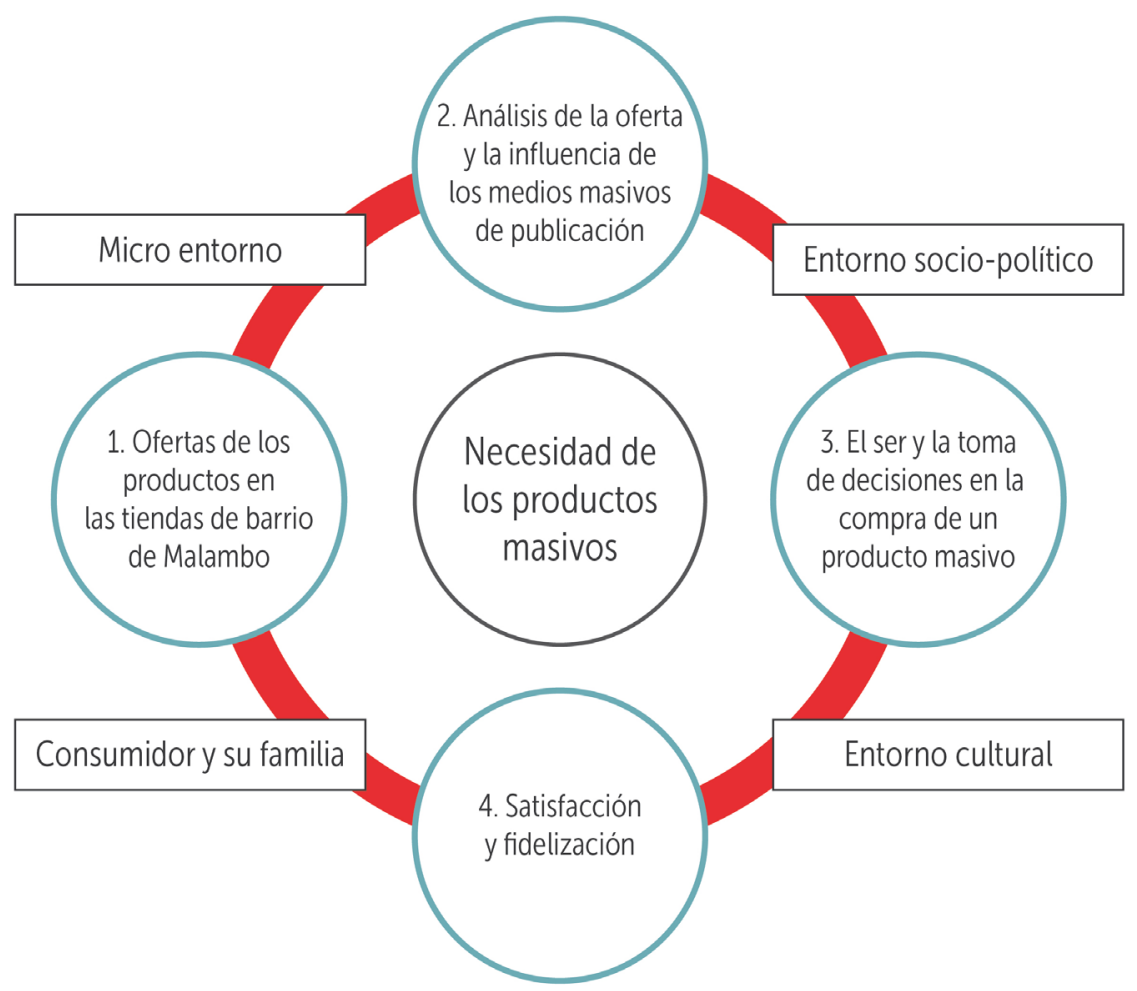

Figura 1. Decisión de compra de consumidores en tiendas de barrio del municipio de Malambo, Atlántico, Colombia. Fuente: Diseño propio.

En la gráfica anterior se muestra cómo el macro entorno cultural proporciona información permanente al micro entorno a través de la radio, televisión, internet, periódico y en algunos casos a través de la técnica de voz a voz. Esta dinámica del entorno, en las que se 
evidencian la producción de factores externos que de alguna manera activan las neuronas o células nerviosas del hombre, dan cabida a las funciones mentales del individuo tales como la atención, la memoria a corto y largo plazo, la capacidad constructiva y el razonamiento, funciones que a la vez son procesadas por el cerebro conservando en su memoria las imágenes, colores que le ayudan al individuo a identificar, reconocer y comparar los atributos del producto, logrando así identificar los beneficios y las alternativas de compra como la cantidad, calidad y los precios.

Lo anterior, según Braidot (2013, p. 25), se encuentra enlazado con las emociones, sensaciones y deseos internos que experimentan los individuos y que de manera directa o indirecta influyen en la decisión de compra del consumidor y su familia hacia los productos masivos ofertados en las tiendas de barrio. Muchos de estos sentimientos son caracterizados de acuerdo al estilo de vida que posee la población en el municipio de Malambo y a la forma como los dueños de los negocios distribuyen sus ingresos para la satisfacción y fidelización de los consumidores.

Es así como en la mente del consumidor de tiendas de barrios emerge un conjunto de procesos conscientes y no conscientes producidos por la interacción y comunicación entre grupos y circuitos de neuronas que se originan en los pensamientos y sentimientos. (Braidot, 2013 p. 22). De esta manera, se logra que los productos sean por un segmento de clientes en el mercado. Es aquí donde el neuromarketing juega un papel predominante ya que, "trae consigo un conjunto de recursos de enorme valor para investigar el mercado, segmentarlo y desarrollar estrategias exitosas en materia de productos (diseño, marca, packaging), posicionamiento, precios, comunicación y canales." Braidot agrega que "estos recursos se basan en el conocimiento de los procesos cerebrales vinculado a la percepción sensorial, el procesamiento de la información, la memoria, la emoción, y los mecanismos que interactúan en el aprendizaje y la toma de decisiones (2013, p. 16).

Inclusive el enfoque motivacional, según Sergueyevna y Mosher, "parte de una perspectiva fundamentalmente socio psicológica, tratando de explicar los procesos subjetivos y el papel de tales en la decisión de compra y en el comportamiento del consumidor". (2013. p. 6) Entonces se hace evidente que la decisión de compra se deriva de todas las emociones transmitidas a través de medios de comunicación, complementándose con la comunicación, y el entorno del diario vivir del consumidor, no alterado por la curva de satisfacción y los patrones culturales. Un ejemplo se da en la segmentación de niñas de dos a cinco años de edad al comprar zapatos. En esta compra va a repercutir el marketing emocional, ya que en su elección se encuentran influenciadas por la marca, los colores, el estilo, además de las sensaciones que les hacen sentir adquirir un producto muy parecido a los de los adultos ya que les da seguridad 
y experimentan estar a la moda. Existen muchos modelos de elección cognitiva en la toma de decisión del consumidor.

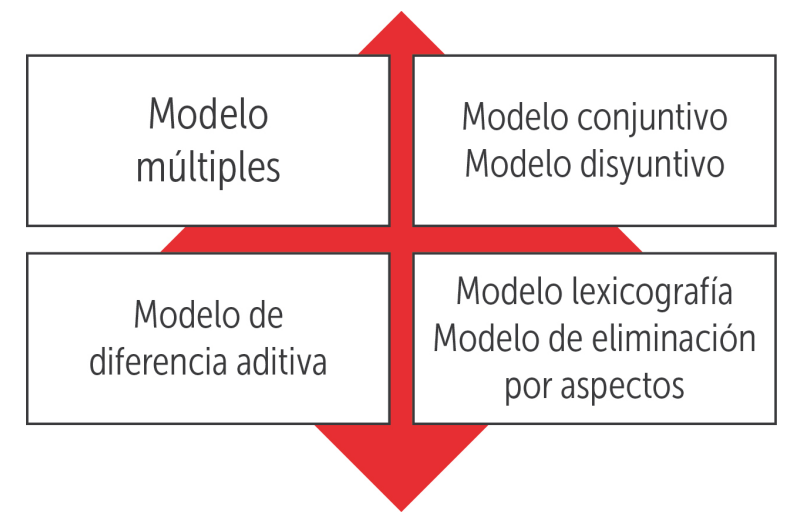

Figura 2. Procesamiento en la toma de decisión. Fuente: Hoyer y MacInnis, 2010.

De la misma forma, la toma de decisión de compra de productos en las tiendas de barrios del municipio de Malambo, inicia por la ubicación del consumidor en su barrio, y la necesidad de cubrir necesidades primarias: desayuno, almuerzo, cena y en algunos casos las meriendas. Otro componente que tienen en cuenta los consumidores es el presupuesto disponible y la capacidad de compra, lo que posteriormente lo lleva a evaluar la oferta de los productos, siempre teniendo en su memoria las marcas de su preferencia, y con una limitante para la satisfacción de sus necesidades, ya que algunos productos se venden fraccionados.

Algo semejante ocurre con el "modelo conjuntivo, no compensatorio, el cual establece límites mínimos para rechazar las opciones malas" (Hoyer y Maclnnis, 2010, p. 230), las cuales toma a consideración y reconoce las razones, permitiendo comparar otras opciones de compra de los productos masivos similares de las tiendas de barrios en el municipio de Malambo. El consumidor percibe, analiza, compara y decide, de acuerdo a su escaso presupuesto o cupo de crédito, de acuerdo a sus ingresos. Teniendo en cuenta lo observado, a este tipo de consumidor le agrada comprar lo que se cosecha como: tomate, mango, etc.

En el modelo anterior, en contra posición surge el "Modelo disyuntivo, no compensatorio, que establece punto de corte aceptables para encontrar opciones que son buenas" (Hoyer y Maclnnis, 2010 p. 231). En relación a esta expresión, los consumidores de tiendas de barrios de Malambo, seleccionadas para este estudio, tienen en sus mentes las marcas y los precios razonables, los consideran justos y acertados, y por los cuales están dispuestos a comprar dicho producto. 
Sin embargo, el "Modelo de diferencias aditiva, compara con base en sus atributos, dos marcas a la vez" (Hoyer y Maclnnis, 2010, p. 231), que establecen diferencias, buscando otra opción de compra que les permita adquirir los productos para satisfacer las necesidades de los consumidores. Igualmente, hay otras características que marcan diferencias para comprar los productos que ofertan y que aprovechan las ventajas como: la cercanía a los hogares, económica, los fraccionamiento de los productos, y demás servicios, para lo cual el consumidor se enfoca en la satisfacción de las necesidades fisiológicas, de acuerdo a la pirámides de Maslow.

\section{Conclusiones}

El consumidor de las tiendas de barrios del municipio de Malambo, Atlántico, Colombia es un ser preocupado, que maximiza los beneficios, se enfoca en la minimización de los precios, no obstante, está conectado y captando los mensajes publicitarios de los proveedores de las tiendas, y de las marcas: Maggi, Royal, Alpina, Fruco, Postobón, Coolechera, Parmalat, Diana, Ricostilla, Nestlé, Lalo, Rica, entre otras, las cuales poseen su código emocional singular, su tiempo específico de negocios los se refieren a la época de mayor fluidez de venta. Este código emocional se constituye en misión institucional, reflejado en símbolo el cual es identificado y entendido por los consumidores (Cisneros, 2012), incluido en la estrategia emocional de comunicación. En este caso particular, los consumidores de las tiendas de barrios del municipio de Malambo responden tomando su decisión de compra por los productos, los cuales se refleja por el posicionamiento en el mercado y precisamente en relación a esto, Champy (2009) explica que una de las clave del éxito es que el cliente vuelva y se logre la satisfacción del consumidor, complementado por el esfuerzo de las tiendas con la estrategia de servicio, basado en la confianza, y aplicando el concepto de neuromarketing -como la disciplina que estudia los procesos cerebrales en la toma de decisión del consumidor, tomando como campo de acción la inteligencia de mercado, los diseños de productos y servicios (Braidot, 2009). 


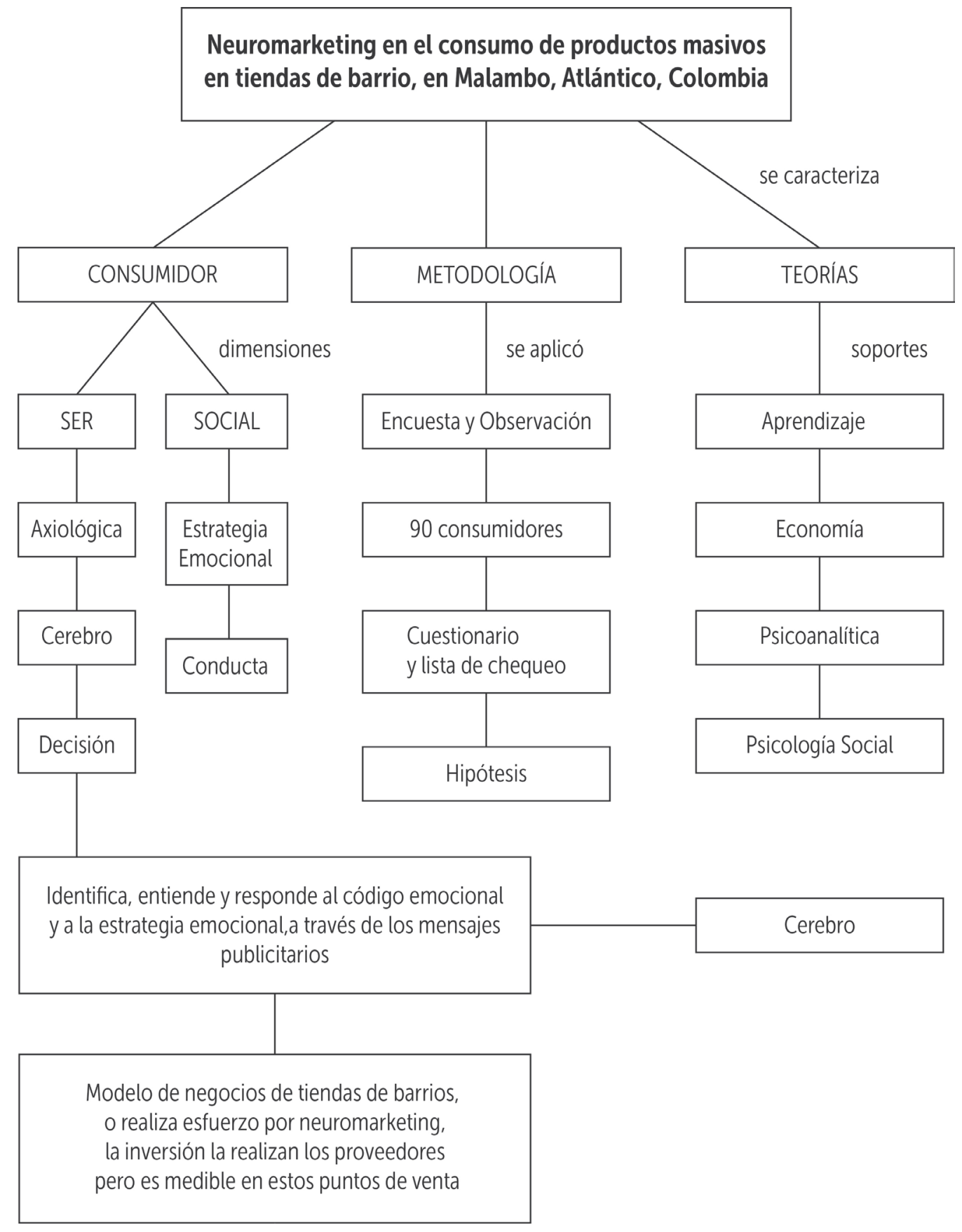

Figura 3. Diagrama unificador del neuromarketing. Fuente: Elaboración Propia. 


\section{Referencias Bibliográficas}

Andreu-Sánchez, C., Contreras-Gracia, A., \& Martín-Pascual, M.A. (2014). Situación del neuromarketing en España. El profesional de la información, 23 (2), 151-157.

Braidot, N. (2013). Neuromarketing en acción: ¿Por qué tus clientes te engañan con otros si dicen que gustan de ti? Buenos Aires: Ediciones Granica.

Cisneros Enríquez, A. (2013). Neuromarketing y neuroeconomía. Código emocional del consumidor. Colombia: Eco Ediciones.

Champy, J. (2010). jInspiración! Qué hacer para que los clientes regresen. Bogotá: Grupo Editorial Norma.

Fernández, A. (2004). Investigación y técnicas de mercados. Madrid: Gráficas Dehon.

García Uceda M. (2011). Las claves de la publicidad. España: Gráfica Dehon.

Gómez, M. (2006). Introducción a la metodología de la investigación científica. Córdoba: Editorial Brujas.

Hoyer, W., \& Maclnnis, D. (2010). Comportamiento del consumidor. México: Cengage Learning.

Kotler, P., \& Armstrong, G. (2002). Fundamentos de Marketing. México: Pearson..

Malhotra, N. (2004). Investigación de Mercados. Un enfoque aplicado. México: Pearson.

Rivera, J., Arellano, R., \& Molero, V. (2013). Conducta del consumidor: estrategias y políticas aplicadas al marketing. Madrid: Esic Editorial.

Sergueyevna, G., \& Mosher, E. (2013, Septiembre-Diciembre). Teoría motivacionales desde la perspectiva del comportamiento del consumidor. Negotium, 5-18.

Schiffman, L., \& Lazar Kanuk, L. (2005). Comportamiento del consumidor. México: Pearson Prentice Hall. 
Taylor, S., \& Bogdan, R. (2009). Introducción a los métodos cualitativos de Investigación. Barcelona: Ediciones Paidós.

Tubert, S. (2000). Sigmund Freud: Fundamentos del psicoanálisis. México: Editorial EDAF.

Yuni, J., \& Urbano, C. (2006). Técnicas para investigar. Córdoba: Editorial Brujas. 


\section{Capítulo 2}

Factores determinantes del índice de competitividad empresarial en el estado de Sonora, México Amado Olivares Leal, José Ángel Coronado Quintana, Francisco Espinoza Morales y María Guadalupe Torres Figueroa

\section{Introducción}

La industria en México ha jugado un papel importante en la economía nacional, y aunque el sector industrial en Sonora presenta un buen desarrollo en los procesos de industrialización, es necesario impulsar el nivel de la competitividad empresarial de acuerdo al Plan Nacional de Desarrollo de México 2013-2016, dada la pérdida de competitividad que presenta nuestro pais (WEF, 2013), y que en los últimos años ha venido experimentando. Esta situación ha incidido de manera fundamental en la industria, y está provocando, de igual manera, una intensa e inadecuada competencia entre empresas nacionales y de estas frente a extranjeras, por lo que resulta de vital importancia alcanzar y sostener la ventaja competitiva. Dado que es una cuestión crucial para el éxito y la supervivencia de las empresas, es prioritario realizar un estudio acerca de la determinación de las variables e indicadores que impulsan la competitividad de las pequeñas y medianas empresas (PyMES), como lo han señalado P. Kotler y L. K. Kevin (2006), M. E. Porter (2007), E. J. McCarthy y W. D. Perreault Jr. (2013), el World Economic Forum (WEF, 2013), W. Peres (1994) y R. (Villareal 2002).

El buscar las causas de las diferencias de competitividad en muchos trabajos lleva a la pregunta: ¿cuáles son los factores explicativos de la competitividad de la empresa? Un análisis de la bibliografía muestra que, si bien son muchos los trabajos que analizan la importancia de las variables externas frente a las internas, son escasos los que profundizan en la parte interna para identificar cuáles son las variables que la empresa debe asegurar o aplicar para ser competitiva, representando aspectos claves a los que hay que prestar especial atención si se quieren conseguir resultados superiores (Jennings P. y Beaver G. 1997; Rogoff, E.G. et al., 2004). Estamos ante un tema de gran complejidad tanto por la falta de consenso existente en 
la literatura acerca de la unidad de análisis o del marco teórico por adoptar como por la dificultad que presenta la elección de una definición clara y operativa de competitividad.

Si consideramos que las pequeñas y medianas empresas son el $42 \%$ y además contribuyen con el $43 \%$ del empleo en México, para el país es un imperativo estratégico impulsar las PyMES y su competitividad (COPARMEX, 2014, y Huerta E. et al. 2003). Las razones de los bajos niveles de competitividad en México se asocian al uso de factores que demandan las PyMES y que usualmente no propician innovación ni impacto en las estrategias, sino solo ventaja comparativa. El nivel de competencias y el uso de los factores que generan ventajas competitivas difieren ampliamente de industria a industria, e inclusive en los segmentos industriales. Otras causas están relacionadas y asociadas al diseño de deficiencias de producto, baja responsabilidad de investigación y desarrollo, mientras que en la producción vemos holguras de energía, abastecimientos en las líneas y en mercadotecnia y finanzas, esquemas muy tradicionales de comercialización y niveles de rendimiento y retorno bajos, etc. (Kotler P. y Kevin L. K., 2006; McCarthy E. J. y Perreault Jr. W. D. 2013; Alvarez Torres M. G. et. al. 1994; y Porter M. E. 2005).

Esta situación nos ha llevado a tratar de clarificar dos cuestiones: ¿qué se entiende por competitividad? y ¿cuál es el estado o nivel de la competitividad de las PyMES del estado de Sonora y qué factores internos y externos propician la competitividad?

Para la consecución de estos objetivos, el presente trabajo se estructura en torno a tres apartados. En el primero de ellos se establece el marco teórico que establece un modelo de gestión que se centra en los factores de éxito competitivo en las PyMES. En el tercer se plantea las hipótesis de investigación y se obtiene el muestreo representativo del universo de las PyMES en el estado de Sonora. Por último, se ofrecen las implicaciones que los resultados obtenidos tienen para la investigación de este fenómeno.

\section{Marco Conceptual}

En el análisis teórico, se plantea un modelo de competitividad industrial, derivado de la bibliografía analizada, y que nos permitirá medir y cuantificar el ICE por municipios, regiones, y global de las PyMES del estado de Sonora. De los resultados del análisis al modelo se destaca la importancia que tienen las Capacidades Administrativas y las Capacidades Operacionales en las empresas, y cómo se integran estas dimensiones para obtener ventajas competitivas.

El enfoque sistémico de competitividad presenta cuatro determinantes de ventajas competitivas nacionales, de acuerdo a Michael Porter (1991), y sus interrelaciones que generan industrias competitivas en las naciones (ver figura 1):

1. Condiciones de los factores

2. Industrias relacionadas y de apoyo 


\section{Estructura y rivalidad industrial \\ 4. Condición de la demanda}

Además se consideran dos variables auxiliares que complementan el marco del análisis:

- Otros agentes: El gobierno, la banca mexicana, centros de investigación, instituciones de educación superior

- Hechos fortuitos o casuales, como la invención y la actitud empresarial.

Para el trabajo de esta investigación se abordará el enfoque sistémico de competitividad, de Porter Michael (1991) en cuanto al primer determinante de condiciones de los factores en las empresas y cómo estos se conciben en factores que pueden separarse en generales frente a especializados y en básicos y avanzados. Los factores generales son comunes a todas las industrias y por lo tanto no generan ventajas sostenibles, mientras que los factores especializados -infraestructura, investigación y desarrollo, educación, habilidades, tecnología de punta- son específicos para cada industria o segmento. Dado el tiempo que lleva generarlos y su difícil acceso, estos factores contribuyen significativamente a la creación de ventajas competitivas sostenibles (ver figura 1).

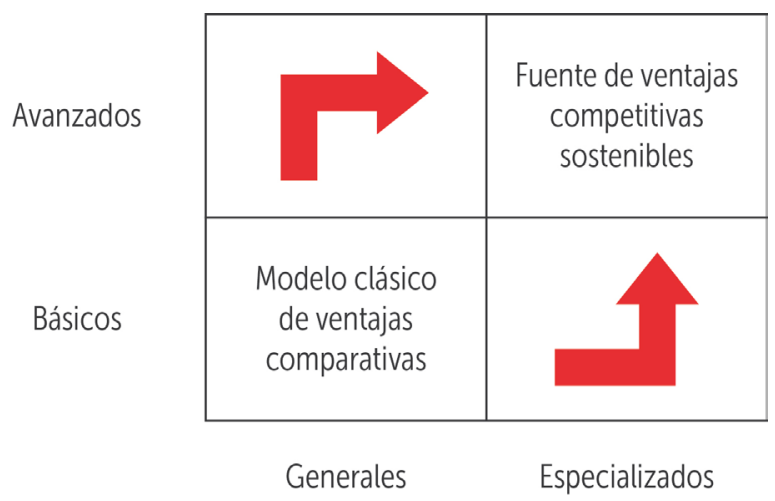

Figura 1. La empresa: condición de los factores. Fuente: Michael E. Porter (1991)

La problemática que han experimentado los diferentes subsectores industriales de nuestro país, provocados por la apertura comercial, así como la aparición en el concierto global de economías emergentes, ha orillado a poner en la mesa de la discusión un concepto que hasta hace pocos años era aún desconocido por muchos, el concepto de competitividad, lo cual ha orillado a las empresas y a los gobiernos a realizar estudios y análisis que les permitan entender y medir el grado de competitividad de las mismas y de su propio país, de tal forma que puedan insertarse de mejor manera en el entorno global. 
Algunas de las primeras definiciones de competitividad empresarial:

- Porter (1991) ha señalado que las que compiten son las empresas y no las naciones. También indica que la rivalidad de unas con otras lleva a una posición competitiva favorable que permite a un país que sus empresas sean competitivas. Por lo tanto, son éstas la base de la competitividad.

- Johnson Gerry et al. (2006), Ansoff H. I. (1969), McCarthy E. Jerome et al. (2013), y David Fred R. (2008) consideran la administración estratégica de la empresa para captar mercados y recursos, y su participación relativa en el mercado, y utilizan la estrategia para valorar sus ventajas competitivas.

- López-Ortega (1999), indica que la competitividad estructural analizada por la Organización para la Cooperación y el Desarrollo Económico (OCDE) menciona que la especialización de la economía, la innovación tecnológica, la calidad de las redes de distribución y los factores de localización, constituyen el estado de suministro de bienes y servicios. La competitividad asi entendida tiende a mejorar el desarrollo de las economías, en particular el desarrollo de una región. (2004, p. 17.)

- El Foro Económico Mundial (World Economic Forum, 2013) cuenta con dos índices que evalúan, por una parte, los niveles microeconómicos -Índice del Crecimiento de Competitividad Empresarial (ICE)- y, por otra, los niveles macroeconómicos -Índice de Competitividad Global para una nación (ICG). Estos índices son publicados anualmente y buscan medir la capacidad de la economía para lograr el crecimiento económico, así como las condiciones que hacen sostenible la productividad y competitividad empresarial y presentan un crecimiento sostenido en los mercados nacionales e internacionales.

No existe una definición única de competitividad, pero la que utilizarnos en esta investigación se puede resumir en la capacidad de las empresas de un país para sostener y expandir su participación en los mercados locales y/o internacionales y obtener ventajas competitivas y elevar el nivel de vida de las personas.

En este trabajo se entiende la competitividad empresarial como "la capacidad para, rivalizando con otras empresas, conseguir alcanzar una posición competitiva favorable, que permita obtener un desempeño superior al de los competidores" de A. Aragón y A. Rubio (2005, pp. 37). Por lo que para el desarrollo de su competitividad y de la misma región en la que se encuentran ubicados, gestando el cambio del paradigma de competitividad de ventajas comparativas" a las "ventajas competitivas" de las industrias y por supuesto de las regiones. 


\section{Determinación de las variables - indicadores de la competitividad}

Aunque no hay un conjunto único de indicadores que sirva para todas las empresas, sí hay un conjunto mínimo de indicadores que permiten una apreciación de los resultados de una empresa con la finalidad de iniciar un análisis competitivo. Se facilita la selección si se plantean los indicadores claves a partir de la orientación del plan de acción de la empresa de acuerdo a R. E. Biasca (2000), E. Mercado (1997) y R. Ruiz (2003):

1. A partir de la orientación de la empresa: visión, misión, valores;

2. Diagnóstico: realizar una análisis de fortalezas, oportunidades, debilidades y amenazas;

3. Pronóstico: tasa salarial nacional, precios industria, tasa de interés, tasa de cambio;

4. Objetivos: claros, breves y medibles;

5. Programa de estrategias: con presupuesto y calendarización;

6. Políticas y procedimientos;

7. Los factores claves de éxito, tal como, ventas, utilidades, retorno de la inversión, participación de mercado, quejas de clientes, calidad, tiempo de entrega, proyectos de nuevos productos, tendencias, etc.

\begin{tabular}{|c|c|c|c|c|}
\hline Dimensiones & Variables & Indicadores & Pregunta & Fuente \\
\hline \multirow[t]{2}{*}{$\begin{array}{l}\text { Capacidad } \\
\text { Administra- } \\
\text { tiva }\end{array}$} & $\begin{array}{l}\text { Posición } \\
\text { Administra- } \\
\text { tiva }\end{array}$ & $\begin{array}{l}\text { Planeación } \\
\text { estratégica }\end{array}$ & $\begin{array}{l}\text { ¿Hay un plan } \\
\text { correctivo o pre- } \\
\text { ventivo? } \\
\text { ¿Hay factores de } \\
\text { éxito en PyMEs? } \\
\text { Visión, misión, } \\
\text { FODA, Objetivos, } \\
\text { estrategias, Facto- } \\
\text { res críticos }\end{array}$ & $\begin{array}{l}\text { Johnson, G. (2006); } \\
\text { Kay, J. (1993); Venka- } \\
\text { traman, N. (1986); } \\
\text { Biasca, R. E (2000) } \\
\text { Dess, G.D. et al. (1984) } \\
\text { Gadenne, D. (1998); } \\
\text { Rogoff, E. G. et al. } \\
\text { (2004). }\end{array}$ \\
\hline & & $\begin{array}{l}\text { Estructura } \\
\text { Organizacio- } \\
\text { nal } \\
\text { y comunica- } \\
\text { cion }\end{array}$ & $\begin{array}{l}\text { ¿Su estructura } \\
\text { organizacional es } \\
\text { plana? ¿Hay prac- } \\
\text { ticas de Desarrollo } \\
\text { Organizacional? } \\
\text { ¿Hay eficiencia? } \\
\text { Número de nivel } \\
\text { jerárquico } \\
\text { Comunicación } \\
\text { interpersonal }\end{array}$ & $\begin{array}{l}\text { David, F. R. (2008); } \\
\text { Dess, G. D. et al. } \\
\text { (1984). }\end{array}$ \\
\hline
\end{tabular}




\begin{tabular}{|c|c|c|c|c|}
\hline Dimensiones & Variables & Indicadores & Pregunta & Fuente \\
\hline & & $\begin{array}{l}\text { Compromi- } \\
\text { so directivo }\end{array}$ & $\begin{array}{l}\text { ¿Institucionales, so- } \\
\text { ciales, ecológicos? } \\
\text { ¿Industrial, educati- } \\
\text { va, ambientales? } \\
\text { ¿Nivel educativo? } \\
\text { Valores } \\
\text { políticas y normas } \\
\text { ¿Se tiene formación } \\
\text { y éxito empresarial? }\end{array}$ & $\begin{array}{l}\text { Viedma, J. M. (1992); } \\
\text { Kotey, M. et al. (1997); } \\
\text { Camisón, C. (1997) } \\
\text { Álvarez, J.C.; García, E. } \\
\text { 1996); Bantel, et al. } \\
\text { (1989); McLarty, R. } \\
\text { (2000). }\end{array}$ \\
\hline & $\begin{array}{l}\text { Competitivi- } \\
\text { dad }\end{array}$ & $\begin{array}{l}\text { Costos } \\
\text { mínimos, } \\
\text { apoyos } \\
\text { públicos y } \\
\text { privados, } \\
\text { IES }\end{array}$ & $\begin{array}{l}\text { ¿Logran ventajas } \\
\text { comparativas? } \\
\text { ¿Logran ventajas } \\
\text { competitivas- com- } \\
\text { parativas? }\end{array}$ & $\begin{array}{l}\text { Porter, M. 1990, 1991, } \\
\text { 1997, 1998, 2005, 2007; } \\
\text { Huck, J. y McEwen, T. } \\
\text { (1991); Chang, S. y Singh, } \\
\text { H. (2000); Jennings, P. } \\
\text { et al. (1997); Kester, C. et } \\
\text { al. (1989); Smith, A. et al. } \\
\text { (1999); } \\
\text { WEF -BCl (2013). }\end{array}$ \\
\hline & $\begin{array}{l}\text { Recurso } \\
\text { hiumano }\end{array}$ & $\begin{array}{l}\text { Programa } \\
\text { de capacita- } \\
\text { ción, entre- } \\
\text { namiento e } \\
\text { incentivos, } \\
\text { RSE }\end{array}$ & $\begin{array}{l}\text { ¿Cumplen con las } \\
\text { exigencias lega- } \\
\text { les? ¿Siguen un } \\
\text { modelo de gestión } \\
\text { las PyMES? }\end{array}$ & $\begin{array}{l}\text { Dollinguer, M. J. (1984); } \\
\text { Dorronsoro et al. (2001); } \\
\text { Gómez-Mejía et al. } \\
\text { (1996); Loan-Clarke, J. } \\
\text { et al. (1999); Vinten, G. } \\
\text { (2000) }\end{array}$ \\
\hline & $\begin{array}{l}\text { Capacidad } \\
\text { de mercado- } \\
\text { tecnia }\end{array}$ & $\begin{array}{l}\text { Tamaño y } \\
\text { porcentaje } \\
\text { de merca- } \\
\text { do, precio, } \\
\text { satisfacción } \\
\text { cliente, } \\
\text { competen- } \\
\text { cia }\end{array}$ & $\begin{array}{l}\text { ¿Porcentaje bajo } \\
\text { o alto de quejas, } \\
\text { avance vs compe- } \\
\text { tencia? ¿Hay orien- } \\
\text { tación al mercado? }\end{array}$ & $\begin{array}{l}\text { Camisón, C. (1997); } \\
\text { Churchill, G. A. (1979); } \\
\text { Conant, J. S. et al. (1990); } \\
\text { Roquebert, J. et al. } \\
\text { (1996); Huck, J, y McEr- } \\
\text { ven, 1991; Verhees, F. et } \\
\text { al. (2004); Wijewardena, } \\
\text { H. (1995). }\end{array}$ \\
\hline
\end{tabular}




\begin{tabular}{|c|c|c|c|c|}
\hline Dimensiones & Variables & Indicadores & Pregunta & Fuente \\
\hline \multirow[t]{4}{*}{$\begin{array}{l}\text { Capacidad } \\
\text { de operación }\end{array}$} & $\begin{array}{l}\text { Innovación } \\
\text { tecnológica }\end{array}$ & $\begin{array}{l}\text { Producto, } \\
\text { proceso, } \\
\text { Investi- } \\
\text { gación y } \\
\text { Desarrollo e } \\
\text { Informática. } \\
\text { ¿Cuenta con } \\
\text { recursos } \\
\text { tecnológi- } \\
\text { cos? }\end{array}$ & $\begin{array}{l}\text { ¿Innova o invierte } \\
\text { para un mejor } \\
\text { futuro? } \\
\text { ¿Innova en proce- } \\
\text { so, producto o en } \\
\text { estructura organi- } \\
\text { zacional? }\end{array}$ & $\begin{array}{l}\text { Álvarez y García 1996, } \\
\text { Dorronsoro et al. 2001; } \\
\text { Ribeiro, D. (2003); } \\
\text { Huerta, E. et al. (2003); } \\
\text { Warren, L (2000). }\end{array}$ \\
\hline & $\begin{array}{l}\text { Proceso } \\
\text { productivo }\end{array}$ & $\begin{array}{l}\text { Manual, } \\
\text { mecaniza- } \\
\text { do, están- } \\
\text { dar, cadena, } \\
\text { continua. }\end{array}$ & $\begin{array}{l}\text { ¿Está cerca o lejos } \\
\text { de la competencia? } \\
\text { ¿Las PyMEs tienen } \\
\text { un estándar de } \\
\text { calidad? }\end{array}$ & $\begin{array}{l}\text { Covin, et al. 1991; } \\
\text { Marbella, F. (1998); } \\
\text { Ahiere, S. L. y Golhar, D.Y. } \\
\text { (1996). }\end{array}$ \\
\hline & $\begin{array}{l}\text { Logística y } \\
\text { cadena de } \\
\text { valor }\end{array}$ & $\begin{array}{l}\text { Contratos, } \\
\text { seguros de } \\
\text { transporte, } \\
\text { TAT. } \\
\end{array}$ & $\begin{array}{l}\text { ¿Hay eficiencia en } \\
\text { su logística y Cade- } \\
\text { na de valor? }\end{array}$ & Rumelt, R. (1991). \\
\hline & $\begin{array}{l}\text { Capacidad } \\
\text { económica y } \\
\text { financiera }\end{array}$ & $\begin{array}{l}\text { VPN, ROI, } \\
\text { MgUt, Ap. } \\
\text { Fin. y Op., } \\
\text { valor de } \\
\text { acción, } \\
\text { porcentaje } \\
\text { y/o montos } \\
\text { en inversión } \\
\text { ¿rentabili- } \\
\text { dad econó- } \\
\text { mica? }\end{array}$ & $\begin{array}{l}\text { ¿Gana utilidad, } \\
\text { aumenta su Valor, } \\
\text { el retorno es alto, } \\
\text { invierte en infraes- } \\
\text { tructura y/o Investi- } \\
\text { gación y Desarrollo } \\
\text { y/o Tecnología de } \\
\text { la información? ¿Se } \\
\text { mide el crecimiento } \\
\text { y el desarrollo en } \\
\text { las PyMES? }\end{array}$ & $\begin{array}{l}\text { Birley y Westhead (1991); } \\
\text { Viedma, (1992); Acar } \\
\text { (1993); Yusulf (1995); } \\
\text { Álvarez y García (1996); } \\
\text { Warren y Hutchinson } \\
\text { (2000); Camisón, C. } \\
\text { (1997); Salomon, G. } \\
\text { (1985). }\end{array}$ \\
\hline
\end{tabular}

Tabla 1. Lista de variables, e indicadores de éxito competitivo.

Fuente: Elaboración propia a partir de la información revisada. 
Para Johnson Gerry (2006) y para Fred R. David (2008), el desarrollo de la estrategia corporativa y el de sus capacidades de crecimiento y diferenciación son las que contribuyen a impulsar la competitividad. Para Michael Porter (2007) el uso de los factores especializados y avanzados generan en la empresa sus ventajas competitivas sostenibles, mientras que Rodolfo E. Biasca (2000) basa el desempeño competitivo en el plan de acción que diseña la empresa.

A partir de las variables de competitividad generadas en la tabla 1, la metodología que utilizaremos será la del ICE del World Economic Forum, (WEF, 2013) a través de un cuestionario que permite generar el posicionamiento de competitividad de las PyMES. También se considerarán variables del enfoque de competitividad sistémica de Michael Porter. El modelo de competitividad empresarial resultante es el presentado en la figura 2, en el que se consideran dos dimensiones: las capacidades administrativas definidas en el eje de las " $Y$ " y las capacidades en la operación en las empresas definido en el eje de las " $X$ ", de tal manera que este cuadrante cartesiano nos permite medir el nivel de la competitividad en la empresa y establecer su posicionamiento respecto a su competencia.

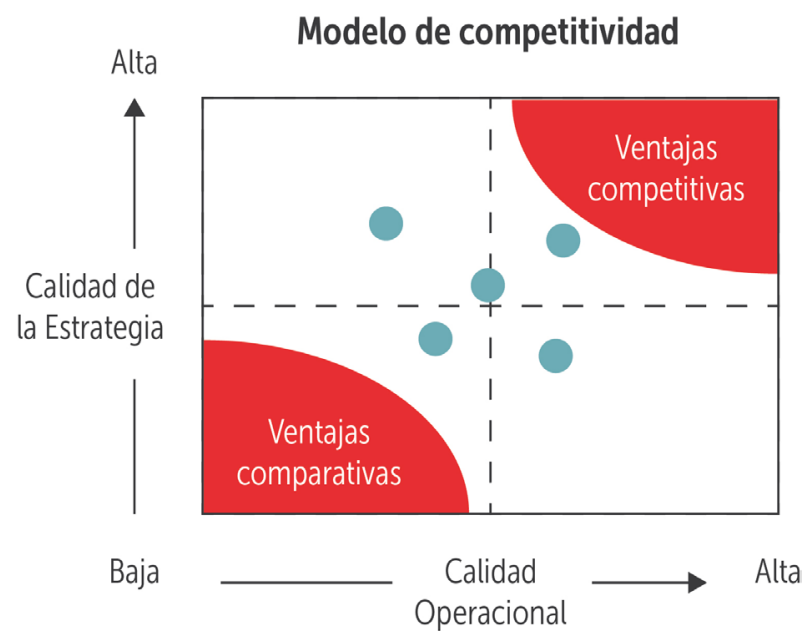

Flgura 2. Modelo de competitividad empresarial.

Fuente: Elaboración propia a partir de la información revisada.

Hoy, la idea dominante es que se está ante una organización que aprende y que lo hace a través de las nuevas exigencias que se le plantean a los recursos humanos y al modelo productivo. En esta visión acerca de la competitividad, es importante reconocer los indicadores de desempeño, que se refieren a la capacidad de mantener mercados y penetrar en nuevos, la eficiencia en el uso de los recursos clave (financieros, materia prima, tiempo), a la actualización 
de las técnicas organizacionales y de las tecnologías, pero es igualmente importante saber cuáles son los valores y las metas estratégicas que se plantea la organización.

Hay empresas que tienen metas específicas dependiendo de las condiciones en que se desenvuelven, tal como ganar más mercados, disminución de costos, producir con calidad, innovación de producto y la mejora de servicio de posventa. Al respecto de los objetivos y la ponderación, los indicadores son diferentes en distintos países. Los norteamericanos, por ejemplo, prestan mucha atención al retorno de capital empleado, retorno de inversión y al valor para el accionista, mientras que los japoneses destacan la participación de mercado (Biasca, 2000).

\title{
Metodología
}

La presente investigación es esencialmente exploratoria ya que se apoya en la utilización de un instrumento para obtener la información (un cuestionario y la visita a la planta productiva) $y$, además, es de tipo transversal, ya que el estudio se realiza en un solo momento en el tiempo (2014), en el estado de Sonora, y de acuerdo a un muestreo aleatorio simple.

La muestra arrojó 84 empresas ubicadas en 8 municipios del estado de Sonora. Se consideró el directorio del Centro Empresarial de Sonora y se utilizó el paquete estadístico SPSS versión 21. La metodología utilizada se describe a continuación:

\author{
Nivel de Competitividad Industrial (Nivel de Competitividad Empresarial) \\ $=f(V 1, V 2, V 3, V 4, V 5, V 6, V 7, y$ V8) \\ V1: Posición Administrativa (PA) \\ V2: Posición Competitividad (PC) \\ V3: Recurso Humano (RH) \\ V4: Capacidades de Mercadotecnia (CM). \\ V5. Posición Tecnológica e Inn (PTI) \\ V6: Proceso productivo (PP) \\ V7: Logística y Cadena de Valor (LCV) \\ V8: Capacidades Económicas y Fin (CEF)
}

Inicialmente, se definen los municipios y regiones de cada estado y el proceso metodológico utilizado. Asimismo, se permite analizar las diferentes variables independientes (VI); primero se obtiene su valor por la sumatoria del valor promedio de sus indicadores entre el número de indicadores, como se expresa a continuación: 


\section{Valor promedio de las variables Independiente (VI) por empresa (VPVIE) = $\Sigma$ indicadores \\ \# de indicadores}

El segundo paso es la sumatoria del valor de cada una de las V1 por empresa entre el número de empresas, lo que permite identificar el valor promedio de cada V1 por empresa, como se expresa a continuación:

\section{Valor promedio de (VI) por municipio (VPVI M) $=\mathbf{\Sigma}$ VPVIE \\ $\overline{\text { \# empresas }}$}

El tercer paso es la sumatoria del valor de cada una de las VI por municipio entre el número de municipios, que permite identificar el valor promedio de cada VI por empresa, como se expresa a continuación:

\section{Valor promedio de $($ VI) por región $(V P V I R)=\Sigma$ VPVIM \\ \# municipios}

Como las medidas de distancia son sensibles a las diferencias de escalas o magnitudes hechas entre variables, es necesaria la estandarización de datos para evitar que las variables con gran dispersión tengan un mayor efecto en la similaridad. La forma de estandarización más común es restarle a cada observación la media de la variable y este resultado dividirlo entre su desviación estándar (Anderson, et al. 2004). Lo que se consigue con ello es eliminar las diferencias introducidas por las diferencias de escalas de las distintas variables (atributos) usados en el análisis. Una vez estandarizados los datos se analizarán y presentarán las tablas y gráficas correspondientes por municipios (Hermosillo, Guaymas, Ciudad Obregón, Navojoa, Caborca, San Luis Río Colorado, Nogales, Agua Prieta Sonora), por regiones (1: Ciudad Obregón - Navojoa; 2: Hermosillo - Guaymas; 3: Caborca - San Luis Río Colorado y 4: Nogales Agua Prieta) y global del estado Sonora.

\section{Objetivo}

- Realizar un diagnóstico acerca de los factores que influyen en la competitividad de las PyMES del estado de Sonora para hacer una detección estratégica de soluciones que les permitan a las empresas en cuestión alcanzar el nivel de competitividad que requieren para permanecer, crecer o desarrollarse en el mercado. 
- Determinar el Índice de Competitividad Empresarial (ICE) por subsectores, por municipios, por regiones y por estados.

\section{Hipótesis}

Se considera que el valor de las Capacidades Administrativas y de Operación de Competitividad empresarial es aún muy bajo en las pequeñas y medianas empresas de Sonora.

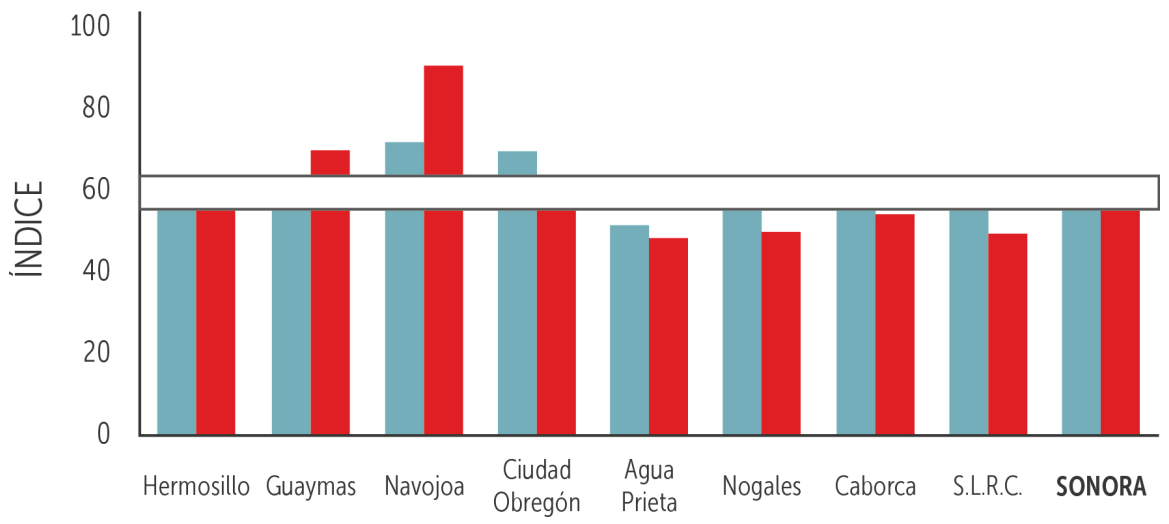

\begin{tabular}{|c|c|c|c|c|c|c|c|c|c|}
\hline Cap. Adm. & 58.59 & 56 & 71 & 68.9 & 50.86 & 57.2 & 58.6 & 58.4 & 59.9 \\
\hline Cap. Op. & 59.18 & 69.33 & 89.73 & 61.86 & 47.7 & 49.6 & 54 & 49.2 & 60.08 \\
\hline
\end{tabular}

Flgura 3. Capacidad Administrativa y de Operación, por municipios. $\mathbf{x}$-media $=\mathbf{6 0}$. Fuente: Elaboración propia a partir de la información revisada.

\section{Análisis y discusión de los datos}

Se puede observar en la Figura 3, que las empresas de la ciudad de Navojoa y Ciudad Obregón rebasan la media de 60 puntos en la Capacidad Administrativa y de Operación, y en esta última también las empresas de Guaymas se encuentran. En la Capacidad Administrativa y de Operación son iguales al promedio las empresas de Hermosillo, y solo son igual al promedio en la Capacidad Administrativa las empresas de Nogales, Caborca y San Luis Río Colorado.

Se puede observar en la Figura 3, que las empresas de la ciudad de Navojoa y Ciudad Obregón rebasan la media de 60 puntos en la Capacidad Administrativa y de Operación, y en esta última también las empresas de Guaymas se encuentran. En la Capacidad Administrativa y de Operación son iguales al promedio las empresas de Hermosillo, y solo son igual al promedio en la Capacidad Administrativa las empresas de Nogales, Caborca y San Luis Río Colorado. 


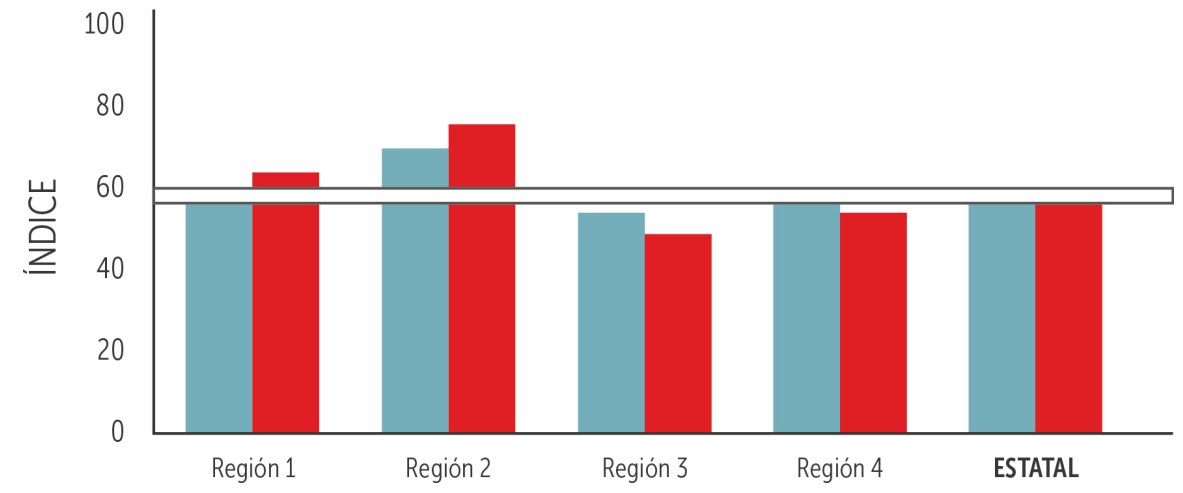

\begin{tabular}{|c|c|c|c|c|c|}
\hline Cap. Adm. & 57.09 & 69.96 & 54.03 & 58.53 & $\mathbf{5 9 . 9}$ \\
\hline Cap. Op. & 64.26 & 75.8 & 48.66 & 54.1 & $\mathbf{6 0 . 0 8}$ \\
\hline
\end{tabular}

Flgura 4. Calidad de la estrategia y Operación, por regiones. $\boldsymbol{x}$-media $=\mathbf{6 0}$.

Fuente: Elaboración propia a partir de la información revisada.

De la misma forma, en la Figura 4 se observa que en las empresas de la Región 1 (Hermosillo y Guaymas), y la Región 2 (Ciudad Obregón y Navojoa) las capacidades de operación rebasan al promedio, mientras que las capacidades administrativas están muy cerca al promedio de la región 3 (Nogales y Agua Prieta) y región 4 (Caborca y San Luis Río Colorado).

A continuación se presenta en la tabla 2 el orden de los municipios y las regiones segun el Índice de Competitividad Empresarial (ICE) con valores estandarizados. De acuerdo a los valores detallados en la tabla 2 del ICE encontramos cuatro regiones clasificadas. La región del sur del estado Sonora representada por los municipios de Ciudad Obregón y Navojoa, de los cuales los subsectores que sobresalen son los de alimentos y bebidas, el de madera, plásticos, envases y metálica básica. En la región del centro de Sonora representada por los municipios de Hermosillo y Guaymas, los subsectores que sobresalen son los de alimentos y bebidas, papel, imprenta y editoriales, madera y sus productos, y transporte. De la región del noroeste de Sonora representada por Caborca y San Luis Río Colorado, los subsectores que sobresalen son alimentos agropecuarios y manufactura de maquila. Finalmente, de la región del noroeste de Sonora representada por Nogales y Agua Prieta los subsectores que sobresalen son la manufactura de productos y de maquila.

Estos ICE' s por municipios confirman que aun los niveles de competitividad son aun bajos, por lo que se confirma la hipótesis de esta investigación. 


\begin{tabular}{|c|c|c|c|c|c|c|c|c|c|c|c|} 
& V1 & V2 & V3 & V4 & V5 & V6 & V7 & V8 & $\Sigma$ & Orden & Orden \\
Región
\end{tabular}

Tabla 2. Índice de Competitividad Empresarial (ICE), valores estandarizados

Fuente: Elaboración propia a partir de la información revisada.

\section{El análisis de correlación}

De las ocho variables independientes consideradas en esta investigación, ocho presentan un nivel medio y alto en su relación con el nivel de ICE (variable dependiente) de cada municipio y por ende de la región, así la estrategia de recursos humanos (ERH), estrategia de producción (EP), estrategia de tecnología (ET), estrategia de logística (EL) y estrategia de finanzas (EF) presentan los valores más altos: $r=.861 r^{2}=.741 ; r=.934 r^{2}=.872 ; r=.695, r^{2}=.483 ; r=.913 r^{2}=.833$; y $r=.714$ y $r^{2}=.509$, respectivamente. Mientras que la Capacidad de Administración (EA), Estrategia de Competitividad (EC), y Estrategia de Mercadotecnia (EM) presentan valores medios: $r$ $=.592 r^{2}=.350 ; r=.463 r^{2}=.214 ; r=.442$ y $r^{2}=.195$, esto se ilustra en la tabla 3 y 4 .

Se puede observar en las Tablas 3 y 4 que las estrategias bien definidas y bien realizadas operativamente son las del recurso humano, las del proceso productivo, de tecnología, de logística y de finanzas; mientras que las que están término medio y que tendrán que ajustar y mejorar son las estrategias de planeación, de administración, de competitividad y de mercadotecnia. Estas deberán buscar ser más puntuales en los aspectos técnicos de definición de la planeación y hacer su difusión interna de manera más amplia. Por otro lado, se requiere realizar con periodicidad estudios pertinentes de mercado que apoyen las acciones de innovación y desarrollo de nuevos productos, establecer que las estrategias sean auténticamente competitivas como rasgo distintivo de su toma de decisiones e impulsar un compromiso de 


\begin{tabular}{|c|c|c|c|c|c|c|c|c|c|}
\hline & $E A$ & $E C$ & ERH & EM & ET & EP & EL & CEF & ICE \\
\hline EA & 1 & & & & & & & & \\
\hline$E R H$ & .344 & 1 & & & & & & & \\
\hline PM & .400 & .214 & $.784^{*}$ & 1 & & & & & \\
\hline$E T$ & .364 & .607 & .434 & $934^{* *}$ & 1 & & & & \\
\hline$E P$ & .426 & .512 & $.791^{*}$ & $.695^{*}$ & .374 & 1 & & & \\
\hline$E L$ & .632 & .620 & .487 & .913 & .598 & .596 & 1 & & \\
\hline$E F$ & .246 & .367 & .199 & $.714^{* *}$. & .468 & $.799 * *$ & .674 & 1 & \\
\hline ICE & .592 & .463 & $.861 * *$ & .442 & .695 & .934 & $.913 *$ & .714 & 1 \\
\hline
\end{tabular}

Tabla 3. Coeficiente de correlación de Pearson. * La correlación es significativa al nivel 0,01 (2 colas). ** La correlación es significativa al nivel 0,05 (2 colas). Fuente: Elaboración propia.

\begin{tabular}{|c|c|c|c|c|c|c|c|c|c|}
\hline & $E A$ & $E C$ & $E R H$ & $E M$ & $E T$ & EP & EL & CEF & ICE \\
\hline$r^{2}$ & .350 & .214 & .741 & .195 & .483 & .878 & .833 & .509 & 1 \\
\hline
\end{tabular}

Tabla 4. Coeficiente de Determinación $\left(r^{2}\right)$

Fuente: Elaboración propia a partir de la información revisada.

los directivos y empleados y flexibilizar una estructura organizacional que les permita obtener ventajas competitivas. La única variable, que aunque resultó baja su relación y explicación para el ICE, es rescatable, ya que se trata de los indicadores de la estrategia de organización, la cual se puede hacer más flexible su estructura organizacional, mejorar la comunicación y deslindar la responsabilidad y autoridad que les permita un avance para ser más competitivos.

\section{Conclusión}

El modelo de competitividad empresarial presentado en la Figura 2 se podrá implementar únicamente cuando exista en la empresa una cultura de calidad y mejora continua fuerte, orientada a la sistematización, es decir, orientada a un esfuerzo coordinado y disciplinado de todos los miembros y departamentos de una organización y del compromiso de la alta dirección. 
El nivel bajo y medio de competitividad de las empresas en los municipios de Sonora ha provocando de igual manera una participación muy moderada en la penetración de mercados nacionales e internacionales. Se tiene entonces que desarrollar las potencialidades detectadas en los municipios y regiones de tal manera que la recomendación es impulsar no solo las empresas del subsector de alimentos, madera, plásticos y papel, sino también los subsectores no tradicionales (electrónica, metalmecánica, química, minería) e impulsar, en algunos casos, la constitución de clusters como la aeroespacial de reciente creación en el estado de Sonora con apenas año y medio, la nanotecnología, productos del mar, frutales y turismo.

Asimismo, se puede observar en las Tablas 3 y 4 que el análisis de correlación y del coeficiente de determinación nos permite comprender que hay variables, y que los empresarios de las PyMES tienen que tomar ajustes inmediatos en cuanto a sus indicadores, como el caso de la estructura organizacional que requiere una revisión profunda; además, deben flexibilizarse para ser eficientes. También se tendrán que revisar los indicadores de diversas variables -mercadotecnia, competitividad, planeación y administración- y redefinir algunos de ellos y su operación. Se requiere darle seguimiento muy cerca de tal modo que les permita mejorar los resultados respectivos que se tienen. Se tendrá que ser más estricto en la definición de su plan estratégico y de las acciones que generan ventajas auténticamente competitivas, porque si no se corre el riesgo de no estar en posición de competir con las empresas mexicanas y extranjeras que ya están en México. Aunque en gran medida las variables sí explican al ICE su eficiencia e indican que las PyMES deben poner mucha atención en plantear y llevar a cabo sus operaciones en sus segmentos de mercado, tener un buen control en comercializar, financiar y cobrar sus operaciones con la banca y sus clientes. Deben, también, darle un seguimiento estricto para hacer los ajustes pertinentes para mejorar sus resultados y así obtener auténticamente ventajas competitivas.

De los resultados del modelo de Competitividad Empresarial presentado en la Figura 2, se destaca la importancia de ICE para las PyMES en los municipios y regiones, los cuáles permiten establecer que a medida que se vinculen los centros de investigación en áreas de investigación y desarrollo, instituciones y organismos públicos y privados y las universidades -en torno a fortalecer el ICE- será posible obtener ventajas competitivas en lo interno y externo de cada empresa, y permitirán desarrollar nuevas industrias y clusters en las opciones no tradicionales para el estado de Sonora.

Finalmente, no se descarta que existan otras variables que afecten el ICE a las empresas PyMES manufactureras de la región; empero, aunque existen pocas aportaciones que permitan cuantificarse, esta investigación representa un esfuerzo y primer acercamiento de medición de la ICE a niveles desagregados. 


\section{Referencias Bibliográficas}

Anderson, A. (1993, octubre). The impact of key internal factors on firms performance the standaring date study. Journal of Small Business Management. 31 (4), 86-92.

Álvarez, J.C., \& García, E. (1996). Factores de éxito y riesgo en la PyME: Diseño e implantación de un modelo para la mejora de la competitividad, Economía Industrial. 310, 149-161.

Álvarez, M., \& Palacios, P. (1994). Estrategias Efectivas para Incrementar su Posición Competitiva. Madrid: Panorama.

Batres, R., \& García, L. (2006). Paper: Competitividad y desarrollo internacional. México: McGraw-Hill.

Ansoff, H. I. (1969). Corporate Strategy. Londres: Pinguin.

Biasca, R. (2000). Resultados: La fórmula para crecer en el vértigo competitivo. Argentina: Granica.

Camisón, C. (1997). La competitividad de la PyME industrial española: estrategia y competencias distintivas. Madrid: Cívitas.

COPARMEX (2014). Estudio de la Empresa Media. México: BMZ, SEQUA, FUNDES.

Chang, S., \& Singh, H. (2000). Corporate and industry effects on business unit competitive position. Strategic Management Journal. 21 (7), 739-752.

David, F.R. (2008). Conceptos de Administración Estratégica. México: Pearson.

Gómez-Mejía, L.R., Balkin, D.B., \& Cardy, R.L. (1996). Gestión de Recursos Humanos, Madrid: Prentice Hall.

HerediaA., \& MiguelA. (2004). La Competitividad y desarrollo en México. Revista Latinoamericana de Economía. 35 (138), 14-31. 
Huck, J., \& McEwen, T. (1991, octubre). Competencies needed for small business success: Perceptions of Jamaican entrepreneurs. Journal of Small Business Management. 29 (2), 90-93.

Huerta, E., Bayo Moriones, J.A., García Olaverri, C., \& Díaz de Cerio, J.M. (2003). Los desafíos de la competitividad. La innovación organizativa y tecnológica en la empresa española. Bilbao: Fundación BBVA.

Jennings, P., \& Beaver, G. (1997, enero-febrero). The performance and competitive advantage of small firms: a management perspective. International Small Business Journal. 15 (2), 63-73.

Johnson G., Scholes K., \& Whittington R. (2006). Dirección Estratégica. Madrid: Pearson.

Kester, C., \& Luehrman, T. (1989). Are we feeling more competitive yet? The exchange rate gambit. Sloan Management Review, 19, 19-28.

Kotler P., \& Kevin L.K. (2006). Dirección de Marketing. México: Pearson.

Mercado, E. (1997). Productividad base de la Competitividad. México: Limusa.

McCarthy E.J., \& Perreault, Jr. W. (2001). Marketing un Enfoque Global. México: McGraw-Hill / Irwin.

Peres, W. (1994). Política para impulsar la competitividad de las empresas, Revista CEPAL, 53. $25-33$.

Porter, M.E. (1998). On competitive. Boston: Harvard Business Review Book.

Porter, M.E. (2005). Ventaja Competitiva creación y sostenimiento de un desempeño superior. México: Continental.

Porter, M.E. (1991). La ventaja competitiva de las naciones, Barcelona: Plaza \& Janes.

Porter, M.E. (2007). Estrategia competitiva: técnicas para el análisis de los sectores industriales y de la competencia. México: Patria. 
Rogoff, E., Lee, M., \& Suh, D. (2004). Who done it? Attributions by Entrepreneurs and Experts of the Factors that Cause and Impede Small Business Success. Journal of Small Business Management, 42 (4), 374-376.

Ruiz, R. (2003), Política económica de competitividad, El Mercado de Valores. 12, año LXII.

Solís, L., \& Díaz, A. (2006). La infraestructura y competitividad en México. México: Instituto de Investigación Económica y Social "Lucas Alamán", A. C.

Viedma, J.M. (1992). La excelencia empresarial española. España: McGraw-Hill.

Villarreal, R. (2002). México competitivo 2020: Un modelo de competitividad sistémica para el desarrollo. México: Océano.

World Economic Forum (2013). The Global Competitiveness Report 2013-2014. Recuperado de http://www3.weforum.org/docs/WEF_GlobalCompetitivenessReport_2013-14.pdf

Yusuf, A. (1995, abril). Critical success factors for small business: perceptions of South Pacific entrepreneurs, Journal of Small Business Management. 33 (2). 


\section{Capítulo 3}

Factores de competitividad de empresas sociales:

La competitividad en las organizaciones Leonardo Vázquez Rueda, Blanca Isela Ramírez y Concepción Suástegui Barrera

\section{Introducción}

Las empresas sociales son agentes económicos derivados de la economía social y solidaria que constituyen una oportunidad para la inserción socio-productiva de la población en condiciones de pobreza, "porque representan una fuente de ocupación laboral y brindan diferentes beneficios tanto a quienes las conforman, como a sus familiares y sus comunidades" (Vázquez, 2015).

En la actualidad existe un creciente interés, público, académico y político, por fomentar el desarrollo de las empresas de economía social y solidaria, porque se han convertido en espacios productivos que ayudan a minimizar los estragos de un crecimiento económico inequitativo que ha prestado una excesiva atención al incremento de rendimientos financieros en el ámbito empresarial tradicional y que ha ocasionado el surgimiento de demandas sociales que ni el estado ni la empresa privada han podido satisfacer.

La principal necesidad que pretende resolver el proyecto, denominado "Factores de competitividad de empresas sociales que son determinantes de un mayor impacto socioeconómico. Análisis de unidades productivas ubicadas en seis comunidades rurales del municipio de Mazatlán, Sinaloa, pertenecientes a la sindicatura de Villa Unión", es la carencia de información primaria sobre los factores endógenos y exógenos que influyen en la competitividad de empresas sociales de las comunidades de La Urraca, El Vainillo, La Tuna, San Francisquito, Loma de Monterrey y Escamillas, ubicadas en la sindicatura de Villa Unión, en el municipio de Mazatlán, Sinaloa, México, y que influyen directamente en un mayor nivel de impacto socioeconómico de estas unidades productivas. 
De esta manera, se podrían desplegar las bondades propuestas por la economía social y solidaria, al replicar las experiencias exitosas a través de un modelo de gestión que ayude a elevar la competitividad de otras empresas sociales y que posibilite el logro de su finalidad social, asegurando que repercutan en el bienestar de los individuos que las integran, la consolidación de la unidad productiva, así como un adecuado impacto comunitario.

La propuesta está basada en un estudio previo de empresas sociales apoyadas por el Fondo Nacional de Empresas en Solidaridad (FONAES), ahora Instituto Nacional de la Economía Social (INAES), que sirvió para atender un problema similar al que aquí se plantea. Dicha investigación titulada "Modelo de Competitividad determinante del impacto socioeconómico de empresas sociales" permitió obtener el grado de doctorado en enero de 2014 a Leonardo Vázquez Rueda, colaborador del CA que presenta el proyecto.

Tradicionalmente, el FONAES y otros programas gubernamentales que apoyan a empresas sociales para su apertura o ampliación son sujetos a análisis por diversas instituciones educativas o centros de investigación a los que se les permiten tener información sobre su funcionamiento (Universidad Autónoma de Chapingo, 2001, 2003, 2004, 2005, 2006, 2007; Colegio de México, 2007; Benemérita Universidad Autónoma de Puebla, 2009; CONEVAL, 2011, 2012; PNUD, 2012; CONEVAL, 2013, como se citó en Vázquez, 2014b). Sin embargo, existe una incipiente investigación enfocada exclusivamente a las pequeñas unidades productivas que no han sido apoyadas por el gobierno o por alguna organización civil.

\section{Objetivo general}

Diseñar un modelo de competitividad estadístico que sea determinante de un mayor impacto social y económico de las empresas ubicadas en seis comunidades rurales de la sindicatura de Villa Unión en el municipio de Mazatlán, Sinaloa. Entendiendo por modelo de competitividad un conjunto de variables asociadas mayormente al éxito o consolidación de una empresa (Vázquez, 2014b).

Este modelo busca identificar los principales factores internos y externos que influyen directamente en el impacto socioeconómico de las empresas sociales ubicadas en las comunidades señaladas y que además podría ser replicado en el análisis de otras organizaciones empresariales, independientemente de que sean derivadas de la economía social y solidaria.

\section{Objetivos específicos}

- Clasificar las empresas sociales con base en el impacto socioeconómico que ha generado su implementación

- Identificar las características competitivas internas y externas de las empresas sociales 
- Analizar y relacionar los factores internos y externos de competitividad que inciden en el nivel de competitividad socioeconómico de las empresas sociales

En el primer apartado se presenta la descripción del problema del proyecto de investigación. Enseguida se hace un acercamiento teórico partiendo de la conceptualización de empresa social que sustenta el proyecto, así como los atributos que caracterizan al emprendedurismo social y que son distintivos de las empresas sociales. Asimismo, se retoma la teoría de la economía social y solidaria, la teoría de la cadena de valor y la teoría del diamante de la competitividad que son las teorías en las que se basa el diseño del modelo teórico de competitividad de empresas sociales. Adicionalmente, se exponen los fundamentos teóricos que sirven de base para proponer el impacto socioeconómico de estas unidades productivas.

En el tercer apartado se determinan los elementos que constituyen el diseño de la investigación: enfoque, método y las técnicas de recolección de datos. En otro apartado se señalan los lineamientos que guiarán el análisis de los resultados de la encuesta aplicada a 48 empresas sociales de La Tuna, El Vainillo, Lomas de Monterrey, San Francisquito, Escamillas y La Urraca. Por último, se presentan las conclusiones surgidas de las reflexiones realizadas hasta esta etapa del proyecto, así como la bibliografía consultada.

\section{Planteamiento del problema}

El desarrollo equilibrado de la actividad empresarial representa una oportunidad para el despliegue de beneficios directos e indirectos en las comunidades o localidades en las que se lleva a cabo, sobre todo cuando los asentamientos donde se realiza se han caracterizado por carecer de las condiciones idóneas para incrementar el bienestar y la calidad de vida de las personas que ahí habitan.

En este sentido, las empresas sociales, como actores importantes de la economía social y solidaria, representan una oportunidad para la inserción productiva de la población que sobrevive en contextos adversos y cuyas necesidades y aspiraciones no han logrado ser satisfechas ni por el estado, ni por el sector privado (Amin, 2009; Azzellini, 2009; Neamtan, 2009; Singer, 2009; Romero y Hurtado, 2011; Chavez y Monzón, 2012).

Las empresas sociales tienen diferentes conceptualizaciones, aunque en la presente propuesta nos apegaremos a una de las definiciones realizada por Yunus (2010), quien afirma que una empresa social también puede ser una iniciativa empresarial de personas que se encuentran en condiciones de pobreza con la intención de obtener rendimientos económicos para mejorar sus ingresos y su nivel de vida. En este sentido se reconoce que una empresa social es "una organización empresarial dirigida por personas de escasos recursos que a través 
de procesos y diversas estrategias buscan obtener beneficios sociales y económicos, internos y externos" (Vázquez, 2014b).

El interés de esta investigación surge porque las empresas sociales son agentes económicos que tienen el potencial para mejorar el bienestar de las personas en condiciones de pobreza, a través de la generación de empleos y de ingresos para quienes participan directa o indirectamente en su operación.

La siguiente interrogante guía el trabajo de investigación: ¿Cuáles son los factores internos y externos que influyen en la competitividad de las empresas sociales de La Tuna, El Vainillo, Lomas de Monterrey, San Francisquito, Escamillas y La Urraca y que, a la vez, son determinantes de un mayor impacto socioeconómico?

\section{Revisión teórica}

En este trabajo se entiende por empresa social "una organización empresarial dirigida por personas de escasos recursos que a través de procesos y diversas estrategias buscan obtener beneficios sociales y económicos para sus integrantes y para sus comunidades" (Vázquez, 2014a). Asimismo, diversos autores concuerdan en que el emprendedurismo social posee atributos particulares que lo distinguen de otro tipo de emprendimientos.

Para Guzmán y Trujillo (2008), el emprendimiento social se caracteriza por buscar soluciones a problemas sociales, a través de construir, evaluar y perseguir oportunidades que generen valor social sostenible, alcanzando equilibrios relacionados con las condiciones sociales de grupos marginados, y que son llevadas a cabo por organizaciones de diversa índole, sin ánimo de lucro, privadas o gubernamentales.

En el emprendimiento social actua únicamente en función de la maximización de beneficios económicos; no es un comportamiento completamente ético, ya que además se necesita que los emprendedores sociales contribuyan en la construcción de una nueva ciudadanía basada en el respeto y la búsqueda del bienestar social.

Entre los atributos que caracterizan al emprendedurismo social existen algunos que lo distinguen, tales como el cumplimiento de un propósito social, el mantener un juicio equilibrado para enfrentar las situaciones y la visión de oportunidades, así como otras cualidades que se comparten con el emprendedurismo en el ámbito comercial como son la tolerancia a los riesgos, la proactividad y la innovación (Sullivan, Weerawardena y Carnegie, 2003).

Por otra parte, Tan, W. L., Williams y Tan, T. M., (2005) señalan que el emprendedor social puede estar ligado a la idea de desempeño de un liderazgo individual que se evalúa en función de los resultados que las acciones de liderazgo tengan en relación al desempeño social, político o cultural de la comunidad. Los logros que definen al emprendedor social es- 
tán ligados al beneficio que recibe la comunidad, como el crecimiento de la riqueza material, pero también la contribución al fortalecimiento de los valores que le dan cohesión al grupo, la innovación que enriquece la cultura tecnológica y, en general, a toda acción que proviene de la sociedad y la enriquece física o simbólicamente.

Los segmentos de la sociedad que un emprendedor social necesita para obtener ganancias no tienen que ser los mismos que aquellos a los que se intenta beneficiar con la actividad empresarial. Por otra parte, se debe recalcar que una persona se convierte en emprendedora cuando se compromete a lograr ganancias, asumiendo los riesgos que ello implica y no necesariamente hasta que se obtienen las ganancias esperadas.

Las principales teorías en las cuales se basa el presente estudio son la teoría de la economía social y solidaria, la teoría de la cadena de valor y la teoría del diamante de la competitividad. La primera se utiliza para determinar las características que distinguen a las empresas sociales por un lado, así como los resultados que se deben alcanzar, mientras que las dos últimas servirán de base para determinar el modelo competitivo de empresa social que se requiere para asegurar el logro de las aspiraciones propuestas.

La teoría de la economía social y solidaria basa sus supuestos en una dignificación del ser humano y asegura que a través del adecuado manejo de los recursos se pueden redistribuir adecuadamente los excedentes que se generen en la realización de las diversas actividades económicas. Esta propuesta considera que a través de la colaboración y el trabajo asociativo se podrán lograr mejores niveles de bienestar entre la población (Robinson y Hanson, 1995, referido en Benemérita Universidad Autónoma de Puebla, 2009).

La teoría de la cadena de valor centra su propuesta en los eslabones internos que conforman una organización empresarial, que se desglosan en diferentes actividades o funciones entrelazadas y que necesitan desempeñarse satisfactoriamente para repercutir en el margen de impactosocialydeutilidadeconómicaquesegeneraenuna organizaciónempresarial(Porter,1991).

Por último, la teoría del diamante de la competitividad se enfoca en determinar los factores externos del entorno competitivo de las organizaciones que tienen un impacto directo en sus resultados. Entre los elementos que considera esta propuesta teórica están los relacionados con el estatus que guardan los factores de la producción, las características de la demanda local para los bienes o servicios que se ofrecen. También se centra la atención en el ambiente competitivo que impera, en las industrias relacionadas con la actividad productiva y que pueden facilitar o limitar el desarrollo de las empresas, así como en el rol que desempeña el gobierno en el funcionamiento del contexto empresarial (Porter 2008a; 2008b).

Las teorías analizadas sirven de base a la propuesta del modelo teórico del presente estudio (Vázquez, 2014b). Por un lado, se encuentra la teoría de la cadena de valor de la cual 
se extraen los factores internos y, por otro, se encuentra la teoría del diamante de la competitividad de donde emanan los factores externos. En ambos casos se trata de propuestas teóricas que identifican diferentes elementos a través de los cuales las organizaciones empresariales de economía social se encaminan a la competitividad.

Adicionalmente, el desarrollo del marco teórico permitió el acercamiento a diferentes perspectivas que fueron de utilidad para la determinación de las condiciones que debía cumplir el impacto socioeconómico de las empresas sociales bajo estudio, específicamente en los niveles individual, empresarial y comunitario.

La búsqueda del desarrollo económico y social ha sido un elemento central al momento de diseñar políticas públicas. Su abordaje ha sido desde diferentes perspectivas las cuales pretenden, en última instancia, incrementar los niveles de bienestar de las regiones donde son implementadas sus estrategias. Naturalmente, los sujetos que necesitan incrementar en mayor medida su calidad de vida son aquellos que se encuentran en condiciones de pobreza.

El desarrollo económico regional implica incrementos en el bienestar de la población de una determinada región, que pueden ser tangibles entre otras cosas en los ingresos de las personas y en la disponibilidad de servicios sociales (Salguero, 2006).

Cabe mencionar que el Programa de las Naciones Unidas para el Desarrollo (2014) ha adoptado desde 1990 un índice para medir el desarrollo humano de países y regiones. Dicho indicador denominado Índice de Desarrollo Humano incorpora la educación, la salud y el acceso a bienes y servicios por medio del ingreso disponible.

En el enfoque antes señalado, el ingreso constituido por la renta de los individuos no representa una finalidad en sí misma, ya que su aprovechamiento o utilización está en función de otros elementos socioculturales, aunque sí representa un instrumento para tener capacidades, que a su vez habilitarían a los sujetos a mejorar sus niveles de bienestar (Cejudo, 2007). La actividad empresarial representa una fuente de capacidades para los individuos, quienes a través de su inserción laboral obtienen además de un empleo, un ingreso que los habilita para conseguir recursos necesarios para incrementar sus niveles de bienestar.

Las empresas sociales en cualquiera de sus modalidades, las cuales son regularmente pequeñas unidades productivas, tienen el potencial para convertirse en agentes económicos importantes del desarrollo, aunque todavía falta camino por recorrer para expandir su uso y sus posibilidades de consolidación (Yunus, 2008).

Algunos indicadores de un incremento en la calidad de vida, comúnmente aceptados, que pueden servir de base para demostrar el nivel de impacto social y económico que ha tenido la operación de las empresas sociales en sus integrantes, son el logro de un incremento en alguna de las siguientes variables: salud, alimentación, educación, vivienda, vestido y calzado 
(Alkire, 2002, citado en Programa de las Naciones Unidas para el Desarrollo, 2012).

La afirmación anterior se realiza considerando que para poder mejorar el bienestar en cualquiera de las variables mencionadas, los individuos necesitan tener un empleo estable e ingresos suficientes para lograrlo, que en ambos casos representan propósitos fundamentales de las empresas sociales (Díaz y Marcuello, 2010; Kerlin, 2010; Romero y Hurtado, 2011; Amat y Perramon, 2011).

En México, la ausencia de condiciones para tener una adecuada alimentación, salud, educación, vivienda y vestido, constituían los principales criterios que el Consejo Nacional de Evaluación de la Política de Desarrollo Social incluye en su concepción de pobreza de patrimonio (CONEVAL, 2010) y que además están presentes en la definición de la misma institución de pobreza multidimensional (CONEVAL, 2009).

La pobreza de patrimonio es definida como la "insuficiencia del ingreso disponible para adquirir la canasta alimentaria, así como realizar los gastos necesarios en salud, vestido, vivienda, transporte y educación, aunque la totalidad del ingreso del hogar fuera utilizado exclusivamente para la adquisición de estos bienes y servicios" (CONEVAL, 2010, p. 13).

De acuerdo a los lineamientos generales para la definición, identificación y medición de la pobreza publicados en el Diario Oficial de la Federación del 16 de junio de 2010, la educación es un elemento trascendental a través del cual se puede lograr la integración de las personas a la sociedad, la economía y la cultura. Mientras que el hecho de contar con una salud satisfactoria permite mejorar el funcionamiento físico y mental de las personas.

El espacio físico representado por la vivienda en la que habitan las personas es un factor determinante en su calidad de vida, en combinación con los servicios básicos de los cuales se dispone. Además, es visto que el contar con una adecuada alimentación permite llevar una vida activa y sana (DOF, 16 de junio de 2010).

De la misma forma, el Informe sobre Competitividad Social en México 2012 elaborado por el Programa de las Naciones Unidas para el Desarrollo (PNUD), toma como referencia diferentes dimensiones universales de desarrollo humano para elaborar sus análisis.

Por otra parte, los proyectos productivos implementados en comunidades que han resultado afectadas por la lógica tradicional con la que se desenvuelve el mercado global, se reconocen como sustentables y de mayor impacto socioeconómico en la medida en que incrementan el arraigo de la población en sus comunidades, generan alternativas de empleo y permiten reproducir y conservar los ecosistemas locales, así como las tradiciones productivas ancestrales (Velázquez, Porras y Touron, 2008).

El estudio de la Confederación Empresarial Española de la Economía Social (2013) reconoce dificultades para avanzar en el análisis del impacto socioeconómico de las empresas 
de economía social y concluye que su valoración se puede visualizar en los efectos que se desglosan en la Tabla 2.

A continuación, en la Figura 1 se presenta gráficamente el modelo teórico del estudio, que incluye los factores internos y externos, así como las teorías en las cuales está basado. Para tener una visión detallada del modelo se pueden consultar los Anexos 1 y 2 de Vázquez (2014a) donde se desglosan los factores internos, los factores externos determinados para el estudio, así como las variables consideradas en cada uno de dichos factores. Asimismo, en el mismo documento en el Anexo 3 se muestran las variables identificadas para la determinación del impacto socioeconómico en los niveles individual, grupal y comunitario, así como las variables consideradas en cada uno de dichos factores.

\section{Competitividad de Empresas Sociales}

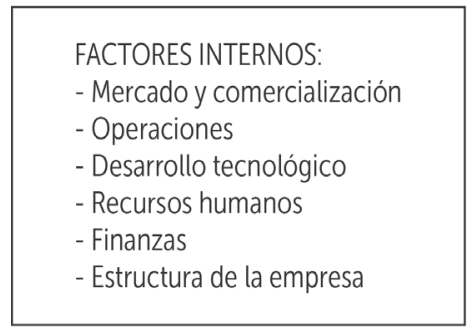

Teoría de la Cadena de Valor

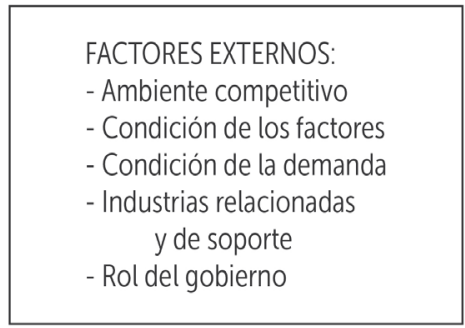

Teoría del Diamante de Competitividad

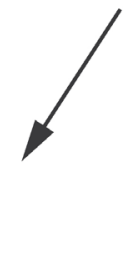

Figura. 1. Modelo teórico general del proyecto de investigación. Fuente: Vázquez (2014b).

\section{Metodología}

El enfoque aplicado es el cuantitativo, ya que -de acuerdo a Hernández, Fernández y Baptista (2010) - se reúnen las características de este tipo de estudios, tales como: necesidad de plantear un problema de investigación, revisar la literatura y paralelamente avanzar en la construcción del marco teórico lo cual proporciona elementos para elaborar la hipótesis.

Con base a lo anterior y de acuerdo a las características del problema se necesita desarrollar un diseño de investigación, determinar la muestra y proceder a recolectar los datos de campo. Por último, se analizarán los resultados obtenidos tomando como referencia las 
hipótesis planteadas y a partir de ello se elaborarán las conclusiones finales de estudio.

El alcance del estudio será explicativo porque está dirigido a reconocer las causas de un evento social, al intentar identificar los factores competitivos que originan un mayor impacto socioeconómico de las empresas sociales. Adicionalmente, a través de los resultados se obtiene un mayor entendimiento del fenómeno estudiado (Hernández, et al., 2010).

La metodología consiste en la utilización de una estrategia de levantamiento de información a través de encuestas aplicadas utilizando la técnica de la entrevista. Con respecto al tamaño de la muestra se destaca que para este estudio se tomó como referencia la base de datos de la Cámara Nacional del Comercio en Pequeño (CANACOPE), la cual muestra que el universo de las empresas micro y pequeñas de estas comunidades es de 82. Las empresas se encuentran distribuidas de la siguiente manera:

\begin{tabular}{|l|l|l|l|}
\hline Comunidad & Cantidad & Comunidad & Cantidad \\
\hline La Urraca & 8 & San Francisquito & 18 \\
\hline El Vainillo & 17 & Loma de Monterrey & 12 \\
\hline La Tuna & 15 & Escamillas & 12 \\
\hline & & TOTAL & 82 \\
\hline
\end{tabular}

De acuerdo a Stevenson (2002) el tamaño de la muestra de una población finita se puede determinar a través de la siguiente fórmula:

$$
n=\frac{z^{2}(x / n)[1-(x / n)](N)}{(N-1) e^{2}+z^{2}(x / n)[1-(x / n)]}
$$

Donde: $z=1.96, p=0.5, q=0.5, N=82, e=10 \%$

Con la sustitución de los datos en la fórmula se obtuvo una muestra representativa de 45 empresas a encuestar con lo cual se garantiza un margen de error del 10\% y un nivel de confianza del $95 \%$.

Debido a las características del universo que cuenta con condiciones socioeconómicas homogéneas derivado de que se encuentra en una región geográfica reducida se realizó un muestreo aleatorio simple.

Las hipótesis que se plantean en el presente estudio se basan en la influencia que tienen los factores internos y externos de competitividad, en un mayor nivel de impacto socioeconómico de las empresas sociales, como a continuación se describen: 


\section{Hipótesis generales}

Hipótesis 1: Existen factores internos, incluidos en la cadena de valor de una empresa social, entre los que se encuentran la administración de recursos humanos, la administración de las operaciones, la administración de la mercadotecnia y las ventas, la administración financiera, la administración del desarrollo tecnológico y la estructura organizativa, que están relacionados y son determinantes de un mayor impacto socioeconómico de estas organizaciones, entendido como el mejoramiento de las condiciones de vida de sus integrantes, los resultados de negocios, asi como de los beneficios aportados a la comunidad.

Hipótesis 2: Existen factores propios del entorno competitivo externo de una empresa social, entre los que se encuentran, la condición de los factores de producción, la condición de la demanda, la dinámica de la rivalidad y la competencia que se vive en una industria, las organizaciones de apoyo y de soporte a la actividad empresarial, así como el rol del gobierno, que se encuentran relacionados y son determinantes de un mayor impacto socioeconómico de estas organizaciones, entendido como el mejoramiento en las condiciones de vida de sus integrantes, los resultados de negocios, así como de los beneficios aportados a la comunidad.

\section{Resultados}

Se encuestaron a 48 empresas sociales de las comunidades de La Tuna, El Vainillo, Lomas de Monterrey, San Francisquito, Escamillas y La Urraca pertenecientes a la sindicatura de Villa Unión de Mazatlán, Sinaloa.

A partir de las encuestas aplicadas se procederá a clasificar a las empresas sociales analizadas con base en el impacto socioeconómico que ha generado su implementación.

Lo anterior es pertinente, ya que para la elaboración del modelo estadístico de competitividad se necesita discriminar entre las empresas exitosas y no exitosas. Para distinguir entre las empresas de menor impacto y aquellas de mayor impacto, se llevará a cabo un análisis estadístico de conglomerados no jerárquico que permitirá formar los dos grupos señalados.

El análisis y la relación de los factores endógenos y exógenos permitirán elaborar el modelo de competitividad estadístico, ya que se podrán identificar en las empresas exitosas los factores de riesgo, asi como los protectores, entendiendo que estos últimos cuentan con una mayor razón de momios.

Respecto al concepto de implementación, cabe destacar en primera instancia que este concepto se refiere a la puesta en marcha de las empresas sociales que se pretenden analizar. Como lo afirman Robbins y Descenzo (2009) la implementación se refiere a poner en 
práctica una empresa, es decir, comenzar a operarla, lo cual lleva implícito el involucramiento de todas las personas y funciones de la organización.

Para lograr lo anterior se realizará un análisis estadístico de componentes principales que servirá para detectar la estructura de las variables que estén relacionadas al éxito de la empresa.

\section{Conclusiones}

Las empresas sociales son entes productivos que tienen la capacidad para generar fuentes de empleo y de ingresos a aquellas personas que se encuentran incrustadas en contextos socioeconómicos tradicionalmente excluidos de los beneficios generados por un sistema que ha privilegiado la obtención de ganancias económicas y ha dejado de lado los beneficios sociales.

El planteamiento de este trabajo surge del interés por lograr que las empresas sociales mejoren significativamente su nivel de impacto, al mismo tiempo que sus empresarios o responsables desarrollan las habilidades gerenciales que les permiten identificar aquellos factores que influyen en la competitividad de sus organizaciones.

El modelo de competitividad resultante del presente trabajo de investigación permitirá predecir un mayor nivel de impacto socioeconómico de las empresas sociales bajo estudio. 


\section{Referencias Bibliográficas}

Amat, O., \& Perramon, J. (2011). High-Growth cooperatives: Financial Profile and Key Factors for Competitiveness. CIRIEC-España. Revista de economía pública, social y cooperativa. 73, 81-98.

Amin, A. (2009). Locating the social economy. The Social Economy. International Perspectives on Economic Solidarity. Londres: Zed books.

Azzellini, D. (2009). Venezuela's Solidarity Economy: Collective ownership, expropriation and workers self-management. Working USA: The Journal of Labor and Society. 12. 171-191.

Benemérita Universidad Autónoma de Puebla. (2009). Evaluación Integral Externa 2008-2009 del Fondo Nacional de Apoyos para Empresas en Solidaridad. Puebla: BUAP.

Cejudo, C.R. (2007). Capacidades y libertad. Una aproximación a la teoría de Amartya Sen. Revista Internacional de Sociología, LXV (47). 9-22.

Chaves, R., \& Monzón, J.L. (2012). Beyond the crisis: the social economy, prop of a new model of sustainable economic development. Service Business: An International Journal. 6, 5-26. http://doi.org/10.1007/s11628-011-0125-7

Constitución Política de los Estados Unidos Mexicanos. (Última reforma Diario Oficial de la Federación 26-02-2013).

Díaz, F.M., \& Marcuello, S.C. (2010). Impacto económico de las cooperativas. La generación de empleo en las sociedades cooperativas y su relación con el PIB. CIRIEC-España. Revista de economía pública, social y cooperativa. 67, 23-44.

Diario Oficial de la Federación de México. (2010, 16 de junio). Lineamientos y criterios generales para la definición, identificación y medición de la pobreza. Segunda sección.

Guzmán, A. y Trujillo, M. A. (2008). Emprendimiento social - revisión de literatura. Estudios Gerenciales, 24 (109) 105-125. 
Hernández, S.P., Fernández, C.C., \& Baptista, L.P. (2010). Metodología de la investigación. México: Mc Graw Hill.

Neamtan, N. (2009). Social economy: concepts and challenges. Universitas Forum, 1 (3) 1-5.

Porter, M.E. (1991). Towards a dynamic theory of strategy. Strategic Management Journal, 12, 95-117.

Porter, M.E. (2008a). The Competitive Advantage of Nations. On competition. Boston: Harvard Business Review Book.

Porter, M.E. (2008b). Competing across locations. On competition. Boston: Harvard Business Review Book.

Programa de las Naciones Unidas para el Desarrollo (2012). Evaluación Específica de CostoBeneficio 2011 del Programa Nacional de Apoyos para Empresas en Solidaridad (FONAES). México: PNUD. Recuperado de http://www.economia.gob.mx/files/transparencia/info_costo_ beneficio_fonaes.pdf

Programa de las Naciones Unidas para el Desarrollo (2012). Informe sobre competitividad social en México 2012. México: PNUD. Recuperado de http://www.mx.undp.org/content/dam/ mexico/docs/Publicaciones/PublicacionesReduccionPobreza/InformesDesarrolloHumano/ UNDP-MX-\%20PovRed-ICSMexico-2012.pdf

Programa de las Naciones Unidas para el Desarrollo (2014). Informe sobre desarrollo humano 2014. Sostener el Progreso Humano: Reducir vulnerabilidades y construir resiliencia. Nueva York: PNUD. Recuperado de http://hdr.undp.org/sites/default/files/hdr14-report-es.pdf

Romero, G.R.M., \& Hurtado, M.J. (2011). La empresa social. Una opción de desarrollo local en la comunidad indígena de San Idelfonso. Gestión y Estrategia, 39, 19-28.

Salguero, J.C. (2006). Enfoques sobre algunas teorías referentes al desarrollo regional. Sociedad Geográfica de Colombia. Academia de Ciencias Geográficas. Conferencia Estatutaria para posesionarse como Miembro de Número de la Sociedad Geográfica de Colombia. 
Singer, P. (2009). Relaciones entre sociedad y estado en la economía solidaria. Iconos, Revista de Ciencias Sociales. 33, 51-65.

Stevenson, W. (2002). Estadística para administración y economía. Oxford: México.

Sullivan, M.G., Weerawardena, J., \& Carnegie, K. (2003). Social entrepreneurship: Towards conceptualisation. International Journal of Non Profit and Voluntary Sector Marketing. 8, (1), 76-88.

Tan, W.L., Williams, J., \& Tan, T.M. (2005). Defining the "social" in "social entrepreneurship": Altruism and entrepreneurship. International Entrepreneurship and Management Journal. 1, 353-365.

Vázquez, R.L., Solís, O.D., \& Ramírez, B. (2015). Gestión administrativa e innovación para el desarrollo de empresas sociales rurales. Disponible en: http://casesis.net/riti/35/Vol3No5_I.pdf

Vázquez, R.L., Ramírez, B., \& Suátegui B.C. (2014a). Modelo teórico de competitividad determinante del impacto socioeconómico de empresas sociales. Panamá: XIV Asamblea General de la ALAFEC.

Vázquez, R.L. (2014b). Modelo de competitividad determinante del impacto socioeconómico de empresas sociales. Análisis de proyectos productivos apoyados por FONAES en el sur de Sinaloa (Tesis Doctoral). Puebla: Universidad Popular Autónoma del Estado de Puebla.

Velázquez, S.I., Porras, M.A., \& Touron, V.L. (2008). Estrategia de desarrollo sustentable para generar alimento y empleo: el gusano cuchamá en Zapotitlán Salinas, Puebla, México. Argumentos, UAM X. 56, 119-135. Recuperado de http://scielo.unam.mx/pdf/argu/v21n56/ v21n56a7.pdf

Yunus, M. (2008). Creating a world without poverty: social business and the future of capitalism. Global Urbandevelopment. 4 (2), 1-19.

Yunus, M. (2010). Empresas para todos. Hacia un Nuevo modelo de capitalismo que atiende las necesidades más urgentes de la humanidad. Bogotá: Grupo Editorial Norma. 


\section{Capítulo 4}

Factores estratégicos en la adopción de la gestión del conocimiento en las pequeñas y medianas empresas Josefina Ochoa Ruiz, Amado Olivares Leal y María Leticia Verdugo Tapia

\section{Introducción}

El mundo globalizado en que se desarrollan las empresas se caracteriza por ser dinámico y complejo y con un alto nivel de desarrollo tecnológico. Esta complejidad se puede traducir, entre otras cosas, en el surgimiento de nuevas áreas del conocimiento, cambios acelerados en la estructura del mercado, aceleración de la innovación científica y tecnológica, rapidez de los flujos de información, así como en la aceptación cada vez más generalizada de que tanto el conocimiento como la tecnología son los elementos de mayor impacto para el desarrollo de los países.

Ante los grandes cambios que se viven actualmente en el desarrollo de la humanidad, el rol del conocimiento se ha constituido el elemento clave y diferenciador del crecimiento económico. La sociedad del conocimiento, la economía de la información, el capital intelectual, son algunos conceptos que las organizaciones deben aprovechar para adaptarse continuamente al entorno, para actualizar sus estructuras y responder a los nuevos retos, y así puedan desarrollarse exitosamente y en algunos casos garantizar su supervivencia. Por otra parte, las pequeñas y medianas empresas (PyMES), aportan a la economía nacional un gran número de unidades económicas y personal ocupado; de ahí la relevancia que reviste este tipo de empresas y la necesidad de fortalecer su productividad. En el presente trabajo se busca presentar los factores estratégicos en la adopción de la gestión del conocimiento (GC) en las PyMES, ya que es una herramienta que les puede ayudar a incrementar su desempeño y por tanto a incidir exitosamente en la sociedad en general. 


\section{Planteamiento del problema}

En el entorno global en que se desarrollan actualmente las organizaciones, la agresividad de la competencia y la rapidez de cambio, está obligando a las empresas a mantenerse actualizadas de todos aquellos recursos que les permitan mejorar su competitividad y su desempeño.

Las empresas, entre ellas las PyMES están obligadas a redefinirse de acuerdo a las necesidades de un entorno cambiante, a buscar continuamente todas aquellas prácticas que las lleven a ser más eficientes en su desempeño para mejorar su competitividad tanto nacional como global. La gestión del conocimiento (GC) se está convirtiendo en un activo importante en el éxito presente y futuro de las organizaciones, pues se debe tener la capacidad de crear, almacenar y difundir el conocimiento.

Ante esta problemática surgen las siguientes preguntas de investigación: ¿Existe en las PyMES una cultura del conocimiento?, ¿Conocen la importancia de adoptar del uso de la GC en sus empresas?, ¿Conocen los factores claves para que el personal de la empresa adopte la GC? Todas ellas preguntas que se han formulado diferentes investigadores, gerentes y administradores de empresas y cuyas respuestas ayudarían a mejorar su competitividad y desarrollo.

\section{Objetivo general}

Determinar cuáles son los factores clave para la adopción de la gestión del conocimiento en el personal de las PyMES de Hermosillo, Sonora.

\section{Revisión teórica}

Como lo señalan Sánchez, Hernández y Haro (2008), "las nuevas condiciones de competitividad obligan a las empresas a entrar en un juego en el que los competidores posibles entrantes en el mercado están planeando cómo posicionarse, lo que obliga también a estar preparados para neutralizar las estrategias y/o desarrollar otras que le permitan por lo menos sobrevivir", en este escenario. Tal como lo indican los autores, "la estrategia de fortalecimiento más sólida que puede tener una empresa es la del desarrollo de sus capacidades para crear e innovar en todas las funciones de la organización", lo cual solo es posible si se implementa y mantiene un sistema de gestión del conocimiento. La habilidad de adquirir y utilizar conocimiento efectivamente es un factor clave en las actividades de innovación y desarrollo de las empresas (Cohen y Levithal, 1990, y Jantunen, 2005). Hicks, Dattero y Galup (2006) señalan una jerarquía que se inicia en el dato, pasa por la información hasta llegar a la gestión del conocimiento.

Entre los más notables investigadores de la GC se encuentran Nonaka y Takeuchi (1995), autores del libro "Las organizaciones que aprenden", quienes plantean que la gestión del conocimiento se centra en fomentar y facilitar las operaciones que transforman el co- 
nocimiento y que dan como resultado la innovación en productos y servicios. Estos autores reconocen la relevancia del conocimiento transformado en nuevos productos y servicios a través de la innovación. Después de Nonaka y Takeuchi, Penrose (1959) en Rutihinda (1996) incorpora nuevos elementos al concepto de gestión del conocimiento, reconociéndola como una fuente de ventaja competitiva, al afirmar que "la competencia distintiva de una firma está basada en los recursos especializados, activos y habilidades que posee y centra su atención en su óptima utilización para construir una ventaja competitiva y riqueza económica".

Guthrie (2000) incorpora otro elemento esencial al análisis, indicando que la administración del conocimiento es la administración del capital intelectual controlado por la compañía; y en ese mismo año Martensson, M. (2000) señala que la administración del conocimiento es un nuevo camino para entender a las organizaciones, una herramienta para explotar el conocimiento.

Alavi y Leidner (1999) definen la GC como "un proceso sistémico y organizativo específico para adquirir, organizar y comunicar el conocimiento tácito y explícito, tanto para los empleados a fin de que otros agentes puedan hacer uso de ella para ser más eficaces y productivos en el trabajo". Las actividades de la GC incluyen la captura de conocimiento, documentación, recuperación y reutilización, creación, transferencia e intercambio de sus activos de conocimientos integrados en sus procesos operativos y de negocio (Dayan y Evans, 2006). En este estudio, la GC se define como "el proceso de identificación, el manejo y el aprovechamiento de los conocimientos individuales y colectivos para apoyar a la empresa ser más competitiva" (Carlsson, 2001).

El aporte de Jenny Darroch (2003) al análisis, además de que desarrolla un instrumento de prueba para evaluar la gestión del conocimiento en el ámbito microeconómico empresarial, define a este conjunto de prácticas o disciplina administrativa como "el proceso que crea o ubica el conocimiento y administra la diseminación y uso del conocimiento dentro y entre las organizaciones". Arbonies (2006) considera que el conocimiento es fundamental para innovar y recomienda quitar la miopía con la gestión del conocimiento en las organizaciones. Todo los conceptos anteriores motivan al presente trabajo para buscar un apoyo que oriente a las PyMES en la adquisición de la gestión del conocimiento en sus organizaciones.

Los procesos de la GC, incluyendo la adquisición, la conversión, la aplicación y la protección, además de una infraestructura de conocimiento de la tecnología, la estructura y la cultura, fueron identificadas como las capacidades organizacionales críticas que podrían positiva y significativamente influir en la eficacia de la organización. Santos (2003) sugirió un marco de organización posible de acuerdo con los procesos de conocimiento diferentes, es decir, procesos de adquisición, transferencia e integración del conocimiento. La adquisición 
del conocimiento se refiere a los mecanismos para la identificación y obtención de acceso a nuevos conocimientos relevantes. La transferencia del conocimiento significa los mecanismos mediante los cuales el conocimiento tácito o conocimiento complicado es transferido entre los grupos de la organización. La integración del conocimiento se refiere a los mecanismos mediante los cuales el conocimiento especializado es compartido dentro o a través de la organización, apoyando la aplicación del conocimiento en nuevos productos y/o procesos (Eisenhardt y Santos, 2002).

Shin, Holden y Schmidt (2001) proponen una cadena de valor de la GC, la cual consiste en cuatro actividades básicas: creación, almacenamiento, distribución y aplicación del conocimiento.

En cuanto a la adopción de la gestión del conocimiento por parte de las empresas, se presentan opiniones de varios autores que consideran fundamental la actitud del recurso humano de la empresa.

Davis, Bagozzi y Warshaw (1992) sugieren que la intención de una persona para usar los sistemas está influenciada por motivaciones extrínsecas, percibiendo que una actividad es fundamental para lograr resultados valiosos, así como las motivaciones intrínsecas, en referencia a la realización de una actividad sin refuerzo aparente que no sea el proceso de realización de la actividad por sí misma. (Venkatesh, et al., 2003).

La utilidad percibida del uso del conocimiento es considerada decisiva en la adopción de la GC según Davis (1989) y Bagozzi y Warshaw (1989) y sus dimensiones se basan en la realización de las tareas más rápidamente, en mejorar su desempeño personal, incrementar su productividad, incrementar su productividad en el trabajo, mejorar su efectividad, realizar más fácilmente su trabajo y que cada individuo le encuentre utilidad a su trabajo.

En investigaciones previas se ha puesto en duda la importancia global de la facilidad de uso percibida en la adopción de sistemas (Straub , Limayem y Karahanna , 1995; Keil, Beranek y Konsynski, 1995), y se indicó que en muchos casos los sistemas fueron adoptados principalmente por su utilidad percibida.

Por otra parte, la complejidad, considerada como el grado en el cual la GC es percibida como difícil de entender y usar, es un factor que se presenta como decisivo en la adopción de la GC, ya que el personal presenta una actitud negativa para adoptar algo complejo. En todo caso, la adopción se vuelve más lenta, ya que los empleados perciben que necesitan más tiempo para entender el sistema y por tanto para realizar las actividades que efectuaban normalmente.

Otros investigadores consideran muy importantes en la adopción de la GC las normas subjetivas, tomadas en cuenta como la opinión y creencias personales de individuos y/o 
grupos dentro de la organización, que influyen en el comportamiento general del recurso humano. Rogers (1995) identifica el sistema social como un elemento en las innovaciones. Un sistema social es considerado como un conjunto de unidades interrelacionadas que se dedican a la solución conjunta de problemas para lograr un objetivo común. Por lo tanto, se propone la norma subjetiva en una organización para tener impacto sobre la población en la adopción y aplicación de la GC.

Venkatesh, M., Davis, G. B. y Davis, F. D. (2003) usan la siguiente proposición para observar la influencia de la norma subjetiva: "La mayoría de la gente que es importante para mí, piensa que yo debería.... Para observar la norma subjetiva se presentan los siguientes ítems: Yo uso el sistema porque la mayoría de mis compañeros de trabajo lo usan; El gerente general de la empresa ha encontrado útil el uso del sistema; Mi supervisor apoya mucho el uso del sistema para mi trabajo; En general, la organización ha apoyado el uso del sistema.

Por su parte, Dishaw y Strong (1999) presentan que la norma social desempeña un papel importante en un contexto organizativo. Los investigadores de campo están de acuerdo en que los empleados eran muy propensos a ser afectados por otros en la adopción y aplicación de la GC.

Cheng y Yeh (2011) han demostrado que la facilidad de uso percibida, la utilidad percibida y la norma social tenían efectos positivos sobre la intención de aceptación de la GC.

Huang y Lai (2014) descubrieron que el género hace una diferencia en los efectos de la complejidad y la norma subjetiva en la actitud hacia la adopción GC. De los resultados que obtuvieron del análisis del modelo estructural de su investigación con hombres y mujeres, observaron en primer lugar, en los caminos de la influencia sobre la actitud hacia la adopción de la GC, que la complejidad tuvo un efecto significativo con los sujetos varones, pero no con los femeninos. La razón podría ser que las mujeres se preocupa más por los beneficios que la GC traería a ellas (es decir, perciben utilidad) y por lo tanto no tienen en cuenta la complejidad y las dificultades asociadas que participan en la adopción de la GC.

En segundo lugar, coincidiendo con la investigación previa (Venkatesh y Morris, 2000 y 2003), las mujeres son más susceptibles a las opiniones de otros y susceptibles a la influencia de colegas y superiores en aceptar la GC, mientras que los hombres no son tan sensibles a la norma subjetiva al decidir si adoptan o no la GC. Los resultados validan que la percepción de utilidad en la formación de sus actitudes que influyen en los comportamientos en GC en ambos sexos, mientras que las mujeres tienden a ser afectadas por los pensamientos y opiniones de los demás en su lugar de trabajo y no tan interesadas en lo referente a cuán complejo sea el proyecto de la GC. 
Los resultados, además, muestran que las mujeres son más sensibles a la norma subjetiva, mientras que los hombres pone menos énfasis en las opiniones de otros. Los resultados también implican que las mujeres estarían más dispuestas a enfrentar los obstáculos involucrados en la gestión del conocimiento si consideran que la adopción y aplicación de la GC mejorará su trabajo y su eficiencia y vale la pena el esfuerzo.

Abril (2007) examinó una organización global de consultoría, Datacon, e indicó que para la implementación exitosa de un programa de habilitación de los conocimientos se deben utilizar agentes como facilitadores del cambio de actitud, incluidos los componentes de investigación-acción que fueron de ayuda activos de conocimiento de recolección de conocimiento tácito y el valor percibido que moderaría la motivación de los asociados a participar en el programa de habilitación de conocimiento. Hung, Chou y Tzeng (2011) encontraron que las brechas de la GC dentro de la industria de servicios fueron mayores que las brechas dentro de la industria de la banca.

Según lo sugerido por Wong y Aspinwall (2005 ), el éxito en la GC requiere un apoyo empresarial proactivo y de liderazgo. La alta dirección y los líderes deben contribuir a promover una mentalidad corporativa que enfatice la cooperación y el intercambio de conocimientos en toda la organización, crear un ambiente en el que la creación de conocimiento y el aprendizaje puedan desarrollarse, así como proporcionar apoyo continuo y compromiso de sostener el esfuerzo para la GC.

El estudio de la gestión del conocimiento en las pequeñas y medianas empresas (PyMES) ha motivado investigaciones específicas, ya que presentan diferencias básicas con las grandes organizaciones. Enseguida se presentan algunos resultados obtenidos por diferentes investigadores.

Tan y Lim (2010) sugirieron que los factores críticos de éxito que influyen en los procesos de la GC en las pequeñas y medianas empresas (PyMES) son la cultura, el liderazgo, la participación de los empleados, de la información y tecnología de las comunicaciones, así como la estructura organizativa.

Dado que las pequeñas y medianas empresas, en general, carecen de los recursos de las grandes empresas, es fundamental que formulan gestiones de actividades de conocimiento (Cantú, Criado y Criado, 2009; Coyte, Ricceri y Guthrie, 2012; Edvardsson y Durst, 2013; McAdam y Reid, 2001). Actividades de la GC implican la creación, captura, intercambio y utilización de conocimiento para mejorar el impacto del conocimiento en el desempeño de las PyMES (Durst y Edvardsson, 2012; Soon y Zainol, 2011).

Por lo tanto, la difusión de la gestión del conocimiento es necesaria debido a los cambios ambientales, tales como la diversificación de estrategias para la adopción y prácticas 
de la GC, la competencia cada vez más globalizada, la vida útil limitada del conocimiento, y la dinámica de las innovaciones de producto y de servicio (Greiner, Bohmann y Krcmar, 2007). En este estudio, la difusión de la GC se define como una serie de etapas desde la iniciación en la empresa de las actividades de gestión, a su adopción formal, y finalmente a la conversión de tales actividades, en tareas diarias institucionalizadas en toda la organización.

La difusión de la GC en la literatura tiende a concentrarse en las grandes empresas (Lee y Kim, 2001; Lin, 2007, 2011; Xu y Quaddus, 2012). Sin embargo, las diferencias fundamentales entre las grandes empresas y las PyMES significan que las conclusiones de los estudios sobre la GC en las grandes empresas no pueden aplicarse plenamente a las PyMES (Cantú et al., 2009; McAdam y Reid, 2001; Wong, 2005). La investigación sobre la difusión de los conocimientos en las PyMES sigue siendo limitada, y se necesitan más investigación para comprender mejor este fenómeno (Chan y Chao, 2008; Chong, Ooi, Bao, y Lin, 2014; Durst y Edvardsson, 2012; Massa y Testa, 2011).

La necesidad de las PyMES para facilitar la difusión de la GC se hace evidente por varias razones. Aunque podrían verse limitadas por insuficiencia de recursos financieros y humanos, su "know-how" y el conocimiento son los más cruciales de los recursos que pueden tener o usar (DeSouza y Awazu, 2006). Promover la difusión de la GC es particularmente crucial en las PyMES, ya que el conocimiento es el recurso más importante de tales organizaciones (Dotsika y Patrick, 2013). Además, en comparación con las grandes empresas, las PyMES, en general, tienen estructuras organizacionales planas y flexibles, procesos elásticos y adaptables, y fuerte potencial de innovación (Hudson, Smart y Bourne, 2001; Wong y Aspinwall, 2004). Estas características dotan a las PyMES con la flexibilidad organizativa y adaptabilidad que es fundamental para la difusión del éxito de la GC (Cantú et al., 2009).

Finalmente, es necesario aumentar las fuerzas competitivas de las PyMES y replantearse sus estrategias de competitividad existentes. De hecho, el conocimiento y su gestión son considerados las más valiosos fuentes de crecimiento y competitividad (Salojarvi, Furu y Sveiby, 2005). Los estudiosos hacen hincapié en que las ventajas de la GC en las pequeñas y medianas empresas, en su mayoría están relacionadas con la reducción de costos, en mejorar la toma de decisiones, en una mayor productividad, en incrementar su participación en el mercado, aumentar la innovación y mejorar su rentabilidad (Lee, Ho y Chiu, 2008; Wang Y. L., Wang, Y. D. y Horng, 2010). Por lo tanto, vale la pena examinar herramientas clave para la difusión de la gestión del conocimiento en las pequeñas y medianas empresas.

Se han propuesto varios aspectos que deben ser considerados para la difusión de la gestión del conocimiento en las pequeñas y medianas empresas (Lee et al., 2008; Massa y Testa, 2011; Palacios-Marques, Soto-Acosta y Merigo, 2015; Wong y Aspinwall, 2005). En primer 
lugar, la mayoría de los estudios se centran en la evaluación de la vinculación de los antecedentes contextuales (como la estrategia y el liderazgo, la cultura, la tecnología, sistemas de recompensas y la presión de la competencia). La difusión de la GC va a través de una serie de etapas, a partir de la evaluación inicial de los proyectos de la GC de una PyME en la etapa de pre-adopción, y progresar a través de la decisión de adopción, y finalmente, a la aplicación formal (etapa de post-adopción).

\section{Metodología}

Primeramente se analizan diferentes investigaciones de autores que han estudiado tanto la adopción de la gestión del conocimiento en las pequeñas empresas como la implementación y la práctica de la GC en sus firmas, seleccionando aquellas que más se relacionan con el tema a trabajarse. Enseguida se analizan las características específicas del universo estudiado, que en este caso lo constituyen las pequeñas y medianas empresas de la ciudad de Hermosillo. A continuación, tomando como base tanto las investigaciones estudiadas como las características propias del escenario definido, se elabora un instrumento de investigación que se aplica en una muestra aleatoria entre las PyMES de Hermosillo. Enseguida se procede a la captura de los datos y después al análisis de los mismos. Finalmente, tomando en cuenta todos los recursos anteriores se analiza cuáles son los factores críticos que influyen en la adopción de la gestión del conocimiento entre las pequeñas y medianas empresas de Hermosillo.

Tomado en cuenta las referencias bibliográficas presentadas, así como las características de la población estudiada que está constituida por las pequeñas y medianas empresas de Hermosillo, se propone el siguiente modelo de investigación:

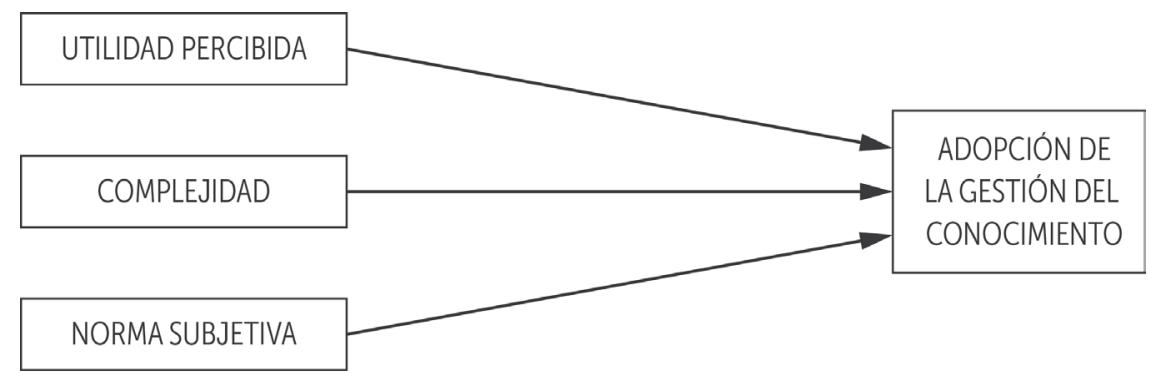

Figura 1. Modelo de Factores para la Adopción del Conocimiento.

Fuente: Elaboración propia. 
Enseguida se elaboró un formato para una entrevista estructurada que representó nuestro instrumento de prueba. En este instrumento se toma en cuenta diferentes factores que se seleccionaron en el Modelo, que puedan influir en la adopción exitosa de la gestión del conocimiento en las PyMES.

Así, en el presente estudio se consideran en qué forma influyen en el éxito de la adopción de la gestión del conocimiento en las pequeñas y medianas empresas, la utilidad percibida por el empleado, la complejidad del sistema de la GC percibida por el empleado y la norma subjetiva del personal.

A continuación se realizó el trabajo de campo mediante la aplicación del instrumento a una selección aleatoria en la población de estudio, o sea en las pequeñas y medianas empresas de Hermosillo. Enseguida se analizaron los datos para llegar a las conclusiones pertinentes del presente trabajo.

\section{Conclusión}

El objetivo de la presente investigación es:

"Determinar cuáles son los factores clave para la adopción de la gestión del conocimiento en el personal de las PyMES de Hermosillo, Sonora".

Tomando en cuenta la literatura estudiada y la información recabada del recurso humano de las PyMES sonorenses, se concluye lo siguiente:

La presente investigación avanza en nuestra comprensión de las construcciones perceptivas y su relación con los empleados, actitudes y comportamientos en el proceso de adopción y la aplicación de la gestión del conocimiento.

Los resultados indicaron que la utilidad percibida y la norma subjetiva fueron significativas en la determinación de las actitudes del personal hacia la adopción de la gestión del conocimiento. Estos resultados coinciden con la información de la literatura analizada.

La utilidad percibida del personal exhibió un efecto directo y significativo en la actitud hacia la adopción de la gestión del conocimiento. Esta investigación verificó la influencia de la utilidad percibida por la gente ante la adopción de la GC. Para los gerentes de las empresas, este estudio sugiere que deberían informar y motivar a los empleados sobre el valor y la importancia que representa para ellos la adopción de la GC, tales como aumentar su productividad, mejorar su eficiencia, pues esto hace su trabajo más fácil, cómodo y flexible. De esta manera, los empleados estarían más dispuestos a aceptar la gestión del conocimiento y darse cuenta que la aplicación de la misma no es sólo importante para las organizaciones, sino también es beneficioso para ellos mismos. 
La norma subjetiva demostró ser esencial en la conducta de un individuo. En este estudio, la norma subjetiva tuvo impactos positivos en las actitudes de los empleados hacia la adopción de la GC. Se observó que los empleados eran muy propensos a ser afectados por otros en la adopción y aplicación de la gestión del conocimiento.

En este sentido, se muestra la importancia decisiva que tiene el papel del alto mando, los líderes de opinión, para influir en las actitudes de los empleados en la adopción de la gestión del conocimiento. La alta dirección y los líderes deben contribuir a promover una mentalidad corporativa que enfatice la cooperación y el intercambio de conocimientos en toda la organización, creando un ambiente en el que la creación del conocimiento y el aprendizaje puedan realizarse, así como proporcionar apoyo continuo y compromiso de sostener el esfuerzo para la gestión del conocimiento.

Aunque el personal prefiere sistemas sencillos, la complejidad no representa un obstáculo para los empleados ya que están dispuestos a enfrentarla, siempre y cuando el sistema les proporcione beneficios. De ahí la importancia de buscar sistemas lo más sencillos posibles y sobre todo informar y capacitar al personal sobre las características de la GC para que lo acepten y se involucren en la adopción del mismo.

En general, el personal presenta una actitud positiva hacia la GC, que deben aprovechar los gerentes y directores de empresas para lograr que tanto la adopción como las prácticas de la gestión del conocimiento lleven a las PyMES a un mejor desarrollo y competitividad global. 


\section{Referencias Bibliográficas}

Abril, R.M. (2007). The dissemination and adoption of knowledge management practices behavioural model. Electronic Journal of Knowledge Management. 5 (2), 131-142.

Alavi, M., \& Leidner, D.E. (1999). Knowledge management and knowledge management systems: Issues, challenges, and benefits. Communications of the AIS. 1 (7), 1-37.

Arbonies, A. (2006). Conocimiento para innovar: Cómo evitar la miopía en la gestión de conocimiento. Madrid: Ediciones Díaz de Santos.

Cantú, L.Z., Criado, J.R., \& Criado, A.R. (2009). Generation and transfer of knowledge in ITrelated SMEs. Journal of Knowledge Management 13 (5), 243-256.

Carlsson, S.A. (2001). Knowledge Management in Network Contexts. En European Conference on Information Systems (9a, 2001, Bled, Eslovenia).

Chan, I., \& Chao, C.K. (2008). Knowledge management in small and medium-sized enterprises. Communications of the ACM. 51(4), 83-88.

Cheng, Y.H., \& Yeh, Y.J. (2011). Exploring radio frequency identification technology's application in international distribution centers and adoption rate forecasting. Technological Forecasting \& Social Change. 78 (4), 661-673.

Chong, A.Y.L., Ooi, K.B., Bao, H., \& Lin, B. (2014), Can e-business adoption be influenced by knowledge management? An empirical analysis of Malaysian SMEs. Journal of Knowledge Management. 18 (1), 121-136.

Cohen, M., \& Levithal, A. (1990). Absorptive capacity: a new perspective on learning and innovation. Administrative Science Quarterly. 35 (1) , 128-152.

Coyte, R., Ricceri, F., \& Guthrie, J. (2012). The management of knowledge resources in SMEs: an Australian case study. Journal of Knowledge Management. 15 (5), 789-807.

Darroch, J. (2003). Developing a measure of knowledge management behaviors and practices. Journal of Knowledge Management. 7 (5), 41-54. 
Davis, D.F., Bagozzi, R.P., \& Warshaw, P.R. (1992). Extrinsic and intrinsic motivation to use computers in the workplace. Journal of Applied Social Psychology. 22 (14), 1111-1132.

Davis, D.F. (1989). User acceptance of computer technology: A comparison of two theoretical models. Management Science. 35 (8), 982-1002.

Davis, D.F., Bagozzi, R.P., \& Warshaw, P.R. (1989). Perceived usefulness, perceived easy of use, and user acceptance of information technology. MIS Quarterly. 13 (3), 319-340.

Dayan, R., \& Evans, S. (2006). KM your way to CMMI. Journal of Knowledge Management. 10(1), 69-80.

Desouza, K.C., \& Awazu, Y. (2006), Knowledge management at SMEs: five peculiarities. Journal of Knowledge Management. 10 (1), 32-43.

Dishaw, M.T., \& Strong, D.M. (1999). Extending the technology acceptance model with tasktechnology fit constructs. Information \& Management. 36 (1), 9-21.

Dotsika, F., \& Patrick, K. (2013), Collaborative KM for SMEs: a framework evaluation study. Information Technology \& People. 26 (4), 368-382.

Durst, S., \& Edvardsson, I.R. (2012). Knowledge management in SMEs: a literature review. Journal of Knowledge Management. 16 (6), 879-903.

Eisenhardt, K.M., \& Santos, F.M. (2002). Knowledge-based view: A new theory of strategy? En: Pettigrew, A., Thomas, H., \& Whittington, R. (Eds.). Handbook of Strategy and Management. Londres: Sage Publications.

Edvardsson, I.R., \& Durst, S. (2013). The benefits of knowledge management in small and medium-sized enterprises. Procedia-Social and Behavioral Sciences. 81 (28), 351-354.

Greiner, M.E., Bohmann, T., \& Krcmar, H. (2007), A strategy for knowledge management. Journal of Knowledge Management. 11 (6), 3-15. 
Guthrie, J. (2000). Intellectual capital review: measurement, reporting and management. Journal of Intellectual Capital. 1 (1), 37-51.

Hicks, R., Dattero, R., \& Galup S. (2006). Los cinco niveles de jerarquía de gestión del conocimiento. Journal of Knowledge Management. 10 (1),19-31.

Huang, L.S., \& Lai, C.P. (2014), Knowledge management adoption and diffusion using structural equation modeling. Global Journal of Business Research. 8 (1), 39-56.

Hudson, M., Smart, A., \& Bourne, M. (2001), Theory and practice in SME performance measurement systems. International Journal of Operations \& Production Management. 21 (8), 1096-1115.

Hung, Y.H., Chou, S.C.T., \& Tzeng, G.H. (2011). Knowledge management adoption and assessment for SMEs by a novel MCDM approach. Decisions Support Systems. 51 (2), 270-291.

Jantunen, A. (2005). Knowledge-processing capabilities and innovative performance: an empirical study. European Journal of Innovation Management, 8 (3), 336-349.

Keil, M., Beranek, P.M., \& Konsynski, B.R. (1995). Usefullness and easy of use: Field study evidence regarding task considerations, Decisions Support Systems, 13 (1), 75-91.

Lee, C.L., Ho., C.T., \& Chiu, Y.L. (2008). The impact of knowledge management enablers on nonfinancial performance in small and medium enterprises. Journal of Technology Management. 43 (1), 266-283.

Lee, J.H., \& Kim, Y.G. (2001). A stage model of organizational KM: a latent content analysis, Expert Systems with Applications, 20 (4), 299-311.

Lin, H.F. (2014). Contextual factors affecting knowledge management diffusion in SMEs. Industrial Management \& Data Systems. 114 (9), 1415-1437.

Lin, H.F. (2007). A stage model of knowledge management: an empirical investigation of process and effectiveness. Journal of Information Science. 33 (6) 643-659. 
Lin, H.F. (2011). Antecedents of the stage-based knowledge management evolution, Journal of Knowledge Management. 15 (1), 136-155.

McAdam, R., \& Reid, R. (2001). SME and large organization perceptions of knowledge management: comparisons and contrasts. Journal of Knowledge Management. 5 (3), 231-241.

Martensson, M. (2000). A critical of knowledge management as a management tool, Journal of Knowledge Management, 4 (3), 204-216.

Massa, S., \& Testa, S. (2011). Knowledge domain and innovation behaviour: a framework to conceptualize KMSs in small and medium enterprise, VINE: The Journal of Information and Knowledge Management Systems. 14 (4), 483-504.

Nonaka, I., \& Takeuchi, H. (1995). The knowledge creating company. Oxford: Oxford University Press.

Palacios-Marqués, D., Soto-Acosta, P., \& Merigó, J.M. (2015). Analyzing the effects of technological, organizational and competition factors on Web knowledge exchange in SMEs, Telematics and Informatics, 32 (1), 23-32.

Penrose E.T. (1959). The Theory of the Growth of the Firm. Oxford: Oxford University Press.

Rogers, E. (1995). Diffusion of Innovations. Nueva York: Free Press.

Rutihinda, C. (1996). Resource-based Internalization. Stockholm: Akademitryck AB.

Salojarvi, S., Furu, P., \& Sveiby, K.E. (2005). Knowledge management and growth in Finnish SMEs. Journal of Knowledge Management. 9 (2), 103-122.

Sánchez, J., Hernández, S., \& Haro, J. (2008). Un modelo de valoración de la gestión del conocimiento de las empresas. Tepic: Universidad Autónoma de Nayarit.

Santos, F.M. (2003). The coevolution of firms and their knowledge environment: Insights from the pharmaceutical industry. Technological Forecasting \& Social Change. 70 (7), 687-715. 
Shin, M., Holden, T., \& Schmidt, R. A. (2001). From knowledge theory to management practice: Towards an integrated approach. Information Processing and Management. 37 (2), 335-355.

Venkatesh, V., Morris, M.G., Davis, G.B., \& Davis, F.D. (2003). User acceptance of information: Toward a Unified view. MIS Quarterly. 27 (3), 425-478.

Venkatesh, V., \& Morris, M.G. (2000). Why don't men ever stop to ask for directions? Gender, social influence, and their role in technology acceptance and usage behavior. MIS Quarterly. 24 (1), 115-139.

Wang, Y.L., Wang, Y.D., \& Horng, R.Y. (2010), Learning and innovation in small and medium enterprises. Industrial Management \& Data Systems. 110 (2), 175-192.

Wong, K.Y. (2005), Critical success factors for implementing knowledge management in small and medium enterprises. Industrial Management \& Data Systems. 105 (3), 261-279.

Wong, K.Y., \& Aspinwall, E. (2005). An empirical study of the important factors for knowledgemanagement adoption in the SME sector. Journal of knowledge Management. 9 (3), 64-82.

Wong, K.Y., \& Aspinwall, E. (2004), Characterizing knowledge management in the small business environment. Journal of Knowledge Management, 8 (3), 44-61.

Xu, J., \& Quaddus, M. (2012), Examining a model of knowledge management systems adoption and diffusion: a partial least square approach. Knowledge-Based Systems. 27 (1), 18-28. 


\section{Capítulo 5}

La sucesión de las empresas familiares en las empacadoras

de frutas y derivados en Tecomán, Colima, México

Hugo Martín Moreno Zacarías, Roberto Espíritu Olmos y Alejandro Rodríguez Vázquez

\section{Introducción}

La empresa es una entidad económica de producción y su principal función es aumentar la utilidad de los bienes para satisfacer las necesidades del ser humano. Su objetivo es elaborar los bienes o servicios que los consumidores demandan para obtener una ganancia. Suelen tener un tiempo de vida que depende de su empresario fundador. La importancia en la pequeña y mediana empresa depende de su proceso generacional. La sucesión en las empresas familiares (EF) ha sido uno de los elementos de mayor eficiencia social.

"Una empresa familiar es la que ha sido fundada por un miembro de la familia y será transmitida, o se espera que se transmitada, a sus descendientes, en ocasiones a través del matrimonio. Los descendientes del fundador o fundadores originales tendrán la propiedad y el control de la empresa. Además, trabajan y participan en las decisiones de dicha empresa y se benefician de ella miembros de la familia" (Bork, 1986, citado por Fuentes, 2007).

El proceso de sucesión generacional no es una tarea fácil, pues el complejo mundo de relaciones que se entremezclan en el proceso origina la aparición de una serie de problemas que pueden dificultar. Tal como señala Gallo (1998), "en España, el 61 \% de las empresas familiares están dirigidas y controladas por la primera generación, el $24 \%$ por la segunda, el 9 \% por la tercera y solo el 6 \% son la cuarta generación siguiente. Una parte muy importante de las EF de primeras generaciones ocurre cuando los hijos de los fundadores se incorporan a la misma".

El fenómeno de la sucesión generacional ha de entenderse desde la importancia que este tiene para las empresas familiares. A la gran cantidad de compañías en edad sucesoria, hay que sumarle el deseo generalizado de fundadores y sucesores de que la propiedad y la direc- 
ción de la empresa continúen en manos de la familia fundadora. El deseo de que la empresa continúe en manos de la propia familia se basa generalmente en razones de alto contenido afectivo y emocional, tales como tradición, historia, seguridad económica e independencia.

\section{Planteamiento del problema}

Las empresas familiares se desarollan en todos los segmentos económicos. Estas pueden ser de todos tamaños, constituidas bajo diversas formas legales y con distintos grados de profesionalización. No obstante, todas estas empresas tienen en comun: la gran influencia que ejerce la familia sobre la empresa.

Hay varias investigaciones que muestran las grandes dificultades que enfrentan las empresas familiares para lograr la continuidad en los cambios generacionales. Aproximadamente, una de cada tres empresas tienen éxito al pasar la estafeta a la siguiente generacion, como se aprecia en la Figura 1 (Belausteguigoitia, 2003; Lea, 993; Handler y Kram. E. 2008). Es importante hacer notar que no todos los casos de desaparición de las empresas familiares se deben a fracasos. Hay empresas que deciden perder su carácter familiar al incorporar a otro accionista y perder el control; tambien puede darse el caso de que haya la oportunidad de cerrar tratos rentables y se decida vender la compañía a terceros.

De acuerdo a Mucci (2008), las empresas familiares constituyen un campo relativamente nuevo. Alrededor de medio siglo ha pasado desde los primeros trabajos sistemáticos que incorporaron a la teoría administrativa este fenotipo organizacional particular.

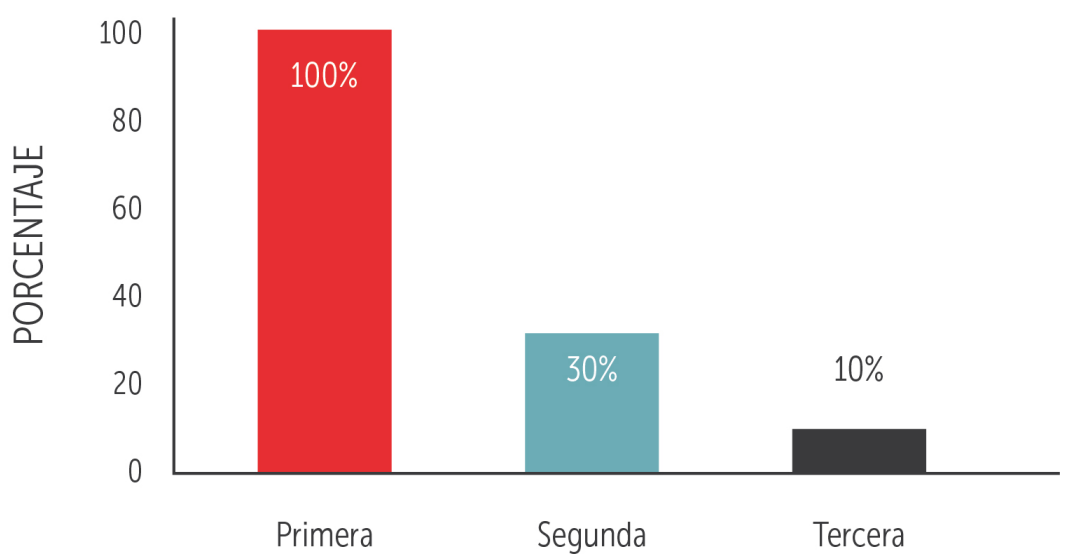

Figura 1. Porcentaje de éxito en la sucesión de las empresas familiares. Fuente: Belausteguigoitia (2003). 


\section{Revisión teórica}

El manejo de las empresas, ya sea de pequeña a gran tamaño, presenta características diferentes de operación, entre las familias que son las dueñas y las administran, de las que no lo son. Aunque en ciertas investigaciones realizadas por Demsetz (1983), Demsetz y Lehn (1985) y Demsetz y Villalonga (2001) citados por Kraiczy (2012), han demostrado que se presenta como una generalidad para el desarrollo endógeno, que las estructuras gerenciales en las empresas familiares son llevadas a cabo durante mucho tiempo y esto hace que no se tengan cambios en la evaluación del desarrollo del mercado. Pero, en otras investigaciones realizadas por Kowalewski et. al, (2010), encontraron que empresas familiares en Polonia presentan un impacto positivo de su manejo dentro del retorno del capital y sobre las acciones. Esto se refuerza con lo encontrado en Morck (1988) y Jensen y Meckling (1976), los cuales mencionan que las empresas familiares presentan un máximo de rendimiento del $40 \%$ del negocio.

Estudios relacionados en Noruega (Mishra, et al. 2001) y en Francia por Corstjens et al. (2004), Sraer y Thesmar (2007) y Martínez et al. (2007), realizan un comparativo entre las empresas no familiares y las familiares. En ellos, se presenta una asociación positiva entre el fundamento de control de la familia y el valor de la firma. En Chile, se encontró que las empresas familiares tienen significativamente un mayor valor de la empresas que las empresas no familiares. Caso contrario reporta Miller et al. (2007), en el que hay menores rendimientos en las empresas familiares en comparación a las no familiares, como lo es sobre el capital y las acciones.

Górriz y Fumás (2005) no encontraron ninguna diferencia significativa en los rendimientos por parte de las empresas no familiares con las sí familiares. Estos resultados no pueden ser concluyentes, ya que los resultados van a depender de varios factores, como el tipo de industria, país, medidas de rentabilidad y como se presentan dichos resultados. En estudios realizados en Alemania, entre estos dos tipos de empresas no se encontraron diferencias significativas entre la rentabilidad sobre el capital y las acciones de las empresas y estos mismos autores investigaron, en otros países, estas interacciones, determinando que esta calificación va a depender mucho de los instrumentos de valuación de la rentabilidad de las empresas. En todos los casos no se encontraron diferencias en la variable de la $Q$ de Tobin.

Desde un ambiente emprendedor, las empresas familiares observan una preferencia hacia los hombres sobre las mujeres en la sucesión gerencial y se toman en cuenta únicamente a los hijos del jefe de la familia que en su mayoría estén solteros (en un $81.2 \%$ ). La presencia de los hijos garantiza que la sucesión se realizará sin menos restricciones. Pero, para el manejo de los recursos humanos se presenta una mayor comprensión en las mujeres que respecto a los hombres. Además, se ha observado que en términos de operación, después de la sucesión 
se registra una reducción de ganancias por un $8 \%$ cuando se es sucedido por un familiar soltero hombre; mientras que cuando se es sucedido a la mujer soltera de la familia, las ganancias se incrementan en un 7\% (Ahrens, Landmann, \& Wooywode, 2015).

En toda decisión de selección de la sucesión se toma en cuenta las habilidades en el manejo del personal (soft skills) y las habilidades para el manejo de la empresa (hard skills). La cuestión que siempre va a ser determinante es cuál tipo de habilidades se debe de tomar como preferente. En un estudio realizado por Schlepphorst y Moog, (2014) en Alemania, en 69 empresas de diferentes estados de sucesión, antes de la selección, durante y después, se entrevistaron sobre cuáles son las habilidades que se consideran como prioridad en determinar a quién se asigna dicha sucesión. Un aspecto de inicio que ya difiere, corresponde a que las prioridades y necesidades manifestadas para la empresa, no son las mismas según los predecesores y los sucesores. De todas maneras, se consideran las apreciaciones más reales y exactas de los predecesores que de los sucesores y con ello se tiene un perfil más preciso de las habilidades que debe tener el sucesor en la gerencia de la empresa. También en este estudio se presentó que la mayoría de los predecesores no conocen exactamente cuáles son las necesidades del perfil de mando y los sucesores carecen la oportunidad de poder adquirir las habilidades necesarias para la buena conducción de la empresa.

Para entender más claramente lo que es una empresa familiar y diferenciarla con una empresa no familiar (ver Tabla 1), Andrade (2002) realiza una comparación resumiendo algunas características relacionadas con la propiedad, como nexos afectivos, visión, propiedad, etc. Se muestra las diferencias que hay respecto al manejo y las decisiones dentro de la empresa en las empresas familiares y no familiares. Se destacan los salarios y la capacidad de dirección como principal diferencia.

Un factor que es importante para el futuro de la empresa es buscar constantemente en la innovación. Pero, dentro de la toma de decisiones en muchas ocasiones el dueñoadministrador se ve influenciado por sus emociones para considerar a su sucesor y el factor innovación no está claramente definido como una acción dentro de la administración de las empresas familiares, como lo mencionan Gudmundson, Tower y Hartman (2003) y Zaira en 2005 citados por Hauck \& Prügl (2015). Este factor se ubica en la paradoja entre la habilidad y el deseo por ser un administrador conservador y asegurar sus operaciones o ser un innovador para invertir y buscar nuevos mercados con el consabido riesgo. 


\begin{tabular}{|c|c|c|}
\hline & \multicolumn{2}{|c|}{ Tipos de Empresa } \\
\hline Rasgos & Empresa Familiar & Empresa no familiar \\
\hline Propiedad & En manos de una misma familia & $\begin{array}{l}\text { No existe una propiedad familiar } \\
\text { mayoritaria. }\end{array}$ \\
\hline $\begin{array}{l}\text { Nexos afectivos } \\
\text { con los } \\
\text { propietarios }\end{array}$ & $\begin{array}{l}\text { Los valores culturales y tradicionales } \\
\text { de la familia están enraizados en la } \\
\text { organización. }\end{array}$ & $\begin{array}{l}\text { Ninguno o en grado menor. Las em- } \\
\text { presas anónimas están menos relacio- } \\
\text { nadas afectivamente. }\end{array}$ \\
\hline Visión y futuro & $\begin{array}{l}\text { Compartida y sustentada en una } \\
\text { motivación y en la confianza más allá } \\
\text { de los aspectos económicos. }\end{array}$ & $\begin{array}{l}\text { Basada en aspectos económicos y en } \\
\text { una motivación semi impuesta. }\end{array}$ \\
\hline $\begin{array}{l}\text { Poder y control } \\
\text { de la actividad } \\
\text { empresarial }\end{array}$ & Miembros de la misma familia. & $\begin{array}{l}\text { No tiene por qué estar relacionados } \\
\text { familiarmente. }\end{array}$ \\
\hline $\begin{array}{l}\text { Continuidad } \\
\text { del negocio }\end{array}$ & Forma sucesoral (hereditario). & $\begin{array}{l}\text { No son determinados por factores } \\
\text { hereditarios. }\end{array}$ \\
\hline Legitmidad & $\begin{array}{l}\text { Podría ser cuestionada, como } \\
\text { consecuencia de una no aceptación } \\
\text { de la sucesión. }\end{array}$ & $\begin{array}{l}\text { La legitimidad está amparada por la } \\
\text { base legal. }\end{array}$ \\
\hline $\begin{array}{l}\text { Capacidad } \\
\text { de dirigir }\end{array}$ & $\begin{array}{l}\text { El propietario siempre tiene la posi- } \\
\text { bilidad de ejercer la dirección de la } \\
\text { empresa. }\end{array}$ & $\begin{array}{l}\text { La dirección está basada en habilidades } \\
\text { y estilo de gerencia. }\end{array}$ \\
\hline $\begin{array}{l}\text { Valoración de la } \\
\text { propiedad }\end{array}$ & $\begin{array}{l}\text { Debido a su estructura de propiedad } \\
\text { familiar, la valoración que se haga de } \\
\text { las acciones de propiedad pudieran } \\
\text { verse subvaluadas ante una eventual } \\
\text { venta del componente accionario. } \\
\text { Puede generarse distorsión basada } \\
\text { en las relaciones afectivas de los } \\
\text { integrantes con la empresa. }\end{array}$ & $\begin{array}{l}\text { Por no existir impedimento en la } \\
\text { estructura accionaria de tipo familiar, } \\
\text { la valoración de las acciones puede ser } \\
\text { más realista y transparente. }\end{array}$ \\
\hline $\begin{array}{l}\text { Empleo, salario } \\
\text { y dividendos }\end{array}$ & $\begin{array}{l}\text { Tiende a ser más laxa e informal. Los } \\
\text { objetivos son menos claros y están } \\
\text { menos definidos. La comunicación } \\
\text { tiende a ser extraoficial. }\end{array}$ & $\begin{array}{l}\text { Hay una tendencia a dejar de lado las } \\
\text { relaciones afectivas para actuar sobre } \\
\text { estas variables. }\end{array}$ \\
\hline $\begin{array}{l}\text { Confianza, } \\
\text { disciplina y } \\
\text { comunicación }\end{array}$ & & $\begin{array}{l}\text { Existe mayor formalidad en los } \\
\text { objetivos y en la comunicación. }\end{array}$ \\
\hline
\end{tabular}

Tabla 1. Comparación entre empresa familiar y empersa no familiar. Fuente: Andrade (2002). 


\section{Metodología}

Se realizó una investigación descriptiva correlacional, en la cual se aplicaron cuestionarios ajustado de la tesis doctoral de Rodrigo Juan Tadeo (2005), referente a las características de sucesión entre los familiares. Como sujeto de estudio fueron las empresas agroindustriales del limón y procesadoras de frutas. Se realizaron gráficos sobre las condiciones que imperan en la empresa para el manejo y sucesión del negocio como pruebas de correlación entre las variables de administración y sucesión familiar.

\section{Resultados}

Durante los meses de septiembre a noviembre del 2014, se tomaron los datos de las empacadoras de limón y derivados de frutas en los municipios de Tecomán y Armería, según la página del INEGI (http://www.inegi.org.mx), y de ello resultaron cuatro empresas procesadoras de frutas que son empresas familiares. Como complemento se tomó la lista de socios del Consejo Estatal de Productores de Limón (COEPLIM-Colima) y similares. Se obtuvieron 14 empresas familiares del sector Empacadoras. Para totalizar con 18 encuestas útiles a ser procesadas.

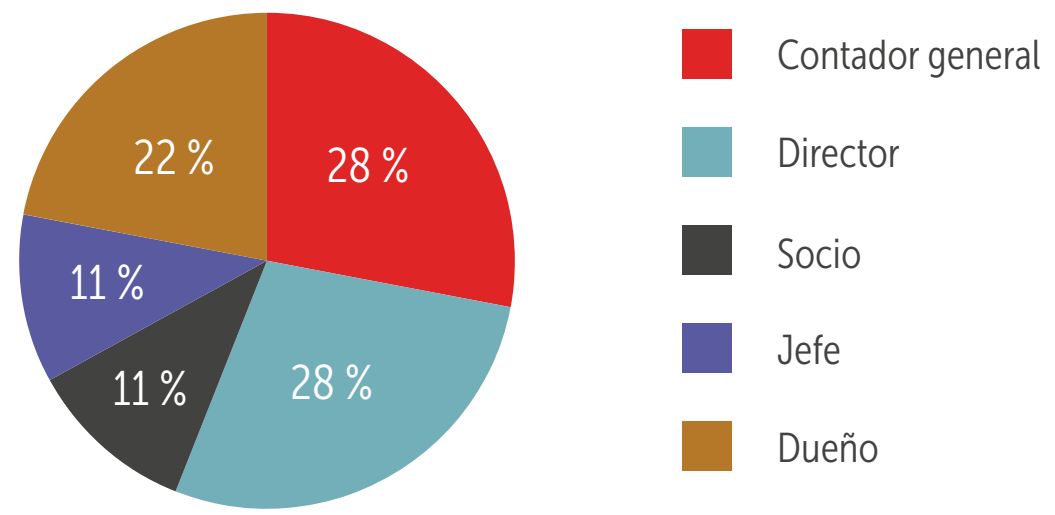

Figura 2. Pueso que ocupan los entrevistados. Fuente: Elaboración Propia.

Se procesaron los datos utilizando las hojas de cálculo de Excel y del paquete estadístico SPSS v.20.

Como se observa en la Figura 2, la mayoría de los puestos pertenecen a los cargos de contador general, director y dueño de la empresa. De acuerdo con las encuestas realizadas, los datos obtenidos son razonablemente confiables. 


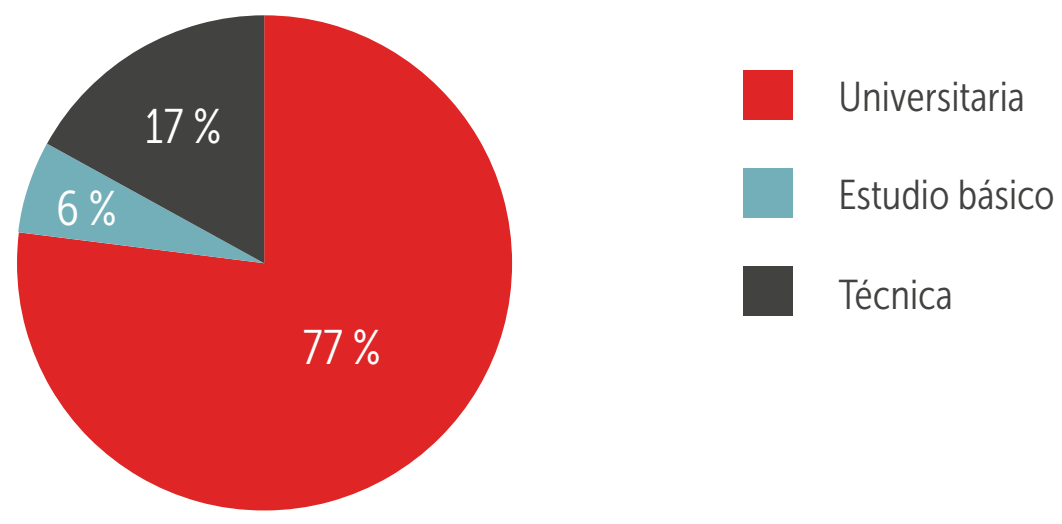

Figura 3. Nivel de educación que posee. Fuente: Elaboración Propia.

Como se aprecia en la Figura3, el nivel más alto de estudio que tuvieron los entrevistados fue universitario, el cual representó el $77 \%$, ya que se necesita de una experiencia académica acerca del funcionamiento de la empresa y una excelente habilidad en los funcionamientos de la misma; el 6\% solo tuvieron estudios básicos y el otro 17\% estudios técnicos.

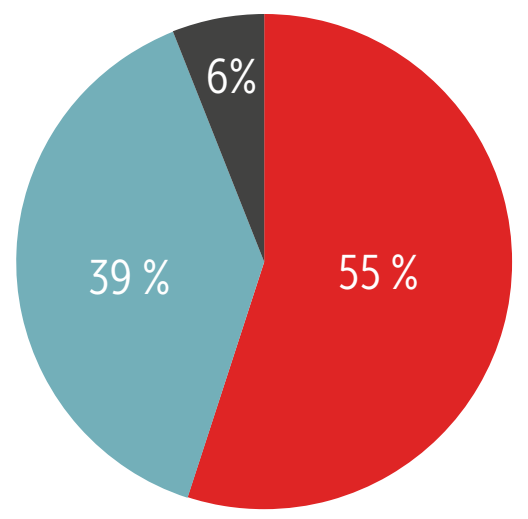

Generación fundadora

Hijo de la generación fundadora

El cargo es ocupado por un miembro de la familia

Figura 4. Generación que dirige la empresa. Fuente: Elaboración Propia.

Como se puede observar en la Figura 4, al respecto de la sucesión generacional de las empresas familiares en las encuestas aplicadas, la mayoría de estas están a cargo de la generación fundadora con un 55\%. Esto reafirma lo antes mencionado en el marco de referencia según Mucci (2008): las empresas familiares crean un campo relativamente nuevo; 
el 39\% de las encuestas están a cargo de los hijos de la generación fundadora y el 6\% a cargo de un miembro de la familia.

En la Figura 5 se puede notar la importancia de las funciones de las empresas familiares. La mayor parte de las empresas encuestadas dan gran relevancia a la planificación de la sucesión, se preocupan por establecer relaciones y contactos con personas ajenas a la empresa, definiendo valores y filosofía que guían a la empresa, así como también la definición de la estrategia en el largo plazo y la participación en las decisiones y actividades operativas cotidianas

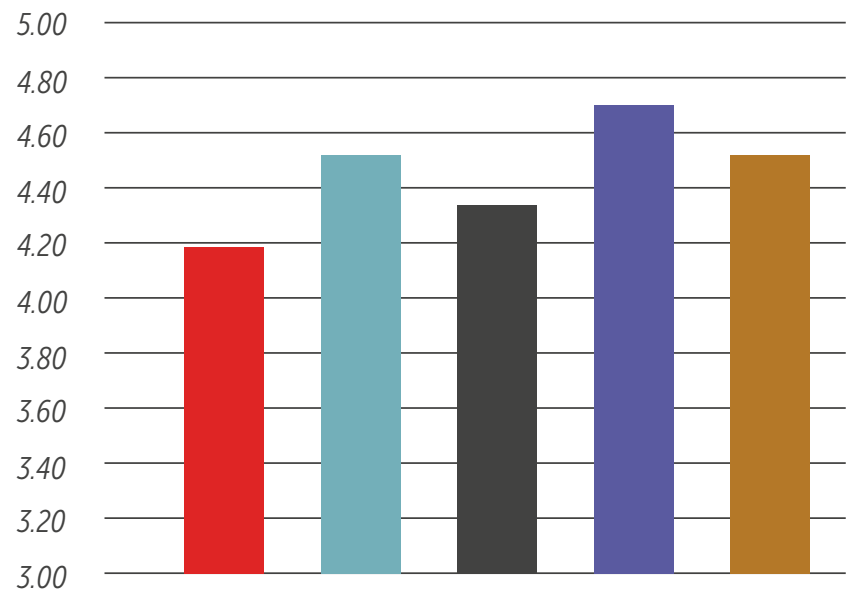

Establecer relaciones y contactos para obtener recursos importantes Definir los valores y filosofía que guían a la empresa familiar

Definir la estrategia a largo plazo

Definir la planificación de la sucesión

Participar en las decisiones y actitudes operativas cotidianas

Figura 5. Importancia de las funciones de la empresa (Parte 1). Fuente: Realización Propia.

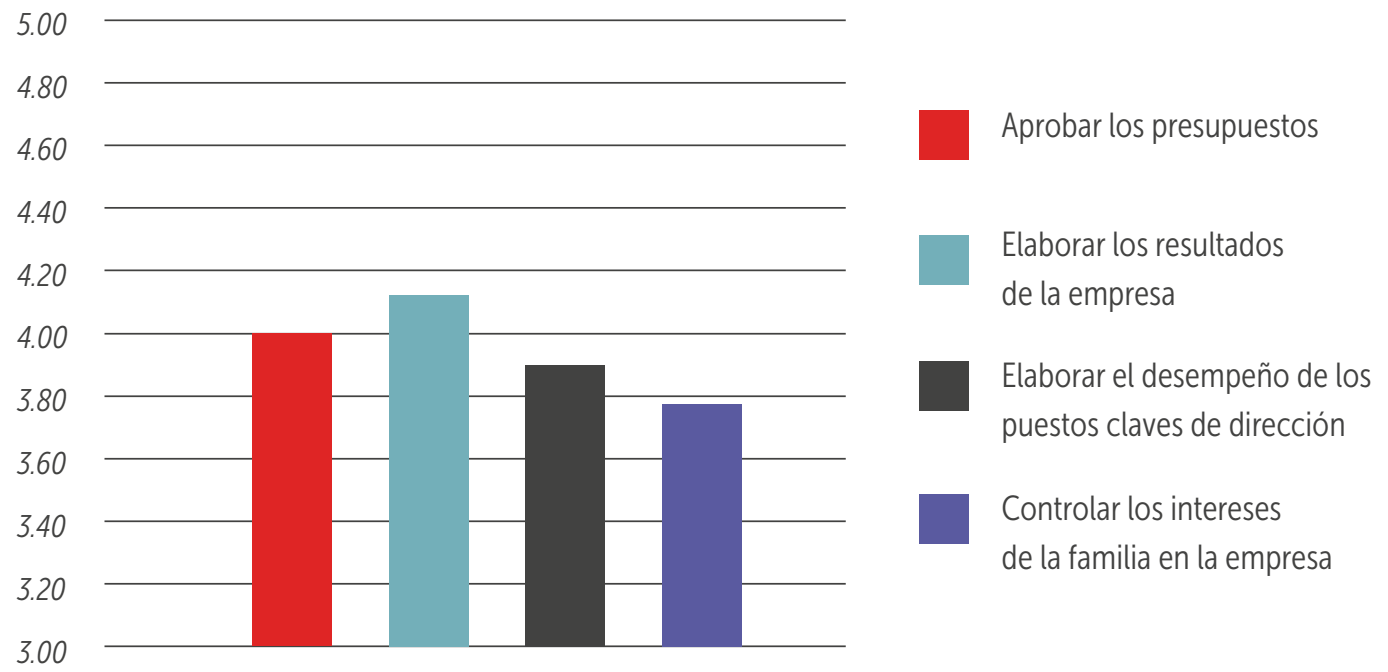

Figura 6. Importancia de las funciones de la empresa (Parte 2). Fuente: Realización Propia. 
En la Figura 6 se observa que en general, dan importancia a la elaboración de los resultados de la empresa, así como aprobar presupuestos, pero no tiene el mismo grado de importancia la elaboración del desempeño de los puestos claves de dirección ni controlar los intereses de la familia en la empresa.

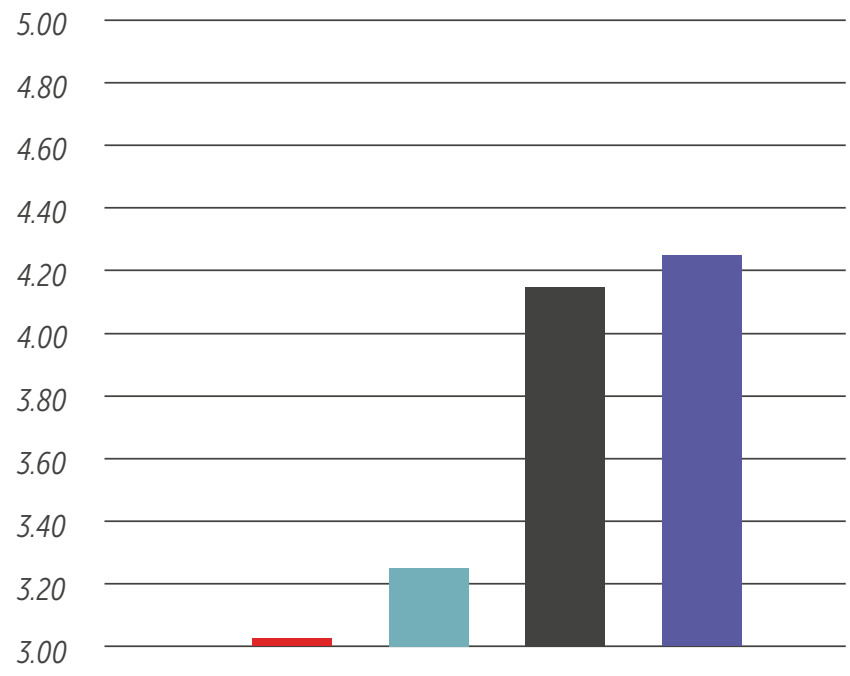

Elaborar el protocolo de familia

Revisar el protocolo de familia

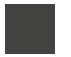

Decidir sobre la entrada de nuevos miembros de la familia

Asesorar en temas familiares que afecta a la empresa

Figura 7. Importancia de las funciones de la empresa (Parte 3). Fuente: Realización Propia.

En la Figura 7, se observa que en general las empresas consideran importante asesorarse en temas familiares que afectan a la empresa, así como las decisiones sobre la entrada de nuevos miembros de la familia (ya que es indispensable para la sucesión generacional en la empresa), sin embargo, no dan tanta relevancia a elaborar el protocolo de familia y revisarlo.

Las encuestas aplicadas a las empresas familiares, dieron como resultado que no se cuenta con un plan de sucesión, dado que el $55 \%$ de dichas empresas está a cargo de la generación fundadora, pero de igual manera se preguntó cuáles serían las características a considerar para la sucesión. Como se aprecia en la Figura 8, la mayoría de las empresas familiares encuestadas buscan los mismos atributos. Según los resultados, el sucesor debe tener cierto nivel de educación, ser emprendedor, tener experiencia en los negocios, entre las de mayor relevancia.

En la Figura 9, se puede apreciar que todos estos atributos son indispensables en la empresa para alcanzar el éxito en la misma: habilidad para las relaciones personales, competencia para la dirección estratégica y capacidad para asumir riesgos, entre los más importantes. Para llevar una buena planeación es fundamental llevar a cabo estos atributos dentro de la empresa. 


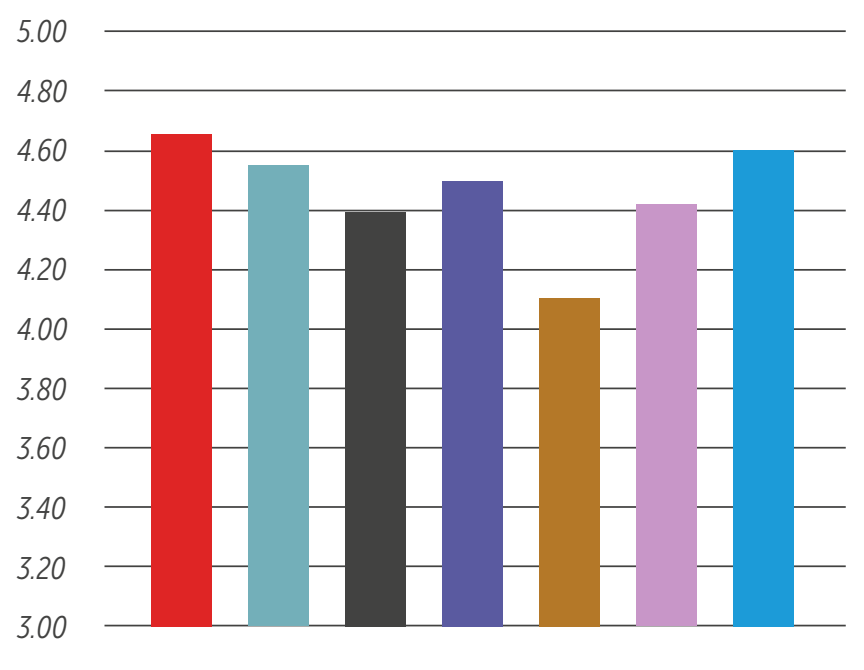

Nivel de Educación

Experiencia en los negocios familiares

Experiencia externa en puestos directivos

Trayectoria y desempeño pasado

Experiencia y habilidades financieras

Experiencia y habilidades en marketing y ventas

Emprendedor

Figura 8. Atributos más importantes que se le exige al sucesor (Parte 1). Fuente: Realización Propia.

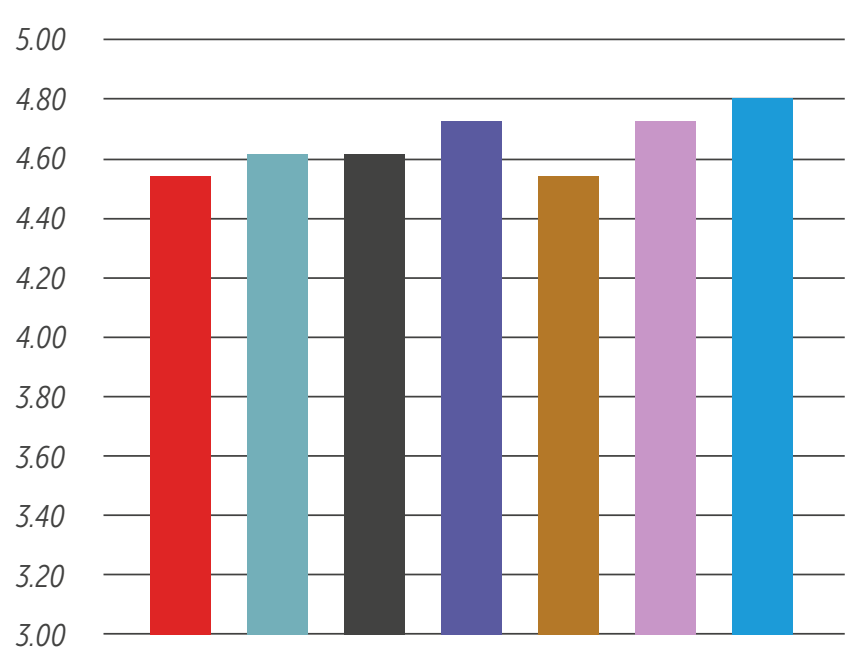

Integridad

Inteligencia

Creatividad

Capacidad para asumir riesgos

Compromiso en el negocio

Competencia para la dirección estratégica

Habilidades para las relaciones personales

Figura 9. Atributos más importantes que se le exige al sucesor (Parte 2).

Fuente: Realización Propia. 
Independencia

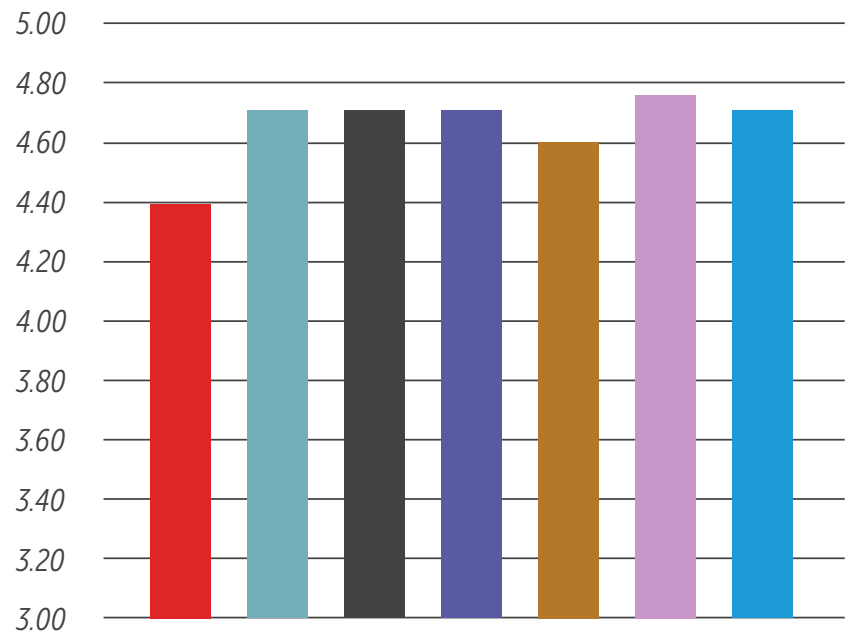

Confianza en sí mismo

Respeto por los empleados

Afinidad con los objetivos y personalidad de líder

Habilidad para la resolución de conflictos

Respeto de los familiares empleados

Respeto de los familiares no empleados

Figura 10. Atributos más importantes que se le exige al sucesor (Parte 3).

Fuente: Realización Propia.

Respeto de los familiares

5.00

4.80

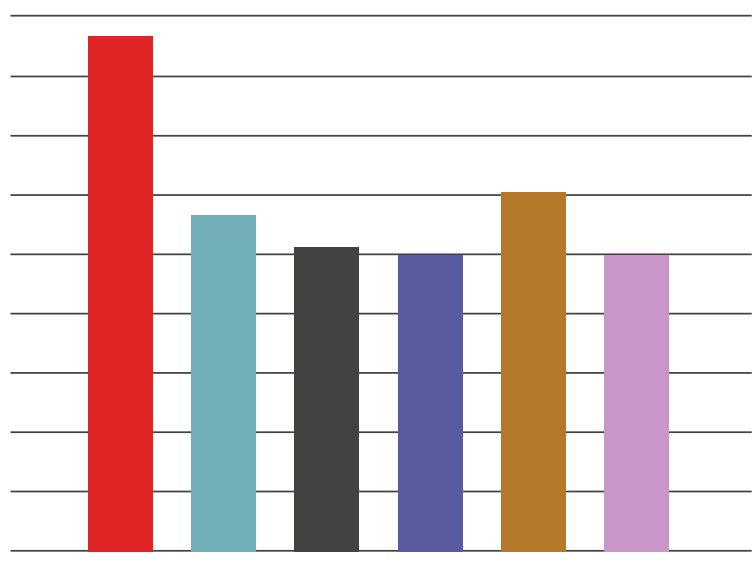

\section{Género}

Porcentaje de participación en el capital

Orden de nacimiento

Relación de consanguinidad

Edad del sucesor

Figura 11. Atributos más importantes que se le exige al sucesor (Parte 4).

Fuente: Realización Propia. 
Como se aprecia en la Figura 11, la relación de la encuesta varia un poco, porque las empresas encuestadas buscan diferentes atributos en el siguiente sucesor. Un atributo de lo más indispensable es el respeto de los familiares, la relación de consanguinidad, el género y la edad del sucesor.

Durante la investigación, también se analizó la relación entre el puesto que se ocupa y el plan de sucesión. Como se observa en Tabla 2, el factor de Pearson que es de 0.094 indica que no existe relación entre ambas variables. Se establece que ninguna persona independientemente del cargo cuenta con un plan de sucesión ni tampoco hay una planeación para la futura generación que deberá llevar el control de la empresa.

\begin{tabular}{|l|l|c|c|}
\hline & & $\begin{array}{l}\text { Puesto que } \\
\text { ocupa }\end{array}$ & $\begin{array}{l}\text { La empresa tiene un plan } \\
\text { de sucesión por escrito que } \\
\text { considera al próximo que haya } \\
\text { cubierto el último traspaso } \\
\text { generacional. }\end{array}$ \\
\hline Puesto que ocupa & $\begin{array}{l}\text { Correlación de } \\
\text { Pearson }\end{array}$ & 1 & .094 \\
\hline & Sig. (bilateral) & & .711 \\
\hline $\begin{array}{l}\text { La empresa tiene un plan } \\
\text { de sucesión por escrito } \\
\text { que considera al próximo } \\
\text { que haya cubierto el últi- } \\
\text { mo traspaso generacional. }\end{array}$ & Sig. (bilateral) & .711 & 18 \\
\hline
\end{tabular}

Tabla 2. Correlaciones entre el puesto y el plan de sucesión Fuente: Realización Propia.

En la Tabla 3, se analiza la relación existente entre el plan de sucesión y el nivel de educación. El factor de Pearson que es de 0.222, indica que no existe relación entre ambas preguntas. Se dice que no cuenta con una buena planeación en la mayoría de los puestos. 


\begin{tabular}{|l|l|c|c|}
\hline & & $\begin{array}{l}\text { La empresa tiene un plan } \\
\text { de sucesión por escrito } \\
\text { que considera al próximo } \\
\text { que haya cubierto el último } \\
\text { traspaso generacional. }\end{array}$ & $\begin{array}{l}\text { Nivel de } \\
\text { educación } \\
\text { que posee. }\end{array}$ \\
\hline $\begin{array}{l}\text { La empresa tiene un plan } \\
\text { de sucesión por escrito } \\
\text { que considera al próximo } \\
\text { que haya cubierto el últi- } \\
\text { mo traspaso generacional. }\end{array}$ & $\begin{array}{l}\text { Correlación de } \\
\text { Pearson }\end{array}$ & 1 & .222 \\
\hline $\begin{array}{l}\text { Nivel de educación que } \\
\text { posee. }\end{array}$ & $\begin{array}{l}\text { Correlación de } \\
\text { Pearson }\end{array}$ & 18 & .375 \\
\hline & Sig. (bilateral) & .222 & 18 \\
\hline & N & .375 & 18 \\
\hline
\end{tabular}

Tabla 3. Correlaciones entre el plan de sucesión y el nivel de educación. Fuente: Realización Propia.

\begin{tabular}{|c|c|c|c|}
\hline & & $\begin{array}{l}\text { Nivel de educación } \\
\text { que posee. }\end{array}$ & Puesto que ocupa. \\
\hline \multirow{3}{*}{$\begin{array}{l}\text { Nivel de } \\
\text { educación } \\
\text { que posee. }\end{array}$} & Correlación de Pearson & 1 & -.356 \\
\hline & Sig. (bilateral) & & .148 \\
\hline & $N$ & 18 & 18 \\
\hline \multirow[t]{3}{*}{ Puesto que ocupa. } & Correlación de Pearson & -.356 & 1 \\
\hline & Sig. (bilateral) & .148 & \\
\hline & $\mathrm{N}$ & 18 & 18 \\
\hline
\end{tabular}

Tabla 4. Correlaciones entre el nivel de educación y el puesto que ocupa. Fuente: Realización Propia. 


\begin{tabular}{|l|l|c|c|}
\hline & & $\begin{array}{l}\text { Participar en las } \\
\text { decisiones y actitudes } \\
\text { operativas cotidianas }\end{array}$ & $\begin{array}{l}\text { Políticas de } \\
\text { funcionamiento } \\
\text { (coadministración) }\end{array}$ \\
\hline $\begin{array}{l}\text { Participar en } \\
\text { las decisiones } \\
\text { y actitudes } \\
\text { operativas } \\
\text { cotidianas }\end{array}$ & Correlación de Pearson & 1 & $-.667\left(^{* *}\right)$ \\
\hline $\begin{array}{l}\text { Políticas de } \\
\text { funcionamiento } \\
\text { (coadministración) }\end{array}$ & S Sig. (bilateral) & 18 & .002 \\
\hline & $\mathrm{N}$ & $-.667\left(^{* *}\right)$ & 18 \\
\hline
\end{tabular}

Tabla 5. Correlaciones entre las decisiones y las políticas. Fuente: Realización Propia.

En la Tabla 5 se analiza la relación entre las decisiones dentro de la empresa y las políticas de funcionamiento de la misma. El factor de Pearson representa el -.667, por lo que muestra que existe una correlación negativa entre estas variables.

\begin{tabular}{|c|c|c|c|}
\hline & & $\begin{array}{l}\text { Políticas de } \\
\text { funcionamiento } \\
\text { (coadministración) }\end{array}$ & $\begin{array}{l}\text { Elaborar los } \\
\text { resultados } \\
\text { de la empresa }\end{array}$ \\
\hline \multirow{3}{*}{$\begin{array}{l}\text { Políticas de } \\
\text { funcionamiento } \\
\text { (coadministración) }\end{array}$} & Correlación de Pearson & 1 & -.413 \\
\hline & Sig. (bilateral) & & .089 \\
\hline & $N$ & 18 & 18 \\
\hline \multirow{3}{*}{$\begin{array}{l}\text { Elaborar los } \\
\text { resultados } \\
\text { de la empresa }\end{array}$} & Correlación de Pearson & -.413 & 1 \\
\hline & Sig. (bilateral) & .089 & \\
\hline & $N$ & 18 & 18 \\
\hline
\end{tabular}

Tabla 6. Correlaciones entre las políticas y los resultados de la empresa.

Fuente: Realización Propia. 
En la Tabla 6 se analiza la relación entre las políticas de funcionamiento y los resultados de la empresa. El factor de Pearson es de -.413, lo cual indica que no hay correlación entre estas variables.

\section{Conclusiones}

Como se ha observado a lo largo de este estudio, las empresas agroindustriales entrevistadas en su mayoría están en la primera generación, lo cual implica una serie de acciones que aún no se toma en cuenta, como qué miembro de la familia puede suceder de una manera óptima al familiar que está en la gerencia. Contestan que todas las habilidades, conocimientos y funciones son importantes a tomar en cuenta, pero en la realidad no se ha hecho ningún análisis que permita determinar cuál es el familiar más adecuado para el puesto.

Aunque estas empresas presentan más de 25 trabajadores y se tiene un conocimiento de su sector de negocios (la comercialización y la transformación de productos, fruta básicamente) y sus canales de comercialización, ya están completamente establecidos. Realizan una actividad administrativa tomando en cuenta solucionar las circunstancias que se presentan al día y no con una base de planeación a mediano y largo plazo.

Destaca que sí se considera la alternativa de género en algunas empresas como factor limitante para la designación de la sucesión. Esto puede ser materia de estudio posterior, ya que se debe determinar si es por cuestiones de misoginia o por la creencia que si la mujer es la que tiene el manejo es casada, el negocio puede llegar a ser heredado por la familia del esposo, y en ese caso se perdería la tradición familiar en primera línea. 


\section{Referencias Bibliográficas}

Ahrens, J. P., Landmann, A., \& Wooywode, M. (2015). Gender Preferences in CEO successions in Family Firms: Family Characteristics and Humnan Capital of the Successor. Journal of Family Business Strategy. 86-103.

Andrade, J. (2002). Sucesión en la empresa familiar. Su futuro cuando la muerte se acerca. Revista Venezolana de Gerencia. 7 (19), 375-389.

Belausteguigoitia, I. (2003). Empresas familiares: su dinámica, equilibrio y consolidación. México: McGraw-Hill.

Fuentes, J. (2007). De padres a hijos. El proceso de sucesion en la empresa familiar. Madrid: Pirámide.

Gallo, M.A. (1998). La sucesión en la empresa familiar. Barcelona: CAIXA/Colección de estudios e informes.

Handler, W., \& Kram E.K. (2008). Succession in Family Firms: The Problem of Resistance. Family Business Review. 1, 361-381. http://doi.org/10.1111/j.1741-6248.1988.00361.x

Hauck, J., \& Prügl, R. (2015). Innovation activities during intra-family leadership succession in family firms: An empirical study from socioemotional wealth perspective. Journal of Family Business Strategy. 104-118.

Kraiczy, N. (2012). Innovations in Small and Medium-Sized Family Firms. Vallendar, Alemania: Springer Gabler.

Lea, J. (1993). La sucesión del management de la empresa familiar: Como mantener el negocio en la familia y la familia en el negocio. Vergara, Argentina: Granica.

Mucci, O. (2008). Empresas familiares: Funcionamiento e identidad. Mar de Plata, Argentina: Universidad Nacional del Mar del Plata.

Schlepphorst, S., \& Moog, P. (2014). Left in the dark: Family successors' requirement profiles in the family business succession process. Journal of Family Business Strategy, 5 (4) 358-371. 
Tadeo, R.J. (2005). Comportamientos en la dirección y gobierno de la empresa familiar: Análisis empírico de la profesionalización como garantía de continuidad. (Tesis Doctoral en Administración). Universidad Complutense de Madrid, Madrid. 


\section{Capítulo 6}

La gestión de la cadena de valor del talento humano como ventaja competitiva. Organización, Administración y Recursos Humanos Martha Lucía Moya y Juan Carlos Mancilla

\section{Introducción}

Las organizaciones del siglo XXI (basadas en los paradigmas de la sociedad del conocimiento, la globalización y las nuevas tecnologías de la información) para generar ventaja competitiva deben centrar su atención en factores que permitan el desarrollo de capacidades organizacionales (también denominadas habilidades distintivas, claves, específicas, capacidades organizativas y capital organizacional), tales como el aprendizaje, innovación, cambio y rapidez en el proceso decisorio, indispensable para la creación del capital intelectual, lo que a su vez exige el desarrollo de estrategias fundamentadas en la gestión del talento humano, con el fin de acrecentarlo a partir de sus tres pilares: el capital humano (innovación, talentos, habilidades), estructural (patentes, servicios) y relacional (servicio, satisfacción y atención al cliente).

El conocimiento se convierte, entonces, en el valor más importante de la organización para generar ventaja competitiva, y el individuo es la fuente donde se origina. Por tanto, los esfuerzos deben centrarse en crear, generar y consolidar, nuevas y mejores estrategias, empleando procesos permanentes orientados a identificar, evaluar, desarrollar y optimizar tanto el capital tangible como el intangible que interactúa dentro y fuera de sus propias estructuras organizacionales (Moya y Ochoa, 2012). Por consiguiente, para ser competitivas, requieren desarrollar y aumentar el capital intelectual a partir de la gestión de los procesos organizacionales que en el caso de la gestión del talento humano implica los 5 procesos básicos a saber: integrar, desarrollar, organizar, retener y auditar el capital humano. Una herramienta que daría claridad es la denominada cadena de valor, la cual permite describir el desarrollo de las actividades de una organización generando valor al cliente y en dependencia directa con el sistema de valor general (cadena de valor de los proveedores y compradores). 
El resultado radica en entregar un mayor valor al cliente a través de mejores relaciones y calidad en el servicio: incluye conocimientos, habilidades y capacidades, que al estar insertas en la estructura, tecnología, procesos y relaciones interpersonales e intergrupales de la organización, no pueden ser fácilmente replicables por la competencia; lo cual constituye una ventaja competitiva sostenible (Porcel y Bohrt, 2008, citado en Moya y Mancilla, 2014, p. 114).

\section{Planteamiento del problema}

El capital intelectual en una organización que se erige como el activo que genera valor. Johnson y Kaplan (1987), citado en Rodríguez (2005), afirman que el valor económico de una organización no es únicamente la suma de los valores de sus activos tangibles, sino que también incluye el valor de activos intangibles como el stock de productos innovadores, el conocimiento de procesos de producción flexibles y de alta calidad, el talento de los empleados, la fidelidad del cliente, la sensibilidad hacia el producto, la confianza en los proveedores.

Por tanto, el valor del talento humano en la organización se afianza en la idea que un individuo competente, idóneo, innovador, comprometido, motivado, etc., influirá positivamente en cada nivel jerárquico; por ejemplo, si las decisiones estratégicas de la alta gerencia son tomadas por presidentes o gerentes competentes, que a su vez las direccionan a los mandos medios (tácticas) con iguales características, estas podrán incidir de una forma organizada, clara y asertiva en el rendimiento del nivel operativo para el logro de los objetivos y metas organizacionales.

Sin embargo, para muchas organizaciones no es claro el valor que genera el capital humano y la importancia de la gestión de los procesos del talento humano que permitan desarrollarlo. Por lo anterior, surge el siguiente interrogante: ¿Por qué la adaptación de la cadena de valor de los procesos de gestión del talento humano como herramienta estratégica genera ventaja competitiva en las empresas objeto de estudio?

\section{Revisión teórica \\ Gestión del conocimiento}

Se define como el aprendizaje organizativo que permite aumentar las capacidades de una organización; es decir, es un medio para que la empresa pueda resolver problemas cada vez más complejos, (Carrión, 1999, citado en Garrido, 2002). Con lo anterior, es posible inferir que, aquellas organizaciones que capitalizan el conocimiento de sus trabajadores (capital intelectual), poseen mayores probabilidades de ser más competitivas, exitosas y productivas. En palabras de Stewart, (1991) citado en Ramírez (2010), el capital intelectual es la suma de todos los conocimientos que poseen los empleados de una empresa y que le dan a esta una ventaja 
competitiva. Constituye el material intelectual que ha sido formalizado, capturado y procesado para generar mayor valor de los activos, cuando son gestionados y medidos adecuadamente.

La mayoría de las definiciones de capital intelectual indican que son únicamente los activos intangibles los que lo conforman; no obstante, Rodríguez (2005) se une al planteamiento de autores como Harvey y Lusch (1999), Caddy (2000), Konar y Cohen (2001), Porto (2003), Viedma (2003), García-Ayuso y Larrinaga (2004), García-Parra, et al., (2004), Lozano y Fuentes (2005), entre otros, quienes proponen que el capital intelectual se calcule como la diferencia entre los activos intangibles de los que dispone la empresa y los pasivos intangibles que debe soportar. Si bien es cierto que el activo intangible genera valor a la organización, el pasivo intangible reduce el valor generado y lo posiciona frente a la competencia de manera negativa.

Edvinsson y Malone (1997) dividen el capital intelectual en humano, estructural y relacional. Esta clasificación conjuga las actitudes, aptitudes y capacidades de los seres humanos, con las rutinas, procesos y sistemas organizativos, y las redes o ámbitos de relación. El capital humano, hace referencia al conocimiento (explícito o tácito) útil para la empresa que poseen las personas y equipos de la misma, así como su capacidad para regenerarlo; es la base de la generación de los otros dos tipos de capital intelectual. En cuanto al capital estructural, este puede ser entendido como el conocimiento que la organización consigue explicitar, sistematizar e internalizar y que en un principio puede estar latente en las personas y equipos de la empresa. Y el capital relacional involucra el valor que tiene para una empresa el conjunto de relaciones que mantiene con el exterior, la calidad y sostenibilidad de la base de clientes y su potencialidad para generar nuevos clientes en el futuro.

Para lograr visualizar los intangibles que permitan generar ventaja competitiva y sostenibilidad a la organización, se debe identificar el capital humano, crear mecanismos para medirlos, establecer procesos para desarrollarlos y potencializarlos y, por último, explicitar, sistematizar e internalizar los productos de tal manera que sean reflejados en los estados financieros.

\section{Cadena de valor del talento humano}

El modelo de la cadena de valor de Porter (1985), citado en Moya y Mancilla (2014), es esencialmente una forma de análisis de la actividad empresarial mediante la cual se descompone una empresa en sus partes constitutivas, buscando identificar fuentes de ventaja competitiva en aquellas actividades generadoras de valor; como instrumento de decisión proporciona información al categorizar las actividades que producen valor agregado en una organización e identificar las actividades que le generan una ventaja competitiva sustentable. 
Las organizaciones de hoy hablan de una cadena de valor de intangibles, es decir, que trabajan en función del desarrollo adecuado de los activos intangibles de la organización: conocimiento, tecnología, propiedad intelectual, cultura organizacional, creatividad, emociones, valores, espiritualidad, etc., para garantizar resultados económicos superiores en cuanto a eficiencia, eficacia y satisfacción del cliente. Para lograrlo, es indispensable poseer una dependencia (área de talento humano) encargada de gestionar y establecer procesos, que permitan potenciar en la empresa el valor estratégico del conocimiento, al cualificar las ideas, convertir el conocimiento tácito en explícito y crear nuevas oportunidades de productos y/o servicios.

Estas actividades - gestionar el conocimiento y su cadena de valor- constituyen un proceso estratégico más eficiente, al crear y desarrollar competencias esenciales dentro de la empresa como una organización que aprende, llevar procesos de aprendizaje hacia dentro y hacia afuera de la empresa, con constante generación de valor. Por tal razón, los autores proponen un modelo de cadena de valor de los procesos de talento humano que permita gestionar el talento humano a partir de los procesos básicos de integrar, desarrollar, organizar, retener y auditar, para aumentar el capital intelectual (humano, estructural y relacional).

Este modelo se construyó a partir de la metodología de análisis funcional, que es una de las formas de aproximación al contenido de las ocupaciones desde la óptica de las competencias, la cual describe el propósito principal, desglosa las funciones claves que deben realizarse, desagrega las funciones principales y culmina en la ramificación de las funciones individuales que se asocian a las competencias laborales.

\section{Metodología}

El estudio se enmarca en el enfoque cualitativo por cuanto pretende analizar y determinar la cadena de valor de los procesos de gestión del talento humano como herramienta estratégica para generar ventaja competitiva. Según la naturaleza de la información, el tipo de investigación es descriptiva.

Para esta investigación el universo fue compuesto por organizaciones que tienen vínculos con estudiantes del programa Administración del Talento Humano de la Fundación Universitaria para el Desarrollo Humano UNINPAHU, en la ciudad de Bogotá, D.C. Base de datos de empresas, compilada en diferentes espacios académicos, con muestreo de tipo no probabilístico, intencional, en donde se eligieron en la primera fase 22 de las empresas y en la segunda 40, estimadas como representativas de la población, con actividad de servicios y cuyo tamaño se encuentra tipificado entre mediana y grande.

Se utilizaron dos instrumentos de recolección de información. El primero se estableció a partir de los cinco procesos planteados por Chiavenato (2011) -integración, or- 
ganización, retención, desarrollo y auditoría- y redefinidos por Rodríguez (2007) y Cuesta, (2010); y de la matriz del análisis funcional, definiendo las categorías de análisis -concepto, función clave, principal, específica y las competencias específicas. El segundo se desarrolla a partir del formato de procedimiento, en donde se caracteriza cada uno de los procesos.

Se desarrollaron tres fases: en la primera, se determinó el modelo teórico, las categorías de análisis, el diseño del instrumento de recolección de información, la aplicación del instrumento a grupo control (22 empresas), el análisis de resultados y la construcción del esquema de procesos de gestión del talento humano. En la segunda, se adaptó el instrumento, se rediseñó el instrumento de caracterización de procesos, se aplicó el instrumento a 40 organizaciones, se realizó análisis de resultados y finalmente se diseñó el modelo de cadena de valor. En la última fase, se realizó la validación del modelo de cadena de valor de los procesos de gestión del talento humano en las empresas objeto de estudio.

\section{Resultados}

En cuanto a la primera fase, se diseñó el esquema de posibles procesos resultado de la aplicación del instrumento a 20 empresas en donde se incluyeron 18 procesos. Del proceso de integración, se determinaron cuatro procesos: investigación de mercado laboral, reclutamiento, selección y contratación; de igual forma, en los procesos de organización se consideran la planeación y ubicación del recurso humano, el análisis y descripción de cargos, la evaluación del desempeño y el plan de vida y carrera, así como la retención (relaciones laborales, administración de sueldo y salarios, planes prestacionales e higiene y seguridad en el trabajo); en cuanto a los procesos de desarrollo se considera el desarrollo organizacional, humano y capacitación; y de la auditoria el banco de datos, el sistema de información administrativa y la auditoria de recursos humanos.

En la segunda fase, estos resultados permitieron una adaptación al instrumento que fue aplicado a la muestra incluyendo otros procesos y unificando criterios, pasando de 18 a 25 procesos en donde se amplia de 4 a 7 el proceso de organización, desarrollo de 3 a 6 , retención de 4 a 7 . En el proceso de integración se mantienen los cuatro pero se elimina contratación y se agrega socialización y, finalmente, se reduce auditoría de 3 a 2 .

Posteriormente se realizó el análisis funcional del proceso de gestión humana a partir de cada uno de los procesos que los integran y que permitieron determinar un modelo de la cadena de valor del proceso. Para tal fin, se establecieron como categorías de análisis, el propósito principal, el concepto, la función clave, la función principal, la función específica, así como las competencias, conformando los siguientes mapas funcionales: 
1. Integración: corresponde a la provisión de personal, obtenida en el mercado laboral, a las personas necesarias, colocarlas e integrarlas a la organización, garantizando su continuidad y desempeño (Chiavenato, 2011).

\section{Proceso de la integración}

Analiza y compara la coherencia que existe entre la requisición y el perfil del cargo.Consulta el sistema de información de personal.

\begin{tabular}{|c|c|c|c|c|}
\hline $\begin{array}{l}\text { Propósito } \\
\text { Principal }\end{array}$ & $\begin{array}{l}\text { Investigación de Mer- } \\
\text { cado Laboral }\end{array}$ & Reclutamiento & $\begin{array}{l}\text { Selección } \\
\text { de personal }\end{array}$ & Socialización \\
\hline Concepto & $\begin{array}{l}\text { Oferta y demanda laboral } \\
\text { como fuente de recluta- } \\
\text { miento. }\end{array}$ & $\begin{array}{l}\text { Técnicas y procedi- } \\
\text { mientos orientados } \\
\text { a atraer candidatos } \\
\text { potencialmente cali- } \\
\text { ficados y capaces de } \\
\text { ocupar cargos dentro } \\
\text { de la organización. }\end{array}$ & $\begin{array}{l}\text { Proceso mediante el } \\
\text { cual se escoge los can- } \\
\text { didatos más adecuados } \\
\text { para dar respuesta a } \\
\text { las necesidades de la } \\
\text { organización. }\end{array}$ & $\begin{array}{l}\text { Integración de } \\
\text { los miembros que } \\
\text { ingresan al sistema } \\
\text { organizacional. }\end{array}$ \\
\hline Función Clave & $\begin{array}{l}\text { Manejar la base de datos } \\
\text { con el fin de buscar el } \\
\text { perfil de vacantes. }\end{array}$ & $\begin{array}{l}\text { Abastecer de } \\
\text { candidatos para el } \\
\text { proceso de selección. }\end{array}$ & $\begin{array}{l}\text { Elegir y contratar al } \\
\text { candidato que más se } \\
\text { adapte al perfil de la } \\
\text { vacante. }\end{array}$ & $\begin{array}{l}\text { Inducir a las personas } \\
\text { al contexto organiza- } \\
\text { cional. }\end{array}$ \\
\hline $\begin{array}{l}\text { Función } \\
\text { Principal }\end{array}$ & $\begin{array}{l}\text { Analizar de forma cuan- } \\
\text { titativa y cualitativa el } \\
\text { mercado laboral. }\end{array}$ & $\begin{array}{l}\text { Identificar los } \\
\text { métodos y técnicas } \\
\text { eficientes para reclu- } \\
\text { tar personal. }\end{array}$ & $\begin{array}{l}\text { Aplicar técnicas y } \\
\text { pruebas que permitan } \\
\text { identificar en los pros- } \\
\text { pectos las caracterís- } \\
\text { ticas solicitadas en el } \\
\text { profesiograma. }\end{array}$ & $\begin{array}{l}\text { Crear y desarrollar } \\
\text { programas de induc- } \\
\text { ción para la socializa- } \\
\text { ción y adaptación de } \\
\text { los nuevos miembros } \\
\text { de la empresa. }\end{array}$ \\
\hline $\begin{array}{l}\text { Función } \\
\text { individual } \\
\text { o específica }\end{array}$ & $\begin{array}{l}\text { - Identificar el macro- } \\
\text { enfoque: Mercado de } \\
\text { trabajo (oferta) y el } \\
\text { mercado de RH (deman- } \\
\text { da) y el microambiente: } \\
\text { (rotación, absentismo) } \\
\text { - Determinar las fuentes } \\
\text { de información de } \\
\text { mayor uso } \\
\text { - Recopilar los datos e in- } \\
\text { formación sobre oferta } \\
\text { y demanda laboral. } \\
\text { - Compilar y consolidar } \\
\text { la información para la } \\
\text { interpretación de los } \\
\text { resultados. }\end{array}$ & $\begin{array}{l}\text { - Identificar las nece- } \\
\text { sidades laborales } \\
\text { de la organización } \\
\text { para su cubri- } \\
\text { miento. } \\
\text { - Determinar las } \\
\text { técnicas y métodos } \\
\text { de reclutamiento } \\
\text { de mayor uso en su } \\
\text { sector. } \\
\text { - Definir el método } \\
\text { más indicado para } \\
\text { implementar su } \\
\text { operacionalización. }\end{array}$ & $\begin{array}{l}\text { - Recibir y sistematizar } \\
\text { las requisiciones de } \\
\text { empleados de las } \\
\text { distintas áreas. } \\
\text { - Establecer las técni- } \\
\text { cas y herramientas } \\
\text { efectivas para la eje- } \\
\text { cución del proceso } \\
\text { de selección. } \\
\text { - Analizar y evaluar los } \\
\text { resultados del proce- } \\
\text { so de forma eficiente } \\
\text { y eficaz. } \\
\text { - Elegir y contratar al } \\
\text { candidato más apto y } \\
\text { que se ajuste al perfil } \\
\text { solicitado. }\end{array}$ & $\begin{array}{l}\text { - Crear y definir } \\
\text { el programa de } \\
\text { socialización que } \\
\text { facilite comprender } \\
\text { la cultura (lenguaje, } \\
\text { usos y costum- } \\
\text { bres), estructura, } \\
\text { productos y ser- } \\
\text { vicios y aspectos } \\
\text { estratégicos de la } \\
\text { organización. } \\
\text { - Seguimiento y } \\
\text { evaluación del pro- } \\
\text { ceso para verificar } \\
\text { su impacto. }\end{array}$ \\
\hline
\end{tabular}




\begin{tabular}{|l|l|}
\hline Competencia & $\begin{array}{l}\text { - Analiza y compara la coherencia que existe entre la requisición y el perfil del cargo.Consulta el siste- } \\
\text { ma de información de personal. } \\
\text { - Identifica y ejecuta el proceso de reclutamiento, con el fin de dar respuesta a las necesidades organi- } \\
\text { zacionales. } \\
\text { - Aplica técnicas y herramientas para evaluar las competencias, con el fin de elegir al candidato idóneo } \\
\text { para el cargo ofertado. } \\
\text { - Elige el candidato idóneo para desempeñar el cargo, de acuerdo con el manual de funciones. } \\
\text { - Identifica, aplica y designa los diferentes contratos según su naturaleza, políticas, normas legales } \\
\text { vigentes y los procedimientos de la organización. }\end{array}$ \\
\hline
\end{tabular}

Tabla 1. Análisis funcional del proceso de integración. Fuente: Moya y Mancilla (2013).

2. Organización: El propósito de este proceso es de planificar y estructurar los recursos disponibles (talentos humanos, financieros y materiales) a nivel específico. Incluye ocho procesos.

\section{Proceso de organización}

Planificar y estructurar los recursos disponibles (talentos humanos, financieros y materiales) de los que dispone la empresa, para alcanzar los objetivos deseados.

\begin{tabular}{|c|c|c|c|c|}
\hline $\begin{array}{l}\text { Propósito } \\
\text { Principal }\end{array}$ & $\begin{array}{c}\text { Planeación y } \\
\text { Ubicación de R.H. }\end{array}$ & $\begin{array}{c}\text { Sistema } \\
\text { de Calidad }\end{array}$ & $\begin{array}{l}\text { Gestión por } \\
\text { competencia }\end{array}$ & Análisis funcional \\
\hline Concepto & $\begin{array}{l}\text { Estructurar la planeación } \\
\text { y ubicación de recursos } \\
\text { humanos con el fin de } \\
\text { asegurar el número y el } \\
\text { tipo correcto de personas } \\
\text { en los puestos correctos y } \\
\text { en el momento adecuado } \\
\text { para lograr los objetivos y } \\
\text { planes de la empresa. }\end{array}$ & $\begin{array}{l}\text { Modelo participativo } \\
\text { de administración, en } \\
\text { el que se consideran } \\
\text { los recursos humanos } \\
\text { como talentos, } \\
\text { capaces de entender } \\
\text { su trabajo y realizarlos } \\
\text { cumpliendo con } \\
\text { normas de calidad y } \\
\text { productividad. }\end{array}$ & $\begin{array}{l}\text { Forma de gestionar de } \\
\text { las personas, basado en } \\
\text { sus capacidades, hacia } \\
\text { la consecución de los } \\
\text { objetivos del negocio. }\end{array}$ & $\begin{array}{l}\text { Mapa que alinea las } \\
\text { funciones con su pro- } \\
\text { pósito o misión y con } \\
\text { su horizonte o visión } \\
\text { como elemento orga- } \\
\text { nizador de la práctica } \\
\text { organizacional. }\end{array}$ \\
\hline Función Clave & $\begin{array}{l}\text { Determinar los requeri- } \\
\text { mientos de la fuerza de } \\
\text { trabajo de las diferentes } \\
\text { áreas y los medios requeri- } \\
\text { dos para lograrlo. }\end{array}$ & $\begin{array}{l}\text { Orientar las } \\
\text { actividades de la } \\
\text { empresa para lograr } \\
\text { el rendimiento } \\
\text { organizacional } \\
\text { a partir de la } \\
\text { eficiencia, eficacia y } \\
\text { competitividad. }\end{array}$ & $\begin{array}{l}\text { Administrar y direccio- } \\
\text { nar a los empleados } \\
\text { adaptándolos a las } \\
\text { estrategias y necesida- } \\
\text { des de la organización } \\
\text { de la empresa. }\end{array}$ & $\begin{array}{l}\text { Describir las unidades } \\
\text { de competencia } \\
\text { laboral. }\end{array}$ \\
\hline
\end{tabular}




\begin{tabular}{|c|c|c|c|c|}
\hline $\begin{array}{l}\text { Función } \\
\text { Principal }\end{array}$ & $\begin{array}{l}\text { Proveer y asegurar de } \\
\text { manera sistemática la } \\
\text { dotación de personal de } \\
\text { forma adecuada y continua } \\
\text { para cubrir la planta de } \\
\text { personal. }\end{array}$ & $\begin{array}{l}\text { Implementar un } \\
\text { sistema de calidad de } \\
\text { la gestión de recursos } \\
\text { humanos. }\end{array}$ & $\begin{array}{l}\text { Implantar la gestión } \\
\text { por competencias en } \\
\text { la organización para } \\
\text { desarrollar el capital } \\
\text { intelectual de la misma. }\end{array}$ & $\begin{array}{l}\text { Determinar los } \\
\text { elementos de com- } \\
\text { petencia laboral para } \\
\text { obtener un resultado } \\
\text { de trabajo. }\end{array}$ \\
\hline $\begin{array}{l}\text { Función } \\
\text { individual } \\
\text { o específica }\end{array}$ & $\begin{array}{l}\text { - Realizar el pronóstico } \\
\text { de personal. } \\
\text { - Identificar y determinar } \\
\text { la demanda de personal. } \\
\text { - Identificar y determinar } \\
\text { la oferta de recursos } \\
\text { humanos. } \\
\text { - Establecer la planeación } \\
\text { y programación del plan } \\
\text { de acción. }\end{array}$ & $\begin{array}{l}\text { - Identificar, deter- } \\
\text { minar y caracterizar } \\
\text { los subprocesos de } \\
\text { gestión humana } \\
\text { relacionados con: } \\
\text { - Cultura. } \\
\text { - Comunicación y } \\
\text { diseño de trabajo. } \\
\text { - Entrenamiento. } \\
\text { - Medición y } \\
\text { evaluación. } \\
\text { - Selección. } \\
\text { - Plan de vida de } \\
\text { carrera. }\end{array}$ & $\begin{array}{l}\text { - Construir el dicciona- } \\
\text { rio de competencias. } \\
\text { - Clasificar, categorizar } \\
\text { y caracterizar: } \\
\text { Competencias } \\
\text { Nucleares. } \\
\text { - Competencias } \\
\text { básicas. } \\
\text { - Competencias } \\
\text { Laborales (genéricas, } \\
\text { y específicas). }\end{array}$ & $\begin{array}{l}\text { - Identificar actores } \\
\text { clave. } \\
\text { - Elaboración del } \\
\text { mapa funcional. } \\
\text { - Identificación de } \\
\text { competencias por } \\
\text { cargos. } \\
\text { - Desarrollo de } \\
\text { estándares de } \\
\text { competencia. } \\
\text { - Validación de } \\
\text { competencias } \\
\text { laborales. }\end{array}$ \\
\hline Competencia & \multicolumn{4}{|c|}{$\begin{array}{l}\text { - Planea y ubica el flujo de recursos humanos basados en el inventario de habilidades del personal. } \\
\text { - Aplica los conocimientos y habilidades del sistema de gestión de la calidad según la norma ISO } 9001 . \\
\text { - Alinear las prácticas de recursos humanos a la estrategia de los negocios basados en competencias. } \\
\text { - Determinar el mapa funcional de las organizaciones. }\end{array}$} \\
\hline $\begin{array}{l}\text { Propósito } \\
\text { Principal }\end{array}$ & $\begin{array}{c}\text { Análisis y Descripción } \\
\text { de Cargos }\end{array}$ & $\begin{array}{l}\text { Plan de vida y } \\
\text { carrera }\end{array}$ & $\begin{array}{c}\text { Evaluación del des- } \\
\text { empeño }\end{array}$ & $\begin{array}{l}\text { Administración } \\
\text { de sueldos. } \\
\text { Valuación de } \\
\text { cargos y escala } \\
\text { salarial }\end{array}$ \\
\hline Concepto & $\begin{array}{l}\text { El análisis del cargo se } \\
\text { ocupa de los requisitos } \\
\text { responsabilidades y condi- } \\
\text { ciones que el puesto exige; } \\
\text { mientras que la descrip- } \\
\text { ción consiste en enunciar } \\
\text { las tareas o responsabilida- } \\
\text { des que lo conforman. }\end{array}$ & $\begin{array}{l}\text { Plan de promoción } \\
\text { y desarrollo del } \\
\text { personal con el fin de } \\
\text { proyectarlos a ocupar } \\
\text { diferentes posiciones, } \\
\text { cargos y actividades, } \\
\text { en una organización. }\end{array}$ & $\begin{array}{l}\text { Implantar la gestión } \\
\text { por competencias en } \\
\text { la organización para } \\
\text { desarrollar el capital } \\
\text { intelectual de la misma. }\end{array}$ & $\begin{array}{l}\text { Determinar los } \\
\text { elementos de com- } \\
\text { petencia laboral para } \\
\text { obtener un resultado } \\
\text { de trabajo. }\end{array}$ \\
\hline Función Clave & $\begin{array}{l}\text { Identificación tanto de } \\
\text { aspectos intrínsecos } \\
\text { (descripción y conteni- } \\
\text { do) como de aspectos } \\
\text { extrínsecos (requisitos } \\
\text { intelectuales, físicos, } \\
\text { responsabilidades y condi- } \\
\text { ciones de trabajo). }\end{array}$ & $\begin{array}{l}\text { Estructuración, diseño } \\
\text { e implementación de } \\
\text { planes de carrera para } \\
\text { las personas en la } \\
\text { organización. }\end{array}$ & $\begin{array}{l}\text { Evaluación y retroali- } \\
\text { mentación del desem- } \\
\text { peño y/o rendimiento } \\
\text { de los trabajadores. }\end{array}$ & $\begin{array}{l}\text { Aplicar técnicas de } \\
\text { valuación de acuerdo } \\
\text { con la complejidad } \\
\text { de la estructura de } \\
\text { cargos que permita } \\
\text { implementar un } \\
\text { sistema de compen- } \\
\text { sación. }\end{array}$ \\
\hline
\end{tabular}




\begin{tabular}{|c|c|c|c|c|}
\hline $\begin{array}{l}\text { Función } \\
\text { Principal }\end{array}$ & $\begin{array}{l}\text { Elaborar los perfiles de car- } \\
\text { gos de una organización } \\
\text { conformando el manual de } \\
\text { funciones. }\end{array}$ & $\begin{array}{l}\text { Integrar el plan y/o } \\
\text { proyecto de vida de } \\
\text { cada persona, con } \\
\text { el escenario laboral } \\
\text { (individuo-organi- } \\
\text { zación) en pro de su } \\
\text { crecimiento y el de la } \\
\text { organización. }\end{array}$ & $\begin{array}{l}\text { Desarrollar e imple- } \\
\text { mentar el registro del } \\
\text { juicio evaluativo de } \\
\text { los empleados de una } \\
\text { organización. }\end{array}$ & $\begin{array}{l}\text { Presentar propuestas } \\
\text { de valuación y clasi- } \\
\text { ficación de sueldos } \\
\text { de acuerdo con la } \\
\text { complejidad y niveles } \\
\text { de competencia } \\
\text { deseados. }\end{array}$ \\
\hline $\begin{array}{l}\text { Función } \\
\text { individual } \\
\text { o específica }\end{array}$ & $\begin{array}{l}\text { - Identificar los conteni- } \\
\text { dos del manual } \\
\text { - Determinar el marco y } \\
\text { la estructura organiza- } \\
\text { cional } \\
\text { - Establecer la planta de } \\
\text { personal } \\
\text { - Construir perfiles de } \\
\text { cargos } \\
\text { - Protocolizar el docu- } \\
\text { mento }\end{array}$ & $\begin{array}{l}\text { - Identificar las nece- } \\
\text { sidades personales } \\
\text { - Definir los } \\
\text { objetivos de cada } \\
\text { persona } \\
\text { - Crear un plan de } \\
\text { acción a corto y } \\
\text { mediano plazo } \\
\text { - Controlar el plan } \\
\text { propuesto } \\
\text { - Optimizar los } \\
\text { conocimientos, } \\
\text { capacidades y } \\
\text { habilidades }\end{array}$ & $\begin{array}{l}\text { - Establecer los datos } \\
\text { de identificación del } \\
\text { empleado y su puesto } \\
\text { - Determinar y definir } \\
\text { un modelo de eva- } \\
\text { luación } \\
\text { - Determinar los indi- } \\
\text { cadores o parámetros } \\
\text { a valorar } \\
\text { - Construir y desarro- } \\
\text { llar el procedimiento } \\
\text { - Construir los forma- } \\
\text { tos de captura de } \\
\text { información } \\
\text { - Desarrollar el análisis } \\
\text { de resultados } \\
\text { - Establecer conclu- } \\
\text { siones } \\
\text { - Remitir a las depen- } \\
\text { dencias los instruc- } \\
\text { tivos para efectuar } \\
\text { la evaluación del } \\
\text { desempeño } \\
\text { - Acompañar el pro- } \\
\text { ceso de retroalimen- } \\
\text { tación }\end{array}$ & $\begin{array}{l}\text { - Identificar la } \\
\text { importancia de los } \\
\text { cargos dentro del } \\
\text { desarrollo organi- } \\
\text { zacional } \\
\text { - Determinar los } \\
\text { parámetros para } \\
\text { la valuación de los } \\
\text { cargos } \\
\text { - Establecer la } \\
\text { clasificación de los } \\
\text { puestos } \\
\text { - Realizar encuesta } \\
\text { - Imalarial } \\
\text { estructura salarial }\end{array}$ \\
\hline Competencia & \multicolumn{4}{|c|}{$\begin{array}{l}\text { - Identifica, describe, analiza y construye los perfiles de cargos, que a su vez, conforman el manual de } \\
\text { funciones. } \\
\text { - Conoce, evalúa e implementa métodos de valuación de cargos y la estructura salarial. } \\
\text { - Diseña e implementa instrumentos para la evaluación del desempeño por competencias. } \\
\text { - Planea y desarrolla planes de vida y carrera dirigidos a incrementar la calidad de vida de los trabaja- } \\
\text { dores. }\end{array}$} \\
\hline
\end{tabular}

Tabla 2. Análisis funcional del proceso de organización. Fuente: Moya y Mancilla (2013). 


\section{Retención: Sistema de relaciones de intercambio entre las personas (contribuciones) y la or- ganización (incentivos y premios, refuerzo positivo) para mantenerlos satisfechos y motivados e inducirlos a permanecer en ella. Se establecieron siete procesos.}

\section{Proceso de retención}

Sistema de relaciones de intercambio entre las personas (contribuciones) y la organización (incentivos y premios, refuerzo positivo) para mantenerlos satisfechos y motivados e inducirlos a permanecer en ella.

\begin{tabular}{|c|c|c|c|}
\hline $\begin{array}{l}\text { Propósito } \\
\text { Principal }\end{array}$ & $\begin{array}{c}\text { Nómina, Registro y control } \\
\text { de personal }\end{array}$ & $\begin{array}{c}\text { Higiene y Medicina del } \\
\text { Trabajo }\end{array}$ & Salud Ocupacional \\
\hline Concepto & $\begin{array}{l}\text { Se refiere a los registros financie- } \\
\text { ros de los sueldos de un emplea- } \\
\text { do, los salarios, las bonificacio- } \\
\text { nes y deducciones, cantidades } \\
\text { pagadas a los empleados por los } \\
\text { servicios prestados durante un } \\
\text { cierto período de tiempo. }\end{array}$ & $\begin{array}{l}\text { Normas y procedimientos } \\
\text { tendientes a la protección } \\
\text { biopsicosocial del trabajador, } \\
\text { preservándolo de los riesgos de } \\
\text { salud inherentes a las tareas del } \\
\text { cargo y al ambiente físico donde } \\
\text { se ejecutan. }\end{array}$ & $\begin{array}{l}\text { Actividades dirigidas a proteger } \\
\text { y promover la salud de los traba- } \\
\text { jadores mediante la prevención } \\
\text { y el control de enfermedades y } \\
\text { accidentes, y la eliminación de } \\
\text { los factores y condiciones que } \\
\text { ponen en peligro la salud y la } \\
\text { seguridad en el trabajo. }\end{array}$ \\
\hline Función Clave & $\begin{array}{l}\text { Gestionar la liquidación de la } \\
\text { nómina de una organización, de } \\
\text { acuerdo con los parámetros y } \\
\text { normas vigentes. }\end{array}$ & $\begin{array}{l}\text { Gestionar la conservación } \\
\text { de la salud y prevención de } \\
\text { enfermedades profesionales. }\end{array}$ & $\begin{array}{l}\text { Gestionar y controlar los riesgos } \\
\text { y accidentes laborales. }\end{array}$ \\
\hline $\begin{array}{l}\text { Función } \\
\text { Principal }\end{array}$ & $\begin{array}{l}\text { Utilización de mecanismos } \\
\text { tecnológicos para liquidar la } \\
\text { nómina, salarios y prestaciones } \\
\text { sociales del personal para regis- } \\
\text { tro y control del personal. }\end{array}$ & $\begin{array}{l}\text { Identificar y aplicar las normas } \\
\text { y procedimientos que permitan } \\
\text { el mejoramiento de las } \\
\text { condiciones de trabajo, salud, y } \\
\text { bienestar organizacional. }\end{array}$ & $\begin{array}{l}\text { Identificar, articular e implemen- } \\
\text { tar el plan básico legal en salud } \\
\text { ocupacional para incrementar } \\
\text { un ambiente seguro en el } \\
\text { trabajo. }\end{array}$ \\
\hline $\begin{array}{l}\text { Función } \\
\text { individual } \\
\text { o específica }\end{array}$ & $\begin{array}{l}\text { - Alimentar el sistema de } \\
\text { información de personal } \\
\text { en lo referente a EPS, ARPy } \\
\text { Pensiones. } \\
\text { - Liquidar devengos, deduc- } \\
\text { ciones, aportes parafiscales y } \\
\text { prestaciones sociales. } \\
\text { - Manejar los diferentes docu- } \\
\text { mentos, formatos y registros } \\
\text { de las carpetas individuales de } \\
\text { los empleados. }\end{array}$ & $\begin{array}{l}\text { - Elaborar e implementar un } \\
\text { plan de higiene laboral en el } \\
\text { lugar de trabajo. Gestionar } \\
\text { exámenes médicos de ingre- } \\
\text { so, ocupacional y de retiro. } \\
\text { - Implementar actividades } \\
\text { de promoción, educación y } \\
\text { control de los accidentes de } \\
\text { trabajo y las enfermedades } \\
\text { profesionales acordes a la } \\
\text { actividad de la empresa, con } \\
\text { el fin de adoptar medidas de } \\
\text { prevención. }\end{array}$ & $\begin{array}{l}\text { - Identificar, analizar y admi- } \\
\text { nistrar las condiciones que } \\
\text { pueden provocar riesgos. } \\
\text { - Identificar los factores de ries- } \\
\text { gos profesionales existentes } \\
\text { en la actividad laboral. } \\
\text { - Incentivar y promover la } \\
\text { conformación del programa } \\
\text { de salud ocupacional y el } \\
\text { comité paritario de Salud } \\
\text { Ocupacional, COPASO. }\end{array}$ \\
\hline Competencia & \multicolumn{3}{|c|}{$\begin{array}{l}\text { - Interpreta y aplica la política de sueldos, salarios y prestaciones sociales, la política de higiene y } \\
\text { seguridad en el trabajo. } \\
\text { - Asegurar un alto grado de bienestar mental, social y físico para los trabajadores y prevenir toda clase } \\
\text { de accidentes e imprevistos. } \\
\text { - Diseña y aplica planes de incentivos y bienestar de los trabajadores. }\end{array}$} \\
\hline
\end{tabular}




\begin{tabular}{|c|c|c|}
\hline $\begin{array}{l}\text { Propósito } \\
\text { Principal }\end{array}$ & Compensación Laboral & Relaciones Laborales \\
\hline Concepto & $\begin{array}{l}\text { Sistema de estimulación del trabajo dirigida a } \\
\text { alcanzar los objetivos y necesidades personales, } \\
\text { tanto de los empleados, como los de la organi- } \\
\text { zación. }\end{array}$ & $\begin{array}{l}\text { Proceso que enfoca orienta y canaliza las relacio- } \\
\text { nes laborales entre los trabajadores y la organi- } \\
\text { zación (de manera individual como colectiva), } \\
\text { relacionadas con las demandas y requerimientos } \\
\text { de la fuerza de trabajo con trascendencia social, } \\
\text { económica y política. }\end{array}$ \\
\hline Función Clave & $\begin{array}{l}\text { Incrementar la calidad de vida y dignidad humana } \\
\text { del trabajador. }\end{array}$ & $\begin{array}{l}\text { Interpretar, comprender e interceder en las } \\
\text { relaciones obrero - patronales. }\end{array}$ \\
\hline $\begin{array}{l}\text { Función } \\
\text { Principal }\end{array}$ & $\begin{array}{l}\text { Implementar el área de Bienestar Social con un } \\
\text { programa de estímulos e Incentivos. }\end{array}$ & $\begin{array}{l}\text { Gestionar y resolver problemáticas referidas a } \\
\text { la relación de la empresa con las asociaciones, } \\
\text { sindicatos, federaciones y cámaras empresariales. }\end{array}$ \\
\hline $\begin{array}{l}\text { Función } \\
\text { individual } \\
\text { o específica }\end{array}$ & $\begin{array}{l}\text { - Identificar y comprender los componentes del } \\
\text { Bienestar Social en la organización. } \\
\text { - Determinar y construir estrategias de estímulos } \\
\text { para las diferentes actividades y áreas en la } \\
\text { empresa. } \\
\text { - Diseñar un programa de bienestar que cubran } \\
\text { aspectos (salariales y extrasalariales), condicio- } \\
\text { nes de trabajo y personales (ego y espirituales). }\end{array}$ & $\begin{array}{l}\text { - Mantener una relación fluida con el sindicato, } \\
\text { el ministerio de trabajo y los delegados de } \\
\text { agremiaciones y asociaciones. } \\
\text { - Negociar los convenios colectivos de trabajo. } \\
\text { - Manejo de mesas de trabajo en temas relacio- } \\
\text { nados con conflictos sindicales (mítines, huel- } \\
\text { gas, paros, plan tortuga, operación reglamento, } \\
\text { procesos disciplinarios, desvinculación de } \\
\text { trabajadores, entre otros). } \\
\text { - Asistir a mediaciones o audiencias laborales en } \\
\text { tribunales. }\end{array}$ \\
\hline Competencias & \multicolumn{2}{|c|}{$\begin{array}{l}\text { - Diseña y aplica planes de compensación laboral a partir de incentivos y bienestar de los trabajadores. } \\
\text { - Fomenta el diálogo y la negociación y resolución de conflictos. } \\
\text { - Conoce la situación laboral actual en el sector y en el resto de las empresas. } \\
\text { - Promueve relaciones armónicas con otros colegas de empresas del mismo sector. } \\
\text { - Domina la normativa legal-laboral del país. } \\
\text { - Maneja el convenio colectivo al que suscriben los empleados. }\end{array}$} \\
\hline
\end{tabular}

Tabla 3. Análisis del proceso de retención. Fuente: Moya y Mancilla (2013).

4. Desarrollo: Estipula acciones que faciliten el aprendizaje organizacional, en procesos de educación, formación y aprendizaje para el desarrollo de las personas y equipos y establece procesos de inducción y capacitación. Incluye seis procesos. 


\section{Proceso de desarrollo}

Estipula acciones que faciliten el aprendizaje organizacional, en procesos de educación, formación y aprendizaje para el desarrollo de las personas y equipos, y establece procesos de inducción y capacitación.

\begin{tabular}{|c|c|c|c|}
\hline $\begin{array}{l}\text { Propósito } \\
\text { Principal }\end{array}$ & $\begin{array}{c}\text { Capacitación y desarrollo } \\
\text { del personal }\end{array}$ & Formación de equipos & $\begin{array}{c}\text { Comportamiento } \\
\text { organizacional }\end{array}$ \\
\hline Concepto & $\begin{array}{l}\text { Transmisión de conocimientos } \\
\text { y habilidades organizada, plani- } \\
\text { ficada y evaluada, que permita } \\
\text { el desarrollo de habilidades, } \\
\text { actitudes y conceptos. }\end{array}$ & $\begin{array}{l}\text { Estrategias que permitan el } \\
\text { fomento y construcción de } \\
\text { personas con habilidades } \\
\text { complementarias, que estén } \\
\text { comprometidas con un propó- } \\
\text { sito común, un método y metas } \\
\text { de desempeño, por los cuales se } \\
\text { responsabilizan mutuamente. }\end{array}$ & $\begin{array}{l}\text { Es el estudio y la aplicación de } \\
\text { los conocimientos acerca de la } \\
\text { forma en que las personas se } \\
\text { comportan individual y grupal- } \\
\text { mente en las organizaciones. }\end{array}$ \\
\hline Función Clave & $\begin{array}{l}\text { Diseñar y desarrollar programas } \\
\text { de formación y capacitación, } \\
\text { empresarial y social. }\end{array}$ & $\begin{array}{l}\text { Apoyar, generar y desarrollar } \\
\text { la integración de personas en } \\
\text { equipos de trabajo. }\end{array}$ & $\begin{array}{l}\text { Identificar y determinar sistemá- } \\
\text { ticamente el comportamiento } \\
\text { de las personas ante diferentes } \\
\text { situaciones. }\end{array}$ \\
\hline $\begin{array}{l}\text { Función } \\
\text { Principal }\end{array}$ & $\begin{array}{l}\text { Desarrollar y efectuar procesos } \\
\text { de inducción, reinducción, } \\
\text { formación, capacitación y } \\
\text { entrenamiento, con el fin de } \\
\text { desarrollar el capital humano en } \\
\text { las organizaciones. }\end{array}$ & $\begin{array}{l}\text { Formar y generar equipos de } \\
\text { trabajos multidisciplinarios. }\end{array}$ & $\begin{array}{l}\text { Fomentar estrategias que } \\
\text { incrementen la comunicación, } \\
\text { cultura y clima organizacional } \\
\text { para mejorar la calidad de vida } \\
\text { de los trabajadores. }\end{array}$ \\
\hline $\begin{array}{l}\text { Función } \\
\text { individual } \\
\text { o específica }\end{array}$ & $\begin{array}{l}\text { - Planea y ejecuta actividades } \\
\text { de inducción y/o socializa- } \\
\text { ción. } \\
\text { - Desarrolla procesos de rein- } \\
\text { ducción, con base en requeri- } \\
\text { mientos organizacionales. } \\
\text { - Crea y desarrolla procesos } \\
\text { de formación o educación } \\
\text { profesional. } \\
\text { - Propende por acciones de } \\
\text { conversión, transformación y } \\
\text { cambio de las personas, cuyo } \\
\text { objetivo es la evolución cons- } \\
\text { tante hacia el crecimiento. }\end{array}$ & $\begin{array}{l}\text { - Identifica el rol del individuo } \\
\text { desde la perspectiva del } \\
\text { trabajo en equipo. } \\
\text { - Determina la relación grupo } \\
\text { - equipo. } \\
\text { - Establece los efectos de } \\
\text { la motivación con el fin } \\
\text { de mejorar los niveles de } \\
\text { participación, contribución e } \\
\text { involucramiento de los miem- } \\
\text { bros de la organización. } \\
\text { - Explica las etapas en la } \\
\text { conformación de los equipos } \\
\text { de trabajo. } \\
\text { - Formula estrategias para } \\
\text { motivar, negociar, comunicar } \\
\text { e integrar a los equipos en los } \\
\text { procesos de gestión de los } \\
\text { recursos humanos. }\end{array}$ & $\begin{array}{l}\text { - Identifica los componentes } \\
\text { del proceso de la } \\
\text { comunicación personal y } \\
\text { organizacional. } \\
\text { - Diseña estrategias de } \\
\text { mejoramiento de los procesos } \\
\text { de comunicación. } \\
\text { - Determina los elementos } \\
\text { constitutivos de la cultura } \\
\text { organizacional. } \\
\text { - Construye y propone } \\
\text { estrategias de sensibilización } \\
\text { de la cultura y valores } \\
\text { organizaciones. } \\
\text { - Establece los elementos } \\
\text { que conformar el clima } \\
\text { organizacional. } \\
\text { - Diseña y aplica instrumentos } \\
\text { para la medición del clima } \\
\text { organizacional. }\end{array}$ \\
\hline
\end{tabular}




\begin{tabular}{|c|c|c|c|}
\hline Competencia & \multicolumn{3}{|c|}{$\begin{array}{l}\text { - Desarrolla actividades de inducción, entrenamiento y capacitación. } \\
\text { - Guía y facilita procesos de educación, formación y aprendizaje para el desarrollo de las personas, } \\
\text { equipos y organizaciones. } \\
\text { - Creación y orientación de personas que asumen tareas de jefatura o supervisión de personas en } \\
\text { gestión y desarrollo de equipos de trabajo } \\
\text { - Identifica los estilos para seguir los comportamientos de las personas y determinar los factores de } \\
\text { motivación de mayor impacto. }\end{array}$} \\
\hline $\begin{array}{l}\text { Propósito } \\
\text { Principal }\end{array}$ & Desarrollo Organizacional & $\begin{array}{l}\text { Negociación y resolución } \\
\text { de conflictos }\end{array}$ & Servicio al cliente \\
\hline Concepto & $\begin{array}{l}\text { Estudia la organización como } \\
\text { sistema total y se compromete a } \\
\text { mejorar la eficacia de la empresa a } \\
\text { largo plazo mediante intervenciones } \\
\text { constructivas en los procesos y en la } \\
\text { estructura de las organizaciones. }\end{array}$ & $\begin{array}{l}\text { Proceso que busca la mejor solución } \\
\text { de problemas para las partes involucra- } \\
\text { das y la organización. }\end{array}$ & $\begin{array}{l}\text { Ofrecer y suministrar al } \\
\text { cliente (interno y externo) } \\
\text { el producto en el momen- } \\
\text { to y lugar adecuado y se } \\
\text { asegure un uso correcto } \\
\text { del mismo. }\end{array}$ \\
\hline $\begin{array}{l}\text { Función } \\
\text { Clave }\end{array}$ & $\begin{array}{l}\text { Evaluar y conducir los cambios en la } \\
\text { cultura de quienes configuran una } \\
\text { organización. }\end{array}$ & $\begin{array}{l}\text { Negociar y encontrar la solución } \\
\text { satisfactoria de conflictos. }\end{array}$ & $\begin{array}{l}\text { Ofrecer y suministrar } \\
\text { al cliente el producto } \\
\text { en el momento y lugar } \\
\text { adecuado y asegurar un } \\
\text { uso correcto del mismo. }\end{array}$ \\
\hline $\begin{array}{l}\text { Función } \\
\text { Principal }\end{array}$ & $\begin{array}{l}\text { Desarrollar e implementar estrate- } \\
\text { gias educativas de intervención en } \\
\text { las organizaciones, en la búsque- } \\
\text { da de cambios planeados para } \\
\text { aumentar la eficiencia, eficacia y } \\
\text { productividad. }\end{array}$ & $\begin{array}{l}\text { Identificar, analizar y resolver conflictos } \\
\text { de la vida interpersonal, en beneficio } \\
\text { del escenario laboral. }\end{array}$ & $\begin{array}{l}\text { Desarrollar estrategias de } \\
\text { Servicio al cliente. }\end{array}$ \\
\hline $\begin{array}{l}\text { Función } \\
\text { individual } \\
\text { o específica }\end{array}$ & $\begin{array}{l}\text { - Identifica elementos de Cultura. } \\
\text { - Determina relaciones interperso- } \\
\text { nales / habilidades sociales. } \\
\text { - Establece elementos de clima. } \\
\text { - Observa aspectos de resistencia } \\
\text { (restrictivas, impulsoras, resisten- } \\
\text { cias) con el propósito de efectuar } \\
\text { el cambio. } \\
\text { - Realiza u diagnóstico organiza- } \\
\text { cional. } \\
\text { - Propone un proceso de interven- } \\
\text { ción (asesoría, consultoría). }\end{array}$ & $\begin{array}{l}\text { - Identifica los alcances de la normati- } \\
\text { vidad existente, ley } 1010 . \\
\text { - Determina las instancias pertinentes } \\
\text { para la negociación y la resolución } \\
\text { de conflictos. } \\
\text { - Establece las técnicas de comunica- } \\
\text { ción, negociación y resolución de } \\
\text { conflictos más asertivas. } \\
\text { - Promueve espacios de negociación } \\
\text { para la resolución de conflictos. } \\
\text { - Implementa protocolos para el } \\
\text { manejo de los conflictos al interior } \\
\text { de la empresa. }\end{array}$ & $\begin{array}{l}\text { - Identifica, entiende y } \\
\text { anticipa las necesida- } \\
\text { des de los clientes. } \\
\text { - Identifica clientes } \\
\text { potenciales. } \\
\text { - Capta y mantiene } \\
\text { clientes. } \\
\text { - Mide la satisfacción del } \\
\text { cliente. } \\
\text { - Implementa y admi- } \\
\text { nistra procesos de } \\
\text { servicio. }\end{array}$ \\
\hline $\begin{array}{l}\text { Competen- } \\
\text { cias }\end{array}$ & \multicolumn{3}{|c|}{$\begin{array}{l}\text { - Diseña y aplica planes de compensación laboral a partir de incentivos y bienestar de los trabajadores. } \\
\text { - Fomenta el diálogo y la negociación y resolución de conflictos. } \\
\text { - Conoce la situación laboral actual en el sector y en el resto de las empresas. } \\
\text { - Promueve relaciones armónicas con otros colegas de empresas del mismo sector. } \\
\text { - Domina la normativa legal-laboral del país. } \\
\text { - Maneja el convenio colectivo al que suscriben los empleados. }\end{array}$} \\
\hline
\end{tabular}

Tabla 4. Análisis funcional del proceso de desarrollo. Fuente: Moya y Mancilla (2013). 
5. Auditoría: Reúne, procesa, almacena y difunde información para la administración del talento humano e implementan estrategias, proyectos y acciones para mejorar la eficiencia en los procesos organizacionales. Incluye dos subprocesos.

\section{Proceso de auditoría}

Forma de garantizar y fomentar la contribución de la administración de recursos humanos a las prácticas de responsabilidad social de una empresa.

\begin{tabular}{|c|c|c|}
\hline $\begin{array}{l}\text { Propósito } \\
\text { Principal }\end{array}$ & Capacitación y desarrollo del personal & Formación de equipos \\
\hline Concepto & $\begin{array}{l}\text { Proceso sistemático para reunir, registrar, almacenar, } \\
\text { analizar y recuperar datos de recursos humanos de una } \\
\text { organización. }\end{array}$ & $\begin{array}{l}\text { Sistema de revisión y control de los pro- } \\
\text { cesos que se gestionan en área del talento } \\
\text { humano, respecto a la eficacia, eficiencia y } \\
\text { productividad en la organización. }\end{array}$ \\
\hline Función Clave & $\begin{array}{l}\text { Implementar y desarrollar el sistema de información de } \\
\text { personal en la organización. }\end{array}$ & $\begin{array}{l}\text { Analizar las políticas y prácticas de personal } \\
\text { de una organización. }\end{array}$ \\
\hline $\begin{array}{l}\text { Función } \\
\text { Principal }\end{array}$ & $\begin{array}{l}\text { Administrar el sistema de información de personal en una } \\
\text { organización. }\end{array}$ & $\begin{array}{l}\text { Realizar diagnósticos e implementar } \\
\text { estándares de desempeños, resultados y } \\
\text { objetivos para el control de las actividades } \\
\text { relacionadas con el talento humano. }\end{array}$ \\
\hline $\begin{array}{l}\text { Función } \\
\text { individual } \\
\text { o específica }\end{array}$ & $\begin{array}{l}\text { - Vincula los sistemas de información con las funciones } \\
\text { gerenciales de planificación, organización, dirección } \\
\text { y control. } \\
\text { - Proporciona información extensa y coordinada de } \\
\text { subsistemas integrados. } \\
\text { - Transforma los datos en información para mejorar la } \\
\text { productividad de acuerdo con los estilos y característi- } \\
\text { cas de los administradores. } \\
\text { - Establece estrategias que permitan que la información } \\
\text { cumpla con los parámetros de calidad, oportunidad, } \\
\text { cantidad y relevancia, para la toma de decisiones. }\end{array}$ & $\begin{array}{l}\text { - Identifica los objetivos de una auditoría. } \\
\text { - Determina las fuentes de información y } \\
\text { - Establertinencia. } \\
\text { toría. } \\
\text { - Realiza el diagnóstico. } \\
\text { - Protocoliza la información obtenida. } \\
\text { - Propone recomendaciones de cambios } \\
\text { y modificaciones. }\end{array}$ \\
\hline Competencia & \multicolumn{2}{|c|}{$\begin{array}{l}\text { - Reúne, procesa, almacena y difunde información para la administración del talento humano. } \\
\text { - Efectúa el análisis y evaluación de políticas y prácticas del personal. }\end{array}$} \\
\hline
\end{tabular}

Tabla 5. Análisis funcional del proceso de auditoría. Fuente: Moya y Mancilla (2013).

Luego de haber construido el mapa funcional del área de gestión humana, se procedió a sintetizar esquemáticamente los procesos realizados por las diferentes organizaciones, configurando como producto, un modelo de cadena de valor de la gestión del talento humano, bajo la premisa de potenciar el capital humano. Para ello, los autores fundamentaron su estrategia con la inclusión de procesos que generan el desarrollo de los activos intangibles 
de la organización (conocimiento, tecnología, propiedad intelectual, cultura organizacional, creatividad, emociones, valores, espiritualidad) para garantizar resultados económicos superiores en cuanto a eficiencia, eficacia y satisfacción del cliente, como lo afirma Porras (2005). El modelo se estructura, entonces como un todo, a partir del "enfoque basado en procesos" definido como "el conjunto de actividades mutuamente relacionadas o que interactúan, las cuales transforman elementos de entrada en resultados" (ISO, 2005), en donde los procesos de integración se identifican en color rojo, los de retención en azul, desarrollo aguamarina, organización verde y auditoria lila.

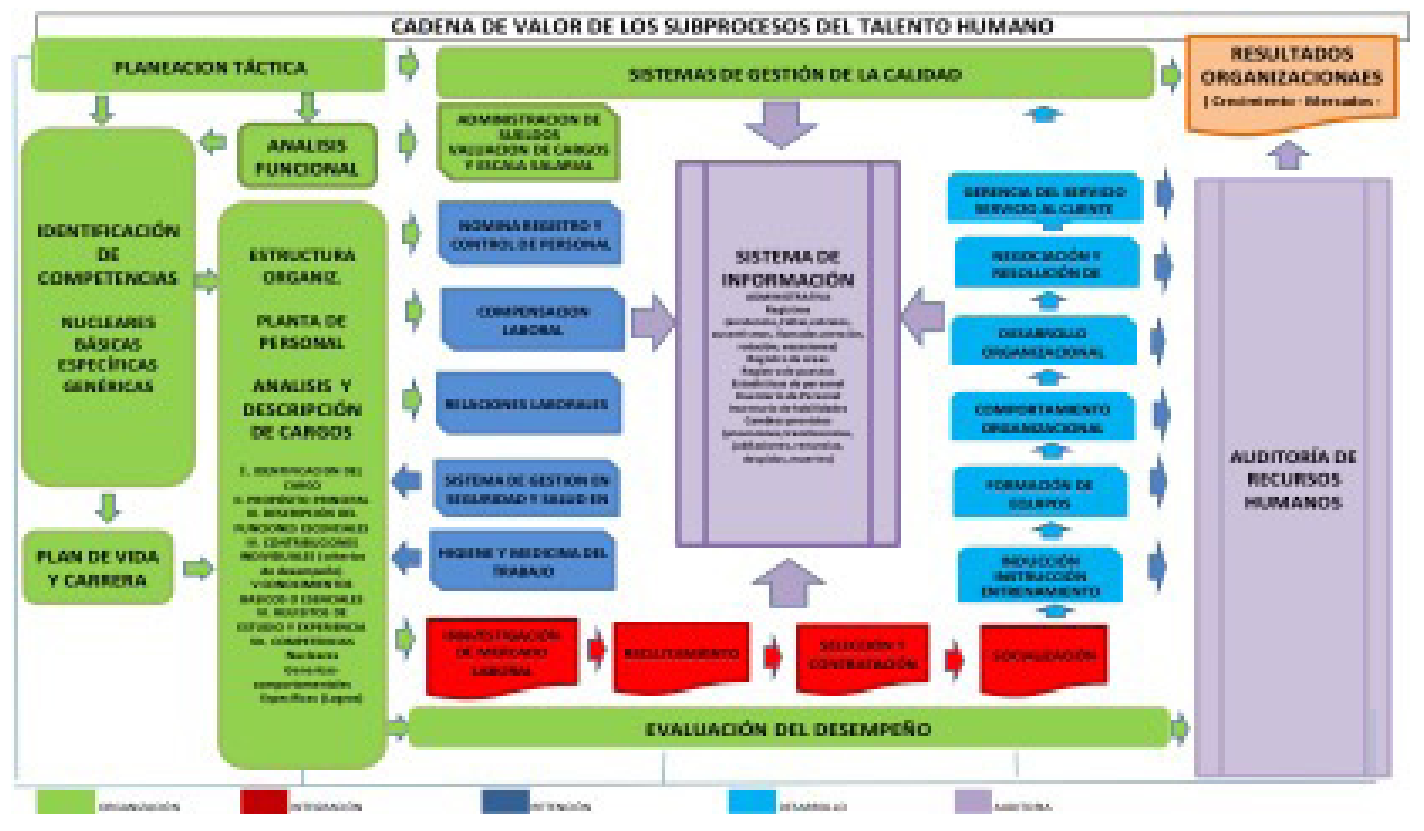

Figura 1. Esquema de procesos aplicados por las organizaciones.

Fuente: Moya y Mancilla (2013).

Desde el punto de vista del número de procesos desarrollados por las empresas, se encontró que las empresas que desarrollan entre 22 y 24 procesos, de los 5 procesos establecidos, se cumplen en su totalidad los de retención, desarrollo y auditoría. En cuanto a los de integración y organización, se deja de lado la investigación de mercado, lo que impediría tener opciones de personal que posean las habilidades, conocimientos y destrezas que se ajusten a las necesidades del cargo, sumado a esto, la inexistencia de plan de vida y carrera cuyo objetivo es obtener un grupo de colaboradores, motivados, capacitados y calificados para satisfacer 
las necesidades actuales y futuras de la organización, afectando directamente la consecución de los objetivos misionales, acrecentando la rotación de personal y, por ende, el aumento de costos en los procesos de reclutamiento, selección, socialización, capacitación etcétera.

Las empresas que desarrollan entre 13 y 15 de los cinco procesos establecidos, ninguno se cumple en su totalidad. En la retención se deja de lado la investigación de mercado; en la organización no se tiene en cuenta la planeación y ubicación del talento humano, lo que impide, como afirmaría Cuesta (2005), asegurar el número suficiente de personal, optimizar el talento humano a partir de las competencias, y ubicarlos en los puestos adecuados, previniendo las futuras necesidades desde criterios de rentabilidad. Si bien es cierto que manejan las competencias, realizan análisis funcional, hacen análisis y descripción de cargos, tienen plan de vida y carrera, también lo es que no se tiene en cuenta el proceso de evaluación de desempeño, vital para identificar la actuación de cada persona en función de las actividades que desempeña, las metas y los resultados que debe alcanzar, las competencias que ofrece y su potencial de desarrollo y las estrategias de inducción interna y externa, capacitación, entrenamiento e instrucción, lo cual se evidencia en la ausencia de este en el proceso de desarrollo.

El proceso de auditoría no es tenido en cuenta; es decir, no se planean e implementan estrategias, proyectos y acciones para mejorar la eficiencia en los procesos organizacionales, la medición de procedimiento y control de los mismos a nivel organizacional, con el fin de mejorarlos y cumplir con los requerimientos actuales de la empresa de revisar y controlar la eficiencia y la eficacia de los estándares de calidad, costos, tiempo y cantidad establecidos por la organización. Finalmente, de los procesos de retención, solamente se realiza los planes de prestaciones sociales, incentivos y bienestar social (lo referente a pagos de ley); sin embargo, no se tienen en cuenta los relacionados con la valuación de cargos y escala salarial y la administración de salarios, que permiten estandarizar los sueldos y salarios de una organización y remunerar con justicia y equidad. En cuanto a las políticas y estrategias para dar respuesta al Decreto 1295 de la Presidencia de la República de Colombia (1994) que se refieren a la protección, y promoción de la salud del trabajador mediante la prevención y control de enfermedades y accidentes; y la Resolución 2400 de 1979 del Ministerio de Trabajo y Seguridad Social de Colombia, que busca establecer normas y procedimientos tendientes a la protección biopsicosocial estudiando al hombre y a su ambiente laboral, no se desarrolla.

Por último, en la cadena de valor establecida en las empresas que solo desarrollan entre 4 y 7 procesos, siendo la integración el único proceso desarrollan en su totalidad, y de los procesos de desarrollo y retención tienen en cuenta aspectos relacionados con la administración de sueldos y salarios, nomina registro y control y atención al cliente; procesos indispensables para desarrollar la actividad económica de subcontratación, externalización o 
tercerización (Outsourcing) en donde la organización mueve o destina los recursos orientados a cumplir ciertas tareas hacia una empresa externa por medio de un contrato.

\section{Conclusiones}

La identificación e implementación de la Cadena de Valor de los procesos de gestión como herramienta estratégica, genera competitividad al crear, mantener y desarrollar el talento humano con habilidades, motivación y satisfacción por alcanzar los objetivos de la organización. El análisis funcional permitió establecer y caracterizar los procesos de integración, organización, desarrollo, retención y auditoría, necesarios para la adecuada gestión del talento humano, y que dio origen a la cadena de valor propuesta por los autores.

Si bien es cierto que la mayoría de las organizaciones, objeto de estudio, consideran importante desarrollar todos los procesos para gestionar el talento humano, como generador de ventaja competitiva, también lo es, que dejan de lado actividades que garanticen que el talento seleccionado quede ubicado en el puesto indicado acorde con sus competencias, de igual forma el desarrollo de recursos humanos y organizacional, pasa a un segundo plano en la mayoría de las organizaciones, siendo estos procesos básicos para crear, mantener y desarrollar personas con habilidades, motivación y satisfacción por alcanzar los objetivos de la organización.

En cuanto a los procesos de integración y organización, en la mayoría de las organizaciones se deja de lado la investigación de mercado, y el plan de vida y carrera, lo que impediría tener opciones de personal que posean las habilidades, conocimientos y destrezas que se ajusten a las necesidades del cargo, y obtener un grupo de colaboradores, motivados, capacitados y calificados para satisfacer las necesidades actuales y futuras de la organización, afectando directamente la consecución de los objetivos misionales, acrecentando la rotación de personal y por ende, el aumento de costos en los procesos de reclutamiento, selección, socialización y capacitación.

Los subprocesos de evaluación de desempeño (que permitiría identificar la actuación de cada persona en función de las actividades que desempeña, las metas y los resultados que debe alcanzar, las competencias que ofrece y su potencial de desarrollo), inducción, capacitación, entrenamiento e instrucción no fueron tenidos en cuenta por las empresas que desarrollan entre trece a quince procesos. En cuanto a la auditoría, no se planean e implementan estrategias, proyectos y acciones para mejorar la eficiencia y eficacia en los estándares de los procesos organizacionales, en cuanto a calidad, costos, tiempo y cantidad establecidos por la organización. 


\section{Referencias Bibliográficas}

Böhrt, R. (2003). La Gestión de Recursos Humanos y El Desarrollo de una Ventaja Sostenible. La Paz: En prensa.

Caddy, I. (2000). Intellectual Capital: recognizing both assets and liabilities. Journal of Intellectual Capital. 2, (1), pp. 129-46.

Cuesta. A ( 2005). Tecnología de Gestión de Recursos Humanos. Revisada y ampliada. Cuba: Editorial Academia.

Cuesta, A. (2010). Gestión del talento humano y del conocimiento. Bogotá: ECOE.

Chiavenato, I. (2011) Administración de Recursos Humanos. El capital humano en las organizaciones. México: McGraw-Hill.

Decreto de Ley 1295 (1994). Fija el nuevo sistema general de riesgos profesionales. Diario Oficial de la República de Colombia.

Edvinsson, L., \& Malone, M. (1997). El capital intelectual: Cómo identificar y calcular el valor intangible de su empresa. (Trad. Jorge Cárdenas, 1999). Barcelona: Gestión 2000.

García-Ayuso, M. y Larrinaga, C. (2004). El lado oculto de los intangibles: activos y pasivos ligados a la sostenibilidad. Revista Finanzas \& Contabilidad. 57, pp.34-41.

García-Parra, M., Simo, P., Mundet, J., \& Guzmán, J. (2004). Intangibles: activos y pasivos. Management \& Empresa. 37, pp. 32-41.

Garrido, R. (2002). Diseño de un modelo de gestión del conocimiento para la Unellez que promueva el desarrollo de ventajas competitivas en el área de investigación. Tesis Doctoral. Universidad Nacional Experimental de los Llanos Occidentales 'Ezequiel Zamora' (UNELLEZ), Barinas. 
Johnson, H.T., \& Kaplan, R.S. (1987). Relevance Lost: The Rise and Fall of ManagementAccounting. Management Accounting. 68 (7), p.22. Harvard Business School Press. Recuperado de http:// coin.wne.uw.edu.pl/pmodzelewski/The\%20rise\%20and\%20fall\%20of\%20management\%20 accounting.pdf

Harvey, M.G., \& Lusch, R.F. (1999). Balancing the intellectual capital books: intangible liabilities'. European Management Journal. 17 (1), pp. 85-92.

Konar, S., \& Cohen, M.A. (2001). Does the market value environmental performance? Review of Economics \& Statistics. 83, (2), pp.281-289.

Lozano, M.C., \& Fuentes, F. (2005). La importancia del intangible en la empresa de internet: una propuesta de medición contable. Economic Analysis Working Papers. 4 (6), pp. 1-62.

Moya, M., \& Mancilla J. (2014). La Cadena de Valor del Talento Humano como Herramienta Estratégica. Revista UNINPAHU. 10, 113-127

Moya, M., \& Ochoa J. (2012). La gestión del talento humano como herramienta competitiva para el desarrollo del capital intelectual. Produção em Foco. 2 (1), 201-221.

Secretaría Central de ISO (2005). Norma Internacional ISO 9000:2005. Sistemas de gestión de la calidad: Fundamentos y vocabulario. Ginebra: ISO. Recuperado de

Porras, S. (2005). El valor humano. Recuperado de http://www.losrecursoshumanos.com/ contenidos/1845--el-valor-humano.html

Porter, M.E. (1985). Competitive Advantage. New York: The Free Press.

Porto, N. (2003). Algunos aspectos a considerar en la contabilidad de intangibles. En Estudios académicos de contabilidad: en homenaje a D. José Rivero Romero. España: Departamento de Economía Financiera de la Universidad de Murcia.

Ramírez, Y. (2010) Aproximación a una taxonomía del capital intelectual. Partida doble. 227, 60-75 
Resolución 2400 (1979). Disposiciones sobre vivienda, higiene y seguridad en los establecimientos de trabajo. Ministerio de Trabajo y Seguridad Social, D.C. Bogotá.

Rodríguez, J. (2007). Administración moderna de personal. México: International Thomson Editores S.A.

Rodríguez, J. (2005). El capital intelectual como diferencia entre los activos y los pasivos intangibles. Revista Madrid. Conocimiento y creatividad. Aula Abierta. 28. Recuperado de http://www.madrimasd.org/revista/revista28/sumario.asp

Viedma, J.M. (2003). Los pasivos intangibles y el capital intelectual en la universidad. I Congreso Internacional y Virtual de Intangibles. 


\section{Capítulo 7}

Las bolsas de valores más competitivas en el 2014 José M. Güereña de la Llata, Maria Leticia Verdugo Tapia

y Luis Fernando Güereña de la Llata

\section{Introducción}

\section{Antecedentes}

La bolsa de valores, como la define Ponce (2010), es una institución autorregulada que tiene por objeto prestar a los intermediarios inscritos todos los servicios necesarios para que puedan realizar eficazmente las transacciones con valores de manera transparente, continua y ordenada, asi como las demás actividades de intermediación.

La bolsa de valores es un mercado organizado de intermediarios que representan los intereses de particulares, sociedades mercantiles y el mismo Estado, en el libre intercambio de valores. Tiene como obligación publicar la información bursátil y supervisar las actividades de las empresas emisoras y casas de bolsa.

Las bolsas de valores deberán mantener una estrecha relación con el sector productivo del país, ya que permite a los empresarios allegarse de recursos para la realización de nuevos proyectos, y brindar a los ahorradores e inversionistas la oportunidad de diversificar sus inversiones para obtener rendimientos acordes a los niveles de riesgo que estén dispuesto a asumir.

Para determinar el comportamiento de las bolsas de valores solo se considerarán aquellas inscritas en el World Federation of Exchanges (WFE), organismo que recientemente cambió su sede de París, Francia, a Londres, Inglaterra.

\section{Justificación}

Debido al impacto que ha tenido la problemática económica mundial, se analizará su efecto en las bolsas de valores en el año 2014. Se hará una presentación gráfica para facilitar la comparación de los resultados. Se determinará el comportamiento de las bolsas respecto a valor 
de capitalización, empresas listadas, valor de las transacciones de acciones y, por último, lo que más interés debe despertar a los inversionistas, sus rendimientos.

\section{Planteamiento del problema}

Las bolsas de valores fueron afectadas negativamente por la recesión económica iniciada en el 2007 y que para algunos países aún no termina, por lo que se analizará si todavía es redituable invertir en acciones y en dónde.

Se verá si persiste el impacto negativo en el valor de capitalización del mercado doméstico de acciones, en el número de empresas locales listadas, en el valor de las acciones negociadas a través de órdenes electrónicas y, por último, en los rendimientos, determinando cuáles son las bolsas de valores que han tenido un mejor desempeño.

\section{Preguntas de Investigación}

Tomando en consideración solo el año 2014:

a. ¿Cuáles fueron las diez bolsas de valores del mundo con el mayor valor de capitalización de su mercado doméstico de acciones?

b. ¿Cuáles cuentan con más empresas locales listadas?

c. ¿A cuánto asciende el valor de las acciones negociadas?

d. ¿Las 10 bolsas con mayores rendimientos de sus acciones?

\section{Objetivos}

Determinar cuáles fueron las diez bolsas de valores del mundo más competitivas en el 2014. El análisis se realizará sobre cuatro factores: valor de capitalización del mercado nacional, número de empresas listadas, valor de las acciones negociadas en cada bolsa y, por último, rendimientos.

\section{Marco Teórico}

\section{Valor de Capitalización del Mercado Nacional}

La capitalización de mercado, de acuerdo a Ponce (2010), representa el valor total del mercado accionario medido por la suma del valor de mercado de todas las empresas que cotizan en él. El valor de mercado se obtiene multiplicando el precio de la acción por el número de acciones de la empresa.

Si se considera solo el valor de capitalización de empresas locales en cada país, se verá el impacto de la bolsa de valores en su propia economía y no de empresas extranjeras registradas en ellas. 


\begin{tabular}{|l|r|}
\multicolumn{1}{|c|}{ Bolsa de Valores } & Valor de Capitalización \\
\hline New York Stock Exchange & $\$ 19,351,417.2$ \\
\hline NASDAQ OMX & $\$ 6,979,172.0$ \\
\hline Japan Exchange Group - Tokio & $\$ 4,377,994.4$ \\
\hline Shanghai Stock Exchange & $\$ 3,932,527.7$ \\
\hline Euronext & $\$ 3,319,062.2$ \\
\hline Hong Kong Exchanges & $\$ 3,233,030.6$ \\
\hline TMX Group & $\$ 2,093,696.8$ \\
\hline Shenzhen Stock Exchange & $\$ 2,072,420.0$ \\
\hline Deutsche Börse & $\$ 1,738,539.1$ \\
\hline Bombay SE India & $\$ 1,558,299.7$ \\
\hline
\end{tabular}

Tabla 1. Valor de capitalización al 31 de diciembre de 2014 (Millones de dólares americanos) Fuente: World Federation of Exchanges (2014a). Statistics, Domestic Market Capitalization. Recuperado de http://www.world-exchanges.org/home/index.php/statistics/monthly-reports

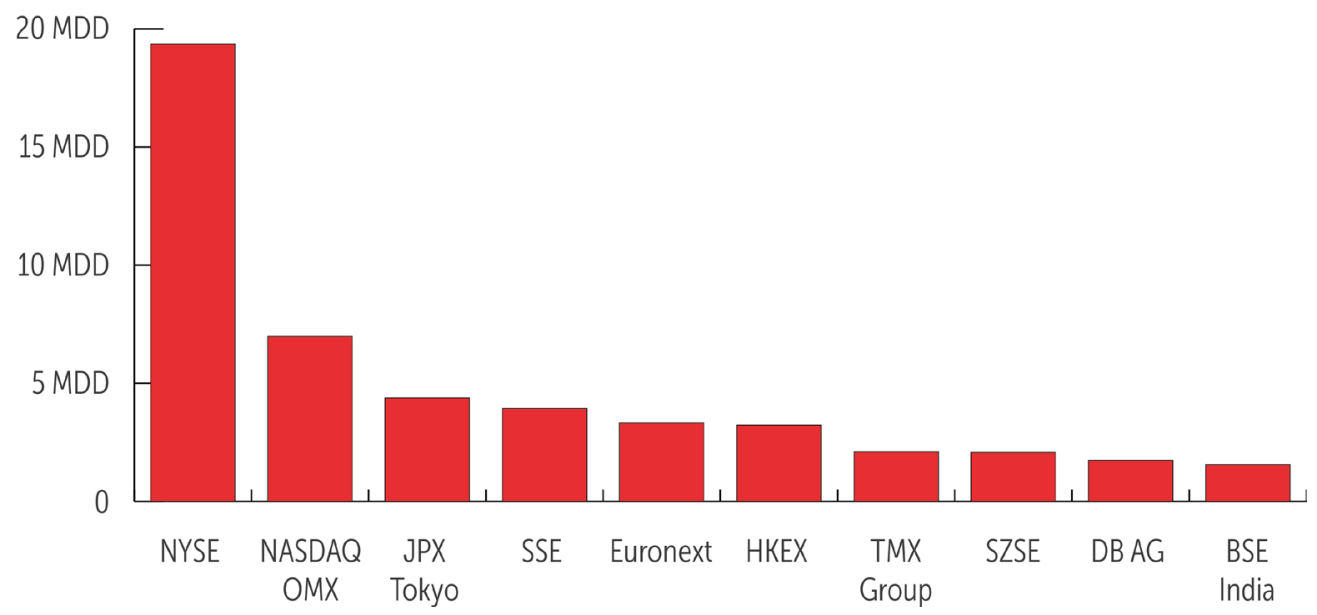

Figura 1. Valor de capitalización al 31 de diciembre de 2014 (Millones de dólares americanos) Fuente: World Federation of Exchanges (2014a). Statistics, Domestic Market Capitalization. Recuperado de http://www.world-exchanges.org/home/index.php/statistics/monthly-reports 
El valor de capitalización se consideró en dólares americanos para todas las bolsas con el fin de una mejor comparación. Según se visualiza en la tabla anterior, la bolsa de valores con mayor valor de capitalización fue Nueva York, superando a las siguientes cinco bolsas en conjunto, seguida por el NASDAQ OMX. En tercer lugar se encuentra Tokio seguida por Shanghai y Euronext (bolsa europea con sede en Amsterdam que resultó de la fusión de las bolsas de París, Amsterdam, Bruselas, Lisboa y Oporto, y la Bolsa Internacional de Futuros Financieros y Opciones de Londres). En sexto lugar, aparece la bolsa de valores de Hong Kong. Hay que hacer notar que las bolsas que ocupan los lugares 4, 6 y 8 son de China. La bolsa de valores de Hong Kong se conectó con la de Shanghai para efecto de transacciones a finales del 2014.

En cuanto al crecimiento porcentual en el 2014, el primer lugar lo obtuvo Cyprus $S$ E con $91.5 \%$, seguida de Shanghai S E con $57.5 \%$ y después Shenzhen, también de China, con $42.7 \%$. El cuarto y quinto lugar lo ocuparon las bolsas de India: BSE India y NSE India con $36.8 \%$ y $36.7 \%$, respectivamente. La bolsa que más decreció fue la de Moscú, disminuyendo en el año 49.9\%. El valor de capitalización de las 57 bolsas de valores registradas en el World Federation of Exchanges, en conjunto creció 5.6\%; de estas bolsas de valores: 26 crecieron, 28 decrecieron y 3 no presentaron información.

\section{Número de Empresas Listadas}

En el número de empresas listadas se consideró únicamente las empresas locales de cada país y no empresas extranjeras registradas en dichas bolsas.

El número de empresas listadas es importante, ya que a mayor cantidad de empresas listadas mejor se refleja la bolsa de valores en la economía de un país.

\begin{tabular}{|l|r|l|r|}
\multicolumn{1}{|c|}{ Bolsa de Valores } & \multicolumn{1}{c|}{$\begin{array}{c}\text { Empresas } \\
\text { Listadas }\end{array}$} & \multicolumn{1}{|c|}{ Bolsa de Valores } & \multicolumn{1}{c|}{$\begin{array}{c}\text { Empresas } \\
\text { Listadas }\end{array}$} \\
\hline Bombay SE India & 5,541 & Australian SE & 1,967 \\
\hline TMX Group & 3,691 & NYSE & 1,939 \\
\hline Japan Exchange Group - Tokio & 3,458 & Korea Exchange & 1,849 \\
\hline BME Spanish Exchanges & 3,419 & NSE India & 1,707 \\
\hline NASDAQ OMX & 2,430 & Hong Kong Exchange & 1,661 \\
\hline
\end{tabular}

Tabla 2. Empresas listadas en las bolsas de valores al 31 de diciembre de 2014. Fuente: World Federation of Exchanges (2014b). Statistics, Domestic Market Capitalization. Recuperado de http://www.world-exchanges.org/home/index.php/statistics/monthly-reports 


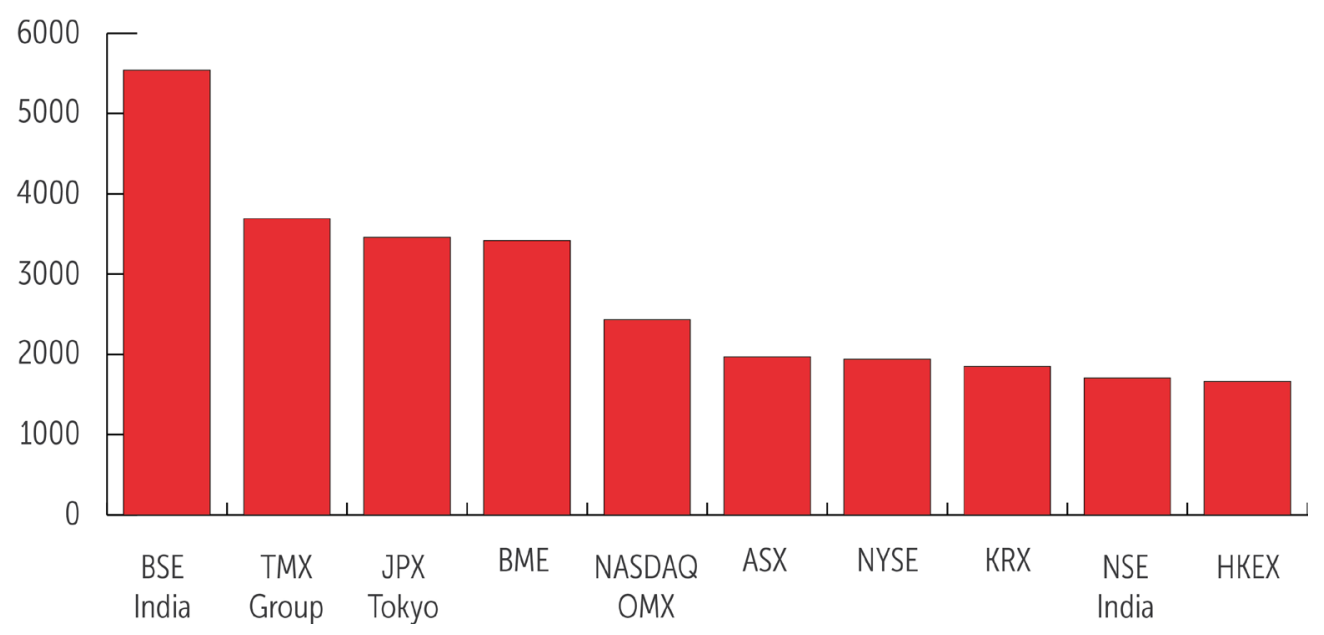

Figura 2. Empresas listadas en las bolsas de valores al 31 de diciembre de 2014. Fuente: World Federation of Exchanges (2014b). Statistics, Domestic Market Capitalization. Recuperado de http://www.world-exchanges.org/home/index.php/statistics/monthly-reports

La bolsa de valores con más empresas listadas es la de Bombay, en India, con 5541 seguida por TMX Group que opera las Bolsas de Valores Nacionales de Canadá: Toronto S E y TSX Venture Exchange, con 3691 empresas. En tercer lugar está el Japan Exchange Group con sede en Tokio con 3458, en cuarto lugar la bolsa de España con 3419 y en quinto lugar el NASDAQ OMX Nordic con 2430 empresas listadas.

Como dato curioso, el New York Stock Exchange ocupa el séptimo lugar con 1939 empresas, no obstante ser la bolsa con mayor valor de capitalización de su mercado doméstico y con mucha diferencia del segundo lugar. Ello implica que las empresas listadas en Nueva York son mucho más grandes que las otras en promedio.

En total, hay 42051 empresas locales listadas en las bolsas de valores afiliadas al World Federation of Exchanges (2014b).

\section{Valor de las acciones negociadas}

Se consideraron solo las negociaciones realizadas a través de órdenes electrónicas, que son casi todas. Es muy importante este concepto ya que nos indica la cantidad de efectivo que se mueve en una bolsa de valores por la compraventa de acciones, siendo un indicador muy importante en el movimiento económico de un país. A continuación mostraremos una tabla y su gráfica correspondiente con los valores de acciones negociadas de las bolsas de valores. 


\begin{tabular}{|l|r|}
\multicolumn{1}{|c|}{ Bolsa de Valores } & \multicolumn{1}{c|}{ Valor de Capitalización } \\
\hline New York Stock Exchange & $\$ 15,867,918.7$ \\
\hline NASDAQ OMX & $\$ 12,237,019.7$ \\
\hline Shanghai Stock Exchange & $\$ 6,085,176.3$ \\
\hline Shenzhen Stock Exchange & $\$ 5,940,955.5$ \\
\hline Japan Exchange Group - Tokio & $\$ 5,443,887.5$ \\
\hline Euronext & $\$ 1,952,004.1$ \\
\hline Hong Kong Exchanges & $\$ 1,520,896.2$ \\
\hline Deutsche Börse & $\$ 1,469,729.1$ \\
\hline TMX Group & $\$ 1,408,145.4$ \\
\hline Korea Exchange & $\$ 1,350,370.1$ \\
\hline
\end{tabular}

Tabla 3. Bolsas de valores con el mayor valor de acciones negociadas en el perído del 1 de enero al 31 de diciembre de 2014 (Millones de dólares americanos). Fuente: World Federation of Exchanges (2014c). Statistics, Value of Share Trading. Recuperado de http://www.worldexchanges.org/home/index.php/statistics/monthly-reports

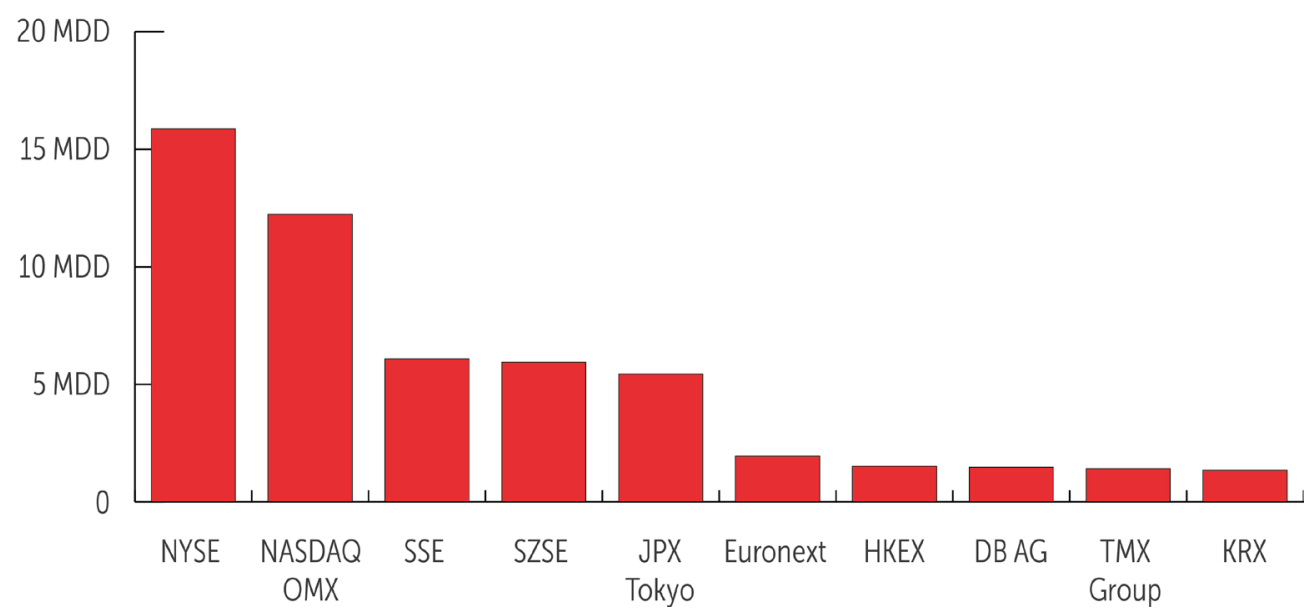

Figura 3. Bolsas de valores con el mayor valor de acciones negociadas en el perído del 1 de enero al 31 de diciembre de 2014 (Millones de dólares americanos). Fuente: World Federation of Exchanges (2014c). Statistics, Value of Share Trading. Recuperado de http://www.world-exchanges.org/home/index.php/statistics/monthly-reports 
En el valor de las acciones negociadas, se tomó el período del 1 de enero al 31 de diciembre de 2014, es decir, un año. Analizando la tabla y gráfica correspondiente se ve una diferencia enorme entre la bolsa de valores de Nueva York y las otras nueve bolsas de valores que le siguen en tamaño. Si acaso, la bolsa que ocupa la segunda posición, NASDAQ OMX se le acerca un poco. En tercero y cuarto lugar aparecen las bolsas de Shenzhen y Shanghai, ambas de China. En quinto lugar aparece la bolsa de Tokio, después Euronext, Hong Kong, Deutsche en octavo lugar, siguiendo la bolsa canadiense TMX Group y por último Korea en décimo lugar.

En total, dentro de los primeros diez lugares se encuentran tres bolsas de valores de América, cinco de Asia (incluyendo las tres de China) y dos de Europa.

Para apreciar el tamaño de las dos bolsas de valores de Estados Unidos registradas, Nueva York (NYSE) y NASDAQ OMX, basta decir que el valor de sus acciones domésticas negociadas representan el $64.43 \%$ del total de América; el $118.72 \%$ de las operaciones de la Zona Asia - Pacífico y el $261.87 \%$ si se agruparan Europa, África y el Medio Oriente, casi el triple si se juntaran todas las bolsas de valores de esta región. En total, su valor representa más de la tercera parte del total de las acciones negociadas en el mundo (36.02\%).

Las tres bolsas de valores registradas en China -Shenzhen, Shanghai y Hong Kong- en conjunto, representan más de la mitad de la zona Asia - Pacífico (57.22\%) y el $17.36 \%$ de todo el mundo, comparándolas con las dos bolsas de valores de Estados Unidos que manejan el 48.2\% de ellas.

\section{Rendimientos}

Para clasificar los rendimientos de las bolsas de valores se tomaron en cuenta los índices más amplios respecto a número de empresas que se consideraron para formarlos y no los tradicionales que únicamente consideran una muestra de las mejores empresas. Por rendimientos se hace referencia al rendimiento promedio de todas las empresas que conforman el índice correspondiente, que son los que se muestran en la Tabla 4.

La bolsa de valores con mayor rendimiento fue la de Buenos Aires con $56.27 \%$, seguida por la de Shanghai con 52.87\%. En tercero y cuarto lugar están las dos bolsas de India: National Stock Exchange con $37.82 \%$ y Bombay Stock Exchange con 36.96\%. En quinto lugar aparece la bolsa China Shenzhen Stock Exchange con un rendimiento de 33.80\%.

El caso de la bolsa de valores de Buenos Aires es muy interesante, ya que en el 2013 fue la segunda mejor bolsa en cuanto a rendimientos con $61.8 \%$, después de Abu Dhabi con 63.1\%. Por el lado contrario, la bolsa con el peor desempeño en el 2014 fue la de Athens Exchange con rendimiento negativo de $28.94 \%$. 


\begin{tabular}{|l|l|r|r|r|}
\hline \multicolumn{1}{|c|}{ Bolsa de Valores } & \multicolumn{1}{|c|}{ Índice } & \multicolumn{1}{c|}{$\mathbf{1 1 / 0 1 / 1 4}$} & \multicolumn{1}{c|}{ 31/12/14 } & Rendimiento (\%) \\
\hline Buenos Aires S E & Composite & $265,347.57$ & $414,609.45$ & 56.27 \\
\hline Shangai S E & SSE Composite Ind. & $2,1115.98$ & $3,234.68$ & 52.87 \\
\hline NSE India & S\&P CNX 500 & $4,914.85$ & $6,773.65$ & 37.82 \\
\hline BSE India & S\&P BSE 500 & $7,828.34$ & $10,721.62$ & 36.96 \\
\hline Shenzhen S E & SZSE Composite Ind. & $1,057.67$ & $1,415.19$ & 33.80 \\
\hline Egyptian Exchange & EGX 30 Index & $6,782.84$ & $8,926.58$ & 31.61 \\
\hline Borsa Istanbul & ISE 100 Index & $67,801.73$ & $85,721.13$ & 26.43 \\
\hline Colombo SE & CSE All Share & $5,912.78$ & $7,299.00$ & 23.44 \\
\hline Philippine S E & PSE Index & $5,889.83$ & $7,230.57$ & 22.76 \\
\hline Indonesia S E & ISX Composite Index & $4,274.18$ & $5,226.95$ & 22.29 \\
\hline
\end{tabular}

Tabla 4. Rendimientos de las bolsas de valores del 1 de enero al 31 de diciembre de 2014. Fuente: World Federation of Exchanges (2014d). Broad Stock Index Levels. Recuperado de http://www.world-exchanges.org/home/index.php/statistics/monthly-reports

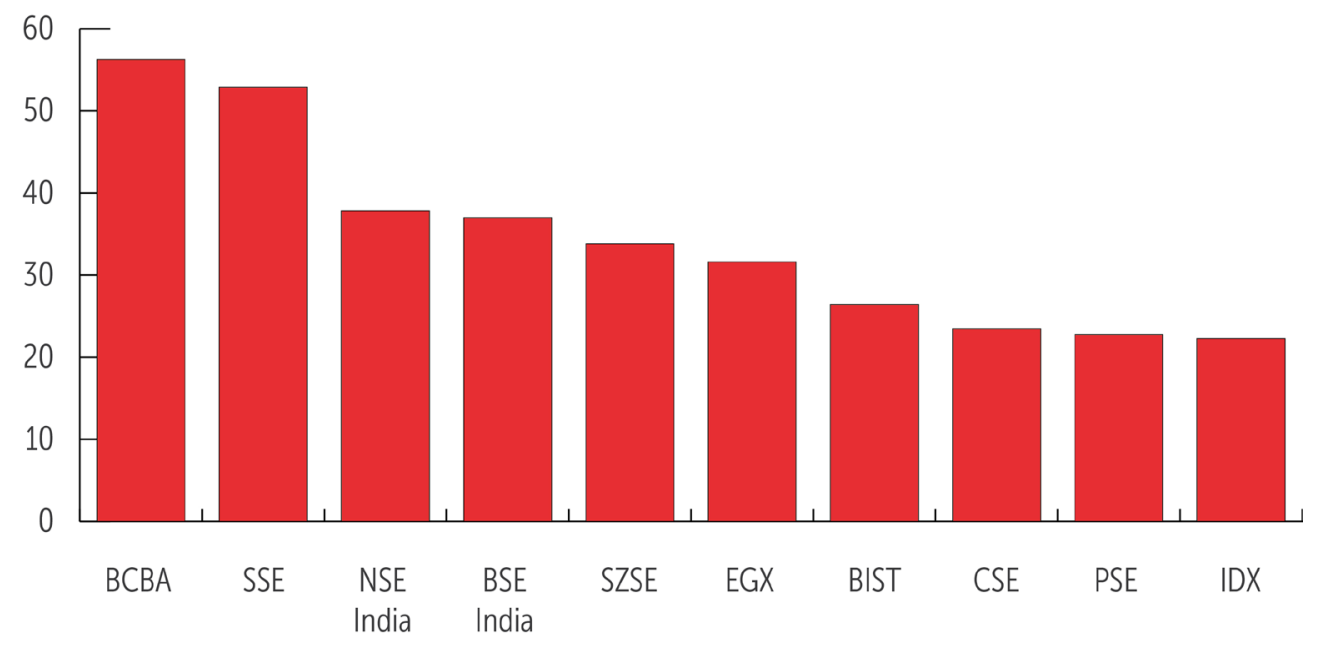

Tabla 4. Rendimientos de las bolsas de valores del 1 de enero al 31 de diciembre de 2014. Fuente: World Federation of Exchanges (2014d). Broad Stock Index Levels. Recuperado de http://www.world-exchanges.org/home/index.php/statistics/monthly-reports 
Además, se presenta una situación extraña, ya que de las diez bolsas de valores con mayores rendimientos, solamente tres aparecen entre las de mayor valor de capitalización de su mercado doméstico de acciones, siendo ellas dos de China: Shanghai y Shenzhen; por otro lado, Bombay Stock Exchange de India. Entre el grupo de mayor valor de acciones negociadas en el período de 12 meses en cuestión solo aparecen entre las de mayor rendimiento las mismas dos bolsa de valores de China: Shanghai y Shenzhen. Lo anterior significa que en el renglón de rendimientos no influye el tamaño de la bolsa.

\section{Metodología}

Se analizaron las distintas bolsas de valores en los rubros señalados anteriormente, de acuerdo a la información presentada por la World Federation of Exchanges, en el período del $1^{\circ}$ de enero al 31 de diciembre de 2014. La información permitió observar cuáles ocupan los diez primeros lugares en cada rubro señalado. Se acompañó el trabajo con tablas y gráficas para su mejor comprensión. El método utilizado fue el Descriptivo Transversal.

\section{Problematización}

Debido a la problemática económica actual en el mundo, es difícil seleccionar un país para invertir en acciones, ya que al estar conectadas entre sí casi todas las economías por el fenómeno de la globalización, los problemas que se presentan en un país repercuten en los demás.

\section{Delimitación y Muestra}

Se consideró el universo formado por todas las bolsas de valores del mundo inscritas en el World Federation of Exchanges, ya que son más formales y envían la información de sus operaciones correspondiente a dicha federación.

La muestra está representada por las 57 bolsas de valores registradas en el World Federation of Exchanges.

\section{Conclusiones}

De acuerdo a la información de la World Federation of Exchanges (WFE), la bolsa de valores con el mayor valor de capitalización fue Nueva York (NYSE), la cual triplica el del segundo lugar (NASDAQ OMX) e incluso supera las cinco bolsas en conjunto que le siguen. Respecto al crecimiento porcentual en el 2014, la bolsa que presenta el mayor crecimiento fue Cyprus Stock Exchange con un $91.5 \%$ y la que más decreció fue Moscow Exchange, disminuyendo un 49.9\%. En conjunto, el valor de capitalización de las 57 bolsas de valores registradas en el WFE, creció $5.6 \%$. 
Otro factor que se analizó fue el número de empresas listadas en las diferentes bolsas de valores; presentando Bombay Stock Exchange, India, el mayor número (5541), lo cual representa el $13.18 \%$ del total de las empresas locales listadas en las bolsas afiliadas al WFE al 31 de diciembre, 2014; las bolsas que le siguen no rebasan las 4000 empresas y es importante mencionar que New York Stock Exchange ocupa el séptimo lugar con 1939 empresas, no obstante es la bolsa con mayor valor de capitalización de su mercado doméstico y con mucha diferencia del segundo lugar, lo cual implica que las empresas listadas en esta son mucho más grandes que las otras en promedio.

Un tercer factor analizado fue el valor de las acciones negociadas, tomando el período del $1^{\circ}$ de enero al 31 de diciembre de 2014, es decir, un año. Este factor complementa el valor de capitalización e indica la cantidad de efectivo que se mueve en una bolsa de valores por la compraventa de acciones. Examinando la tabla y gráfica correspondiente se observa una vasta diferencia entre la bolsa de valores de Nueva York y las otras nueve que le siguen en tamaño. Si acaso, la bolsa que ocupa la segunda posición, NASDAQ OMX se le acerca un poco. Para apreciar el tamaño de estas dos bolsas estadounidenses es preciso mencionar que en total, su valor representa más de la tercera parte del total de las acciones negociadas en el mundo (36.02\%). A pesar de que las Bolsas de Shenzhen y Shanghai han tenido un crecimiento muy pronunciado, y que éstas junto con Hong Kong, representan más de la mitad de la zona Asia - Pacífico (57.22\%), el total de acciones negociadas constituyen solo el $17.36 \%$ de todo el mundo. Comparándola con las 2 Bolsas de Valores de EE UU, manejan el 48.2\% de ellas.

Respecto al factor Rendimiento, la Bolsa de Valores con mayor porcentaje fue la de Buenos Aires con $56.27 \%$. En la tabla y gráfica correspondiente se observa además que las dos bolsas con mayor valor de capitalización (Nueva York y NASDAQ OMX) no aparecen dentro de las 10 Bolsas de Valores con mayor rendimiento, solamente 3 de ellas: Shanghai, Shenzhen y Bombay. Lo anterior indica que en el renglón de rendimientos no influye el tamaño de la Bolsa. 


\section{Referencias Bibliográficas}

Ponce, C. (2010). El riesgo es no invertir en la bolsa: 20 lecciones sobre la crisis de 2008 en el mercado accionario en México. México: LID.

World Federation of Exchanges (2014a). Statistics, Domestic Market Capitalization. Recuperado de http://www.world-exchanges.org/home/index.php/statistics/monthly-reports

World Federation of Exchanges (2014b). Statistics, Number of listed companies. Recuperado de http://www.world-exchanges.org/home/index.php/statistics/monthly-reports

World Federation of Exchanges (2014c). Statistics, Value of Share Trading. Recuperado de http://www.world-exchanges.org/home/index.php/statistics/monthly-reports

World Federation of Exchanges (2014d). Broad Stock Index Levels. Recuperado de http://www. world-exchanges.org/home/index.php/statistics/monthly-reports 


\section{Capítulo 8}

Análisis del consumidor hacia la compra de tortillas de maíz en Santa Ana, Sonora, México Brenda Elizabeth Durón González, Elsa Armida Ortega Verdugo y Josué Castillo Muñoz

\section{Introducción}

Actualmente, para los consumidores permanecer fiel a un producto resulta poco fácil; esto se debe a que la competencia oferta el mismo o similar, y lo que reconocen de su producto favorito es la imagen, calidad y sabor que lo caracteriza. El objetivo de esta investigación es determinar cuáles son los factores que intervienen al momento de adquirir tortillas de maíz, qué opinan los compradores acerca de su calidad y conocer si les gustaría que se incluyeran otros sabores. El estudio tipo descriptivo fue aplicado en la ciudad de Santa Ana, Sonora, en la cual existen seis tortillerías que compiten con la empresa familiar denominada Tortillería "Isahi". El estudio se realizó para determinar las preferencias del consumidor hacia la compra de tortillas de maíz, para poder incrementar su cartera de clientes con los factores resultantes del presente análisis y obtener así una ventaja competitiva. La hipótesis planteada es que el principal factor que influye en la compra de tortillas de maíz es el sabor y la textura. Para comprobar los objetivos y determinar si la hipótesis planteada fue real, se aplicaron 350 encuestas al azar a consumidores de tortilla. Se recomendó a la empresa la posibilidad de introducir un sabor nuevo como: nopal y linaza, además de otras presentaciones a la línea de productos ya existentes.

\section{Planteamiento del problema}

Según Pérez (2012), para competir en un mundo con una gran sobresaturación de productos, es necesario regresar a la esencia del marketing, centrándose en dos áreas clave: la gestión de marcas y la innovación, para asegurar el éxito tanto presente como futuro.

Cada día el consumidor mira, asimila y reconoce 16,000 logos diferentes. Estos son los modernos faros que nos guían en nuestra experiencia y recorrido por el mundo. El logotipo puede crear historias interesantes, mostrar la verdadera identidad de la marca y sus aspiraciones (Merca 2.0, 2014). 
Para que las organizaciones puedan funcionar, permanecer y destacar en el mercado vigente, es primordial distinguir las variables más importantes que lo hacen inestable y completamente interconectado. Los recursos y capacidades, tan valiosos como escasos, otorgan a la empresa lo que necesita para obtener una ventaja competitiva (Thompson, Peteraf, Gamble y Strickland III, 2012).

El problema es que los consumidores, para elegir un producto determinado, deben conocer opciones que les faciliten las decisiones de compra. En el caso de este estudio descriptivo, se deben analizar las variables que más influyen en el poder de compra hacia el sabor, calidad y textura del alimento a base de tortilla.

\section{Revisión teórica}

Producto en marketing es algo que puede adquirirse por medio del intercambio para satisfacer una necesidad o un deseo. Esta definición permite clasificar un amplio número de "cosas" como productos (Ferrell y Hartline, 2012).

Para Kotler y Armstrong (2013), el diseño de un producto es más que algo superficial: va a la esencia misma del producto y este a su vez contribuye tanto a la utilidad del producto, como a su apariencia. Hace referencia al arreglo de los elementos unidos que conforman un bien o un servicio y que al momento de diseñarlo se debe pensar más en cómo el cliente utiliza el producto y lo satisface.

\section{Concepto de marca}

De acuerdo con la definición dada por la American Marketing Association (s.f.) una marca es un nombre, término, señal, símbolo o diseño, o una combinación de todos ellos, que busca identificar los bienes y servicios de un vendedor, o un grupo de vendedores, y diferenciarlos de los de sus competidores.

Según Kotler y Armstrong (2012), una marca es un nombre o símbolo con el que se trata de identificar el producto de un vendedor o un grupo de vendedores y diferenciarlo de los productos competidores. Los consumidores consideran la marca como parte importante de un producto, y la asignación de marca podría agregarle valor.

\section{Valor de marca}

Es el valor dado por los clientes, actuales y potenciales, al nombre, símbolos y personalidad de una marca, la cual se agrega al valor proporcionado por los productos, servicios y/o empresas que se identifican con ella. El valor de marca es el valor añadido que proporciona al producto, tal como lo percibe el consumidor. Quedará establecido en la medida en que pueda conocer- 
se y medirse cuál es el tipo y grado de satisfacción que provoca en los consumidores y cómo afecta a sus respuestas. El valor de la marca puede considerarse como un conjunto de activos y pasivos vinculados a la misma, que incorporan o disminuyen el valor (Santesmases, 2012).

\section{Lealtad de marca}

Los clientes muestran diversos niveles de lealtad a marcas, tiendas y empresas específicas. Oliver define la lealtad como "un profundo compromiso de recompra, o la tendencia a seguir siendo cliente habitual de un producto o servicio en el futuro, a pesar de los factores situacionales y de los esfuerzos de marketing que potencialmente pudieran causar cambios en el comportamiento" (Kotler y Keller, 2012).

\section{Metodología}

El presente estudio de investigación se realizó en el municipio de Santa Ana, Sonora, el cual se encuentra ubicado al norte del estado de Sonora; colinda al Norte con los municipios de Tubutama y Magdalena, al Sur con Benjamín Hill y Opodepe, al Este con Cucurpe y al Oeste con Trincheras.

Santa Ana cuenta con una extensión territorial de 1,620.65 kilómetros cuadrados, los cuales representan 3.5\% de la superficie total del estado; su población, hasta el año 2010, era de 16,014 habitantes de los cuales 7,687 son hombres y 8,327, mujeres (INEGI, 2010).

El objeto del estudio es determinar las preferencias del consumidor en la compra de tortillas de maíz en este municipio. La información generada será proporcionada a la empresa familiar "Isahí" con el fin de lograr una ventaja competitiva que la diferencie de la competencia.

La obtención de información se realizó a través de encuestas, las cuales fueron aplicadas durante los meses de junio y julio de 2015, se encuestaron a 350 consumidores entre 19 y 75 años, debido a que estas personas son las que tienen mayor decisión en el poder de compra. La encuesta consistió en diez preguntas de opción múltiple, cuyo objetivo fue conocer el motivo por el cual el consumidor adquiere tortillas de maíz, su percepción respecto al sabor, textura e imagen, la frecuencia con la que consume este tipo de producto y el lugar donde lo adquiere.

Las encuestas se realizaron en supermercados, tiendas y tortillerías ubicadas la ciudad de Santa Ana. El número de encuestas se determinó de acuerdo a la fórmula de Münch y Ángeles (1990), dando como resultado 350 para el tamaño de la muestra.

La información arrojada por las encuestas realizadas se capturó en una base de datos, para lo cual se utilizó una hoja de cálculo Excel 2010 de Microsoft Office, que permitió graficar los datos y analizar los resultados obtenidos. 
De la muestra de 350 personas seleccionadas al azar, los resultados arrojaron que el género predominante en las encuestas es el femenino, con un $74 \%$, mientras que sólo el $26 \%$ son del sexo masculino.

Según la encuesta, la mayoría de las personas que respondieron se encuentran en un rango de edad de 19 a 40 años, lo que representa un 65\%; así mismo, las personas de 41 a 60 años que suelen consumir dicho producto representan el $22 \%$, mientras que los consumidores cuya edad se ubica en un rango de 61 a 75 años, suelen consumirlo muy poco (Figura 1).

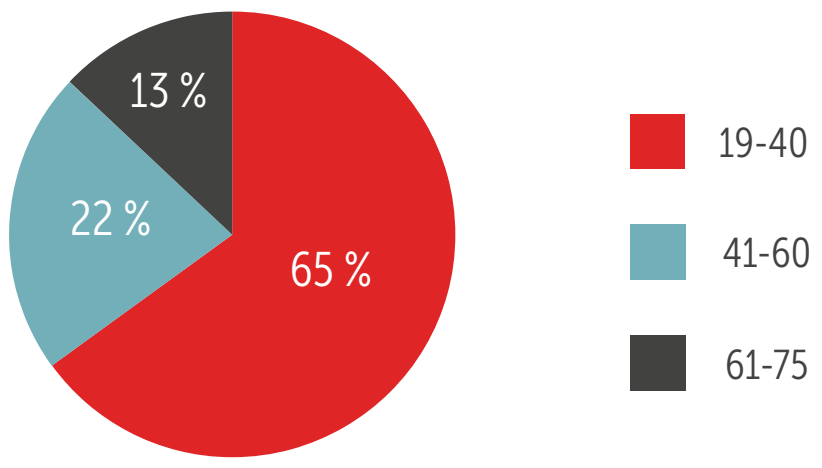

Figura 1. Rangos por edad. Fuente: Realización Propia.

En la Figura 2, se muestra la preferencia que tiene cada consumidor por las diferentes texturas. Se puede ver que la más consumida es con poco grosor $54.3 \%$, pasando a segundo lugar con mayor grosor $28.6 \%$. Un $17.1 \%$ de los encuestados reveló que no tienen preferencia por una sola textura sino más bien consumen según la preferencia del sabor.

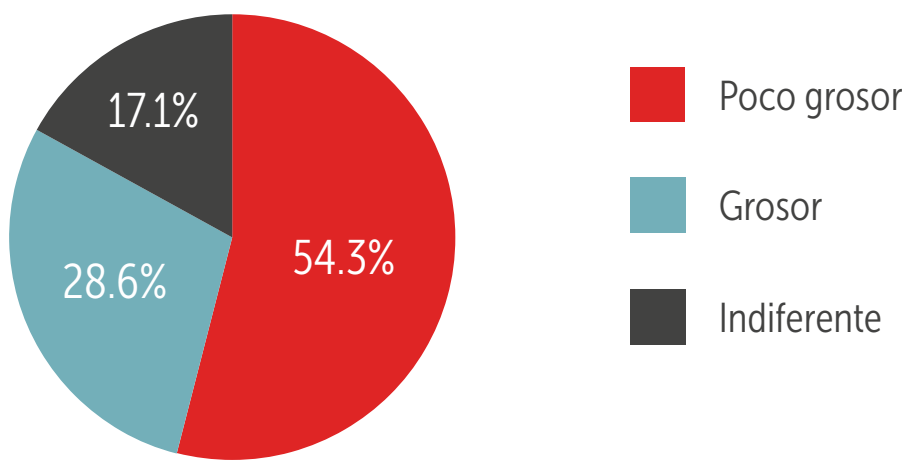

Figura 2. Preferencias por las diferentes texturas. Fuente: Realización Propia. 
En cuanto a la frecuencia en el cosumo de tortillas de maíz, se encontró que el $52 \%$ las consumen de una a cuatro veces por semana, el 15\% sólo ocasionalmente, y $28 \%$ al diario (Figura 3).
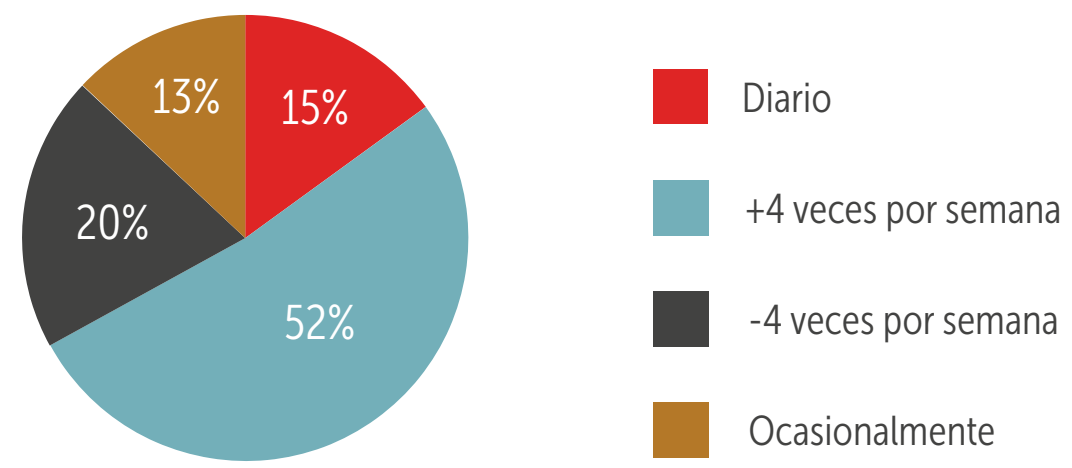

Figura 3. Frecuencia con la que consumen tortilla de maíz. Fuente: Realización Propia.

Se cuestionó los motivos por el cual los consumidores adquieren la tortilla de maíz, a lo cual la mayoría de los encuestadas coincidió que suelen adquirirla debido a su sabor en un $72 \%$. Un $18 \%$ comentó que la consumen por el precio y el $10 \%$ restante varía en sus respuestas al señalar que compra la tortilla de maíz porque se encuentra en su tienda de abarrotes más cercana y tiene un sabor mucho mejor que las que no son locales (Figura 4).

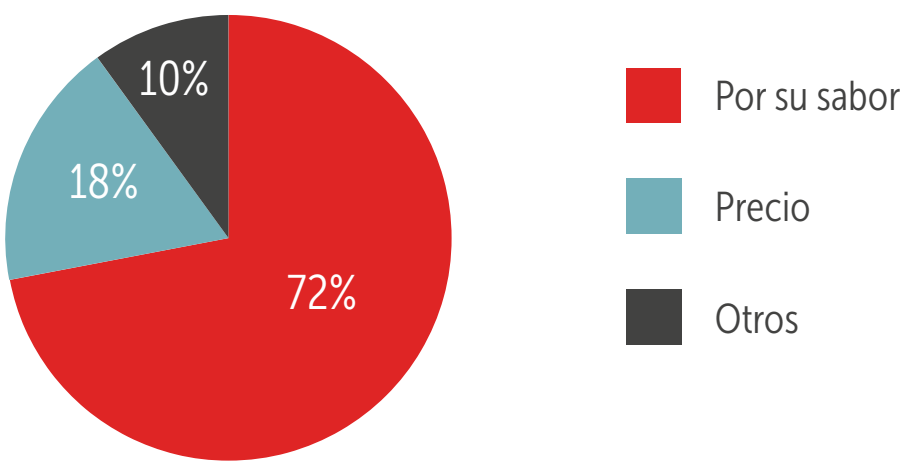

Figura 4. Motivos por el cual consumen tortilla de maíz.Fuente: Realización Propia.

Con la encuesta se dieron a conocer los lugares en que se adquiere la tortilla. Los resultados arrojaron que un 33\% lo hace en la tortillería, un 50\% en tiendas de abarrotes, y un $17 \%$ lo compra en supermercado (Figura 5). 


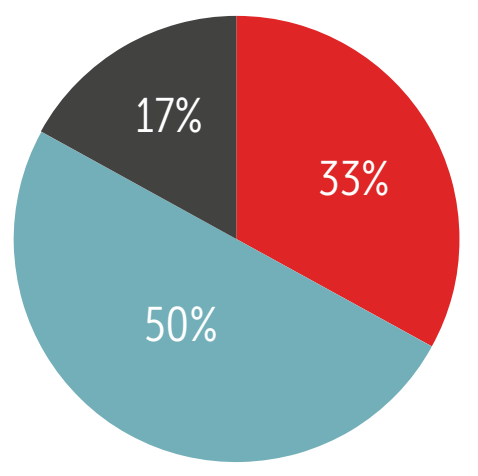

Tortillería

Tienda de abarrotes

Supermercados

Figura 5. Lugares donde el consumidor adquiere la totilla de maíz. Fuente: Realización Propia.

A los consumidores encuestados se les pidió que señalaran qué les atrae más de la imagen de la tortilla de maíz. El 40\% dijo que la etiqueta, el 24\% dijo que el empaque, un $20 \%$ comentaron que el color de la tortilla y 16 \% contestó que nada sino solo el contenido (Figura 6).
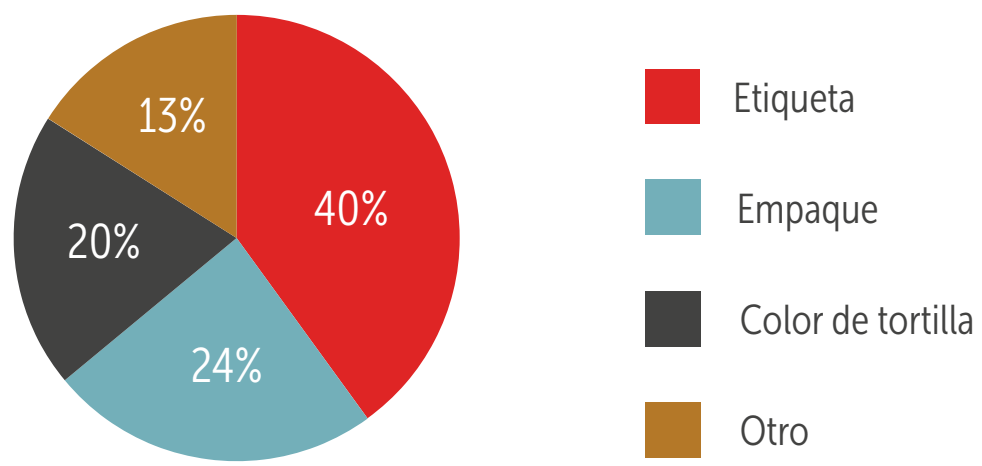

Figura 6. Atributos del producto con mayor impacto visual. Fuente: Realización Propia.

Se buscó que mencionaran el grado de importancia que tiene para ellos consumir tortilla de maíz elaborada en las tortillerías ubicadas en Santa Ana, Sonora. Un 55\% dijo que es de suma importancia, siendo el valor de mayor importancia (5) y un $28 \%$ comentó que no le tomaba mucha importancia (4), tal como se aprecia en la (Figura 7). 


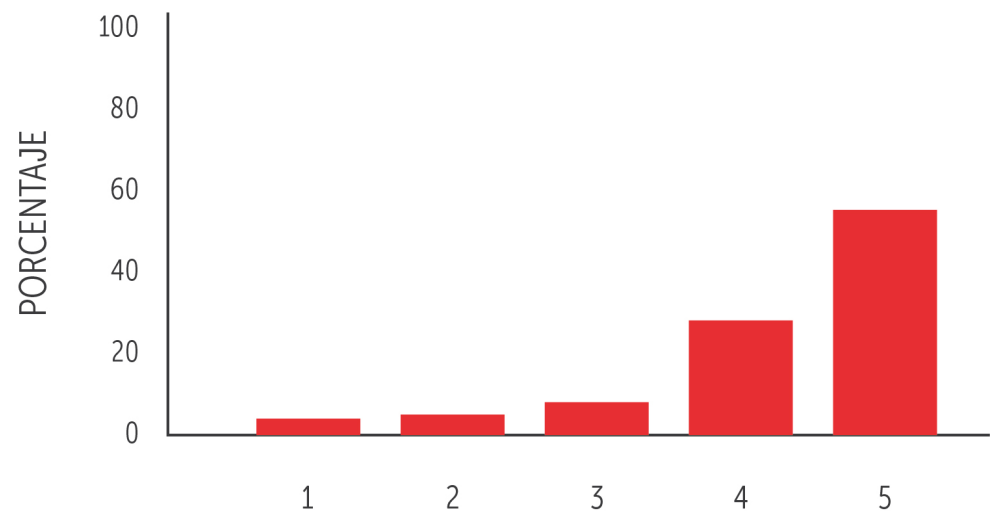

Figura 7. Importancia que tiene el consumir tortilla de maíz. Fuente: Realización Propia.

Como parte de este estudio se tomó en cuenta la satisfacción del consumidor mediante pruebas de degustación del producto elaborado por Tortillería "Isahi", donde 190 personas encuestadas admitieron estar satisfechos con el producto, 125 personas se encontraron totalmente satisfechas, 27 personas dijeron estar poco satisfechas y sólo 8 consumidores mencionaron estar insatisfechos (Figura 8).

Finalmente se les preguntó a los encuestados si propondrían algún cambio a la Tortillería "Isahi". El 33\% dijo que no harían ninguna modificación; el 30\% mencionó que la empresa debía considerar incluir otro sabor, como nopal y linaza; destacó también la recomendación de ofrecer otra presentación o más presentaciones del producto (25\%). En cuanto al volumen del producto por empaque y otros (12\%) opinaron que la empresa ofrece un buen producto en calidad, sabor y textura (Figura 9).

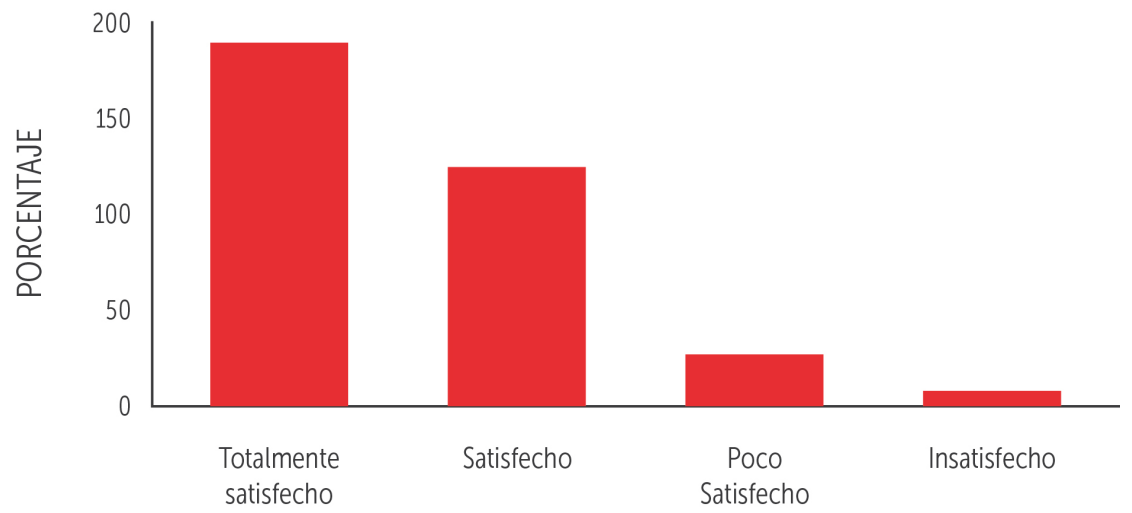

Figura 8. Grado de satisfacción con la calidad de la tortilla de maíz. Fuente: Realización Propia. 


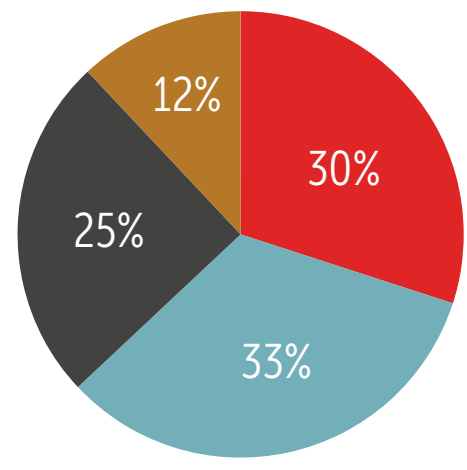

Incluir otro sabor

Ninguna modificación

Más presentaciones

Otros

Figura 9. Propuestas realizadas por los consumidores. Fuente: Realización Propia.

\section{Conclusiones}

Con base en los resultados obtenidos en esta investigación, se concluye que la edad no es un factor determinante para la adquisición y consumo de tortillas de maíz, debido a que según los encuestados al azar no hay gran influencia en los rangos de edades para consumirla. También se muestra que la tortilla de maíz que produce la empresa de este estudio se encuentra bien posicionada en el mercado local de consumidores, en donde los compradores demandan más la tortilla de maíz de mesa; así mismo, se demostró que más de la mitad de los encuestados adquieren este producto de una a cuatro veces por semana en la tortillería "Isahí" de Santa Ana, Sonora.

Respecto a los objetivos planteados se encontró que el factor más influyente en la adquisición de la tortilla de maíz es el sabor; de los atributos del producto el que más atrae a los compradores es la etiqueta, seguido del color. También se demostró que los lugares donde más compran estos productos es en las tortillerías y tiendas de abarrotes. Sobre lo que piensan los consumidores de la importancia de consumir tortillas de maíz, la mayoría de los encuestados comentó la razón primordial que los lleva a consumirla. De igual forma, a través de las encuestas se demostró que más de la mitad de estas personas han quedado satisfechas con la adquisición de este producto.

En lo que a la hipótesis se refiere, se ha podido comprobar, pues los factores más influyentes en la en la adquisición de la tortilla son el sabor y su textura.

Las recomendaciones realizadas en este estudio es que se incluyan nuevos sabores de tortilla, como nopal y linaza, ya que la empresa Tortillería "Isahí" está preparada para hacer las adecuaciones posibles en el producto y así satisfacer la demanda que los consumidores requieren, lo cual generaría un aumento en sus ventas. 
Los resultados implican un perfil del consumidor ligeramente por encima de las características que la tortilla de maíz en el mercado está manejando. Las empresas de este giro deben realizar ciertos cambios al producto para lograr satisfacer a un mayor número de consumidores, basados en las propuestas realizadas por ellos mismos: variedad en sabor y diferentes presentaciones en cuanto al contenido.

De igual forma, queda claro que existen clientes potenciales a los que quizá no se ha logrado satisfacer, pues buscan otro tipo de sabores o presentaciones que aún no se han introducido al mercado local. 


\section{Referencias Bibliográficas}

American Marketing Association (s.f.). Dictionary. Recuperado de http://www.marketingdictionary.org/ama

Pérez, C. (2012). La Esencia del marketing: Desde la fórmula secreta de Coca-Cola hasta Facebook y Barack Obama. Madrid: Imprintalia.

Ferrell, M., \& Hartline D. (2012). Estrategia de marketing. México: Cengage Learning.

Kotler, P., \& Armstrong, G. (2012). Marketing. México: Pearson Educación.

Kotler, P., \& Armstrong, G. (2013). Fundamentos de marketing. México: Pearson Educación.

Kotler, P., \& Keller, K. (2012). Dirección de marketing. México: Pearson Educación.

Thompson, A., Peteraf, M., Gamble, J., \& Strickland III A. J. (2012). Administración estratégica. México: McGraw-Hill.

Instituto Nacional de Estadística y Geografía (INEGI). (2010). XIII censo de población y vivienda 2010. Recuperado de http://www.inegi.org.mx/

MERCA 2.0 (2014, enero 22). Definición de Logotipo. Recuperado de http://www.merca20. com/definicion-de-logotipo

Münch, L., \& Ángeles, E. (1990). Métodos y técnicas de investigación. México: Trilllas.

Santesmases, M. (2012). Marketing: Conceptos y Estrategias. Madrid: Pirámide. 


\section{Capítulo 9}

La gestión financiera en las PyMES yucatecas de la industria textil Martha Isabel Bojórquez Zapata y Antonio Emmanuel Pérez Brito

\section{Introducción}

Las empresas familiares en la mayoría de los paises del mundo representan el principal motor de las economías (Klein, 2000; Morck y Nakamura, 2003; Lee, 2004; Astrachan y Shanker, 2003; Amat, 2004). En economías emergentes como la de México, las PyMES familiares representan prácticamente la mayoría del sector empresarial y se enfrentan a una serie de problemas estructurales que impiden el desarrolloy, por tanto, la permanenciay competitividad empresarial.

Durante los últimos años, ha surgido el interés por estudiar a las PyMES familiares ya que proveen ciertas ventajas competitivas, al estar más orientadas al consumidor, más enfocadas a la calidad y más activas dentro de las comunidades (Ibrahim, Angelidis y Parsa, 2008).

Aldrich y Cliff (2003) sostienen que cada negocio es un poco familiar y cada familia es un poco negocio. Las características que distinguen a las empresas familiares de aquellas que no lo son, radican en las peculiaridades relacionadas con la propiedad, el control y la gestión (Maseda, Iturralde y Arosa, 2009), así como la voluntad de estabilidad y perdurabilidad ante adversidades económicas. Naldi, Nordqvist, Sjöberg y Wiklund (2007) señalan que los dueños y los gestores son los mismos individuos o representan a la misma familia propietaria. LópezGracia y Sánchez-Andújar (2007) afirman que en una empresa familiar los roles de propietario y directivo recaen sobre la misma persona, y así se eliminan costos debido a la supresión de las relaciones de agencia, lo cual permite obtener una serie de ventajas que no poseen el resto de empresas no familiares. Para Esparza, García-Pérez y Duréndez, (2010) cuando más del $50 \%$ del capital es propiedad de la familia o grupo familiar, los puestos gerenciales o de dirección son ocupados al menos por un representante de esa familiar y existe continuidad en el negocio. Se considera que de 30 a 35 años, se produce un relevo generacional y que el $30 \%$ 
de las empresas familiares sobrevive a la segunda generación y únicamente el $13 \%$ a la tercera (Ward, 2004).

Según Ruelas (2008) citado en Esparza et al, (2010), más del 95\% de las empresas en América Latina son PyMES, de las cuales señala Belausteguigoitia (2010), que nueve de cada diez PyMES son familiares, y que suelen tener una vida más corta que las no familiares.

En opinión de Macías (2003), las PyMES son el principal generador de empleos, el mejor distribuidor de ingresos entre la población y entre las regiones.

Uno de los componentes fundamentales del sistema de gestión empresarial es la función financiera, encargada de la obtención y asignación de los recursos necesarios para el desarrollo de las operaciones del negocio, en el corto y largo plazo. En el caso de las PyMES, a medida que se logre un mayor uso y coordinación de las herramientas de gestión financiera puede lograrse un mejor desempeño, resultados superiores en materia de inversiones y acceso a fuentes variadas de financiamiento (Burk y Lehnman, 2004).

Para efectos conceptuales y operativos, se define la gestión financiera como un proceso empresarial, que parte de la formulación de la estrategia organizacional, y comprende el diseño de objetivos, selección de estrategias y políticas, ejecución de acciones y aplicación de mecanismos de control relacionados con las decisiones de inversión y financiamiento, en el corto y largo plazo (Brealey y Myers, 2005; Suárez, 2003). Una buena gestión financiera supone el conocimiento de las variables, tales como crecimiento en ventas, utilización de la información contable y financiera, los sistemas de control de gestión (SCG) y el rendimiento (Castán, 2005).

El objetivo de este trabajo consiste en analizar las principales diferencias en la gestión financiera en las PyMES familiares y no familiares de la industria textil del estado de Yucatán, tomando en consideración variables, tales como crecimiento en ventas, utilización de información contable y financiera e implementación de los sistemas de control de gestión (SCG), como factores estratégicos y sostenibles de competitividad empresarial. Para desarrollar este trabajo se realizó un estudio empírico de corte transversal del ejercicio 2012, con una muestra de 24 familiares y no familiares, de la industria textil yucateca.

Esta investigación se presenta organizada como sigue. En la sección de revisión de literatura se plantean los argumentos que sustentan los conceptos de industria textil, gestión financiera, crecimiento y sistemas de control de gestión (SCG). Posteriormente se presenta la metodología que se aplicará, en donde se describe el procedimiento para la correlación de las variables con el fin de identificar la importancia en la competitividad en las PyMES de la industria textil en el estado de Yucatán, México. Finalmente, se presentan los resultados esperados de la investigación, el alcance y las limitaciones. 


\section{Revisión teórica}

La industria textil en la nueva configuración de la división internacional del trabajo ha derivado de la creciente importancia del comercio internacional y con ello de las exportaciones como motor del crecimiento y desarrollo, principalmente de los países en desarrollo. La estrategia exportadora de estas naciones funcionó como un mecanismo de desarrollo económico, principalmente por los bajos salarios pagados, lo cual implica bajos costos de producción. Actualmente, este mecanismo no es suficiente para alcanzar un crecimiento económico, mucho menos ser competitivo en el mercado mundial. Ahora, es necesario desarrollar una estrategia para apoyar aquellos sectores que generan mayor valor agregado, la cual permita una especialización que los haga ser competitivos en el mercado mundial, aprovechando de esta manera las oportunidades de acceso al mercado mundial y acelerando la extensión de redes de distribución de forma global (Aguilar, 2005).

En México, en la actualidad, el avance de la industria textil depende de la aplicación de la informática y el continuo perfeccionamiento de los insumos. Los nuevos tipos de fibras artificiales (que hacen más confortables las prendas de vestir) han contribuido a modificar el diseño del equipo y maquinaria, tanto para productos en masa, como para la alta moda (Secretaría de Economía, 2011), y a la vez ha mejorado la producción dirigida hacia la exportación.

Entonces ¿cuáles han sido los factores que han permitido la inserción de la industria textil mexicana en el mercado mundial?

La competitividad de la industria textil mexicana, principalmente en las empresas familiares, se ha sustentado en los bajos salarios y bajos costos de producción, deficiente gestión financiera, lo que al final no refleja un aumento de la competitividad, sino más bien, un mecanismo temporal de competitividad. Mientras no incorporen nuevas tecnologías al proceso productivo, no se logrará aumentar la competitividad de la industria, en el contexto de la globalización (Secretaría de Economía, 2011).

La industria del vestido es un sector estratégico a nivel nacional por la importante contribución a la producción: 5\% del PIB manufacturero y 1\% del nacional (INEGI, 2012). Esta cadena es la séptima actividad económica por la contribución al PIB manufacturero: más de 76 mil 465 millones de pesos (INEGl, 2012). Respecto a la contribución a las exportaciones: \$5,107 mdd, $2 \%$ de las exportaciones manufactureras totales (Administración General de Aduanas, 2012). Respecto a la contribución a la Balanza comercial: más de $\$ 3,000$ mdd de superávit (Administración General de Aduanas, 2012). Además, es el quinto proveedor en Estados Unidos (Office of Textiles and Apparel, 2012). 
La llegada a Yucatán de empresas maquiladoras ligadas a corporativos transnacionales fue motivada por la firma del Tratado de Libre Comercio de América del Norte (TLCAN). Las "ventajas" que ofrecía el estado de Yucatán se basaban en la posición geográfica y mano de obra barata (Alonzo, 2011).

Schumpeter (1990) reconoce que para crecer en la empresa requiere de una buena gestión financiera empresarial, y para Machado (1999) para una adecuada gestión empresarial es importante la información contable y financiera.

El crecimiento de las empresas familiares se ve influenciado, principalmente, por los objetivos, las metas del negocio y las prácticas de gestión que persigue el grupo familiar y también por los diferentes resultados que generan en el respectivo desarrollo. Este planteamiento se basa en la teoría de la agencia que sugiere que los gestores ajenos a la familia persiguen objetivos personales diferentes a los que mantienen los propietarios de la empresa, de tal forma, que los directivos pueden anteponer el objetivo de crecimiento sobre el de rentabilidad (Fama, 1980).

En el Reino Unido, Cromie, Dunn, Sproull y Chalmers (2001), señalaron que existe un conflicto de intereses entre la eficiencia del negocio y el interés de las familias en la empresa, lo que da como resultado una baja en el crecimiento.

En México, Esparza et al, (2010) en un estudio en las PyMES del sector turístico señalaron que no se encontraron disimilitudes relevantes entre el crecimiento de las empresas familiares y las no familiares.

Las empresas familiares prefieren mantener el control de la empresa aún si esto afecta negativamente el propio crecimiento de la empresa (Gallo, Tápies y Cappuyns, 2004), y García (2008) comenta que en México no hay facilidades para el crecimiento de las pequeñas empresas.

El rendimiento de las empresas familiares, a través de la implementación y utilización de los sistemas de control de gestión (SCG), también juega un rol importante, pues se convierten en herramientas prioritarias que los gerentes deberían adoptar para planear, presupuestar, analizar, medir y evaluar información útil para la adecuada toma de decisiones (Dávila y Foster, 2005; Duhan, 2007).

Widener (2007) menciona que el propósito primordial de los SCG es basarse en una forma de control como las medidas de rendimiento, así como en múltiples sistemas de control trabajando de manera conjunta y que tienen la finalidad de proveer información útil para planificar, evaluar y tomar decisiones. Dávila y Foster (2005) mencionan que son una herramienta de gestión que permite planear, presupuestar, analizar, medir y evaluar la información contable y financiera. Abdel y Luther (2008) indican que los SCG ayudan a 
la dirección en la capacidad del sistema de la organización, de información relevante para planear, supervisar, tomar decisiones, crear e incrementar valor.

En cuanto a los SCG y el rendimiento, Dávila (2000) relaciona positivamente el uso con la innovación y el rendimiento de la empresa. Bisbe y Otley (2004) con una muestra de empresas españolas, obtienen que cuanto mayor sea el uso, mayor es el efecto de la innovación sobre el rendimiento de las pequeñas y medianas empresas.

\section{Metodología y datos}

El trabajo de investigación se realizó con información que se obtuvo de las PyMES de la industria textil del estado de Yucatán, del ejercicio 2011.

Con base en los datos proporcionados por la Cámara Nacional de la Industria del Vestido (CANAINVES), delegación Yucatán, la población queda conformada por 26 empresas PyMES del sector textil con un mínimo de 11 trabajadores y un máximo de 250. Por lo tanto, el tamaño de la muestra debe ser de 24 encuestados. El tamaño de las PyMES se encuentra establecido en los criterios de estratificación de empresas publicado en el Diario Oficial de la Federación con fecha 30 de junio de 2009. La fórmula que se utilizó para obtener el tamaño de la muestra es la de estimación de intervalo de la proporción poblacional finita. Se consideró una probabilidad de $p=q=0.50$, una población de 26 empresas a un nivel de confianza del $95 \%$ y un error muestral del $5 \%$. La selección se hizo a través de un proceso aleatorio.

Considerando el tipo de fenómeno que se investigó, se empleó el enfoque cuantitativo, correlacional, no experimental, transversal y se realizó un análisis estadístico aplicando la prueba U de Mann Whitney, la prueba de bondad de ajuste de Kolmogorov-Smirnov y, para la corroborar los datos obtenidos, se aplicó el método de Monte Carlo para la hipótesis 1.

Con respecto al análisis de la relación entre variables $(\mathrm{H} 2)$ se revisó dicha relación mediante los coeficientes de correlación Tau-b de Kendall y $r$ de Pearson, considerando su naturaleza ordinal acumulativa.

La bondad del ajuste se mide por el coeficiente de correlación múltiple (R), que varía entre 0 y 1 , mientras que el coeficiente de determinación es R2 y expresa la proporción de la varianza de la variable dependiente explicada (Kazmier, 1998).

En el caso en que se cumplió el supuesto de normalidad (H3) se aplicaron pruebas t acompañadas del método de Monte Carlo, nuevamente para corroborar los resultados obtenidos. Este método es un proceso de simulación que permite calcular probabilidades y otras cantidades relacionadas a partir de muestras aleatorias obtenidas a partir de la información disponible. A partir de los resultados de la simulación es posible efectuar pruebas estadísticas que pueden aplicarse en el caso de no cumplirse los supuestos de la estadística 
paramétrica y no paramétrica. Este tipo de pruebas se denominan pruebas exactas. El empleo de las pruebas exactas, como las obtenidas a partir de dicho método es una alternativa que concibe resultados más generales que la estadística tradicional, pero que son de utilidad en las tareas de investigación.

Para la obtención de datos y para determinar la existencia de relaciones de causa y efecto entre los fenómenos del estudio se utilizó una encuesta (Hernández, Fernández y Baptista, 2006; Díaz de Rada, 2007). El instrumento de medición seleccionado fue el cuestionario estructurado, en dos bloques de 10 preguntas dirigido directamente a los gerentes de las empresas. Las solicitudes para contactar a los entrevistados se hicieron a través de llamadas telefónicas y por correo electrónico, logrando un total de 24 citas, validadas en su totalidad. El trabajo de campo se realizó durante los meses de marzo y abril de 2013, en dos ciudades textiles del estado de Yucatán.

Para efectos de este trabajo, la descripción de variables es la siguiente: la variable dependiente es la empresa familiar y la independiente, el crecimiento en ventas.

Se considera empresa familiar cuando más del $50 \%$ del capital es propiedad de la familia o grupo familiar, los puestos gerenciales o de dirección son ocupados al menos por un representante de esa familiar y existe continuidad en el negocio (Esparza et al., 2010).

El crecimiento se midió en ventas de la empresa de un año a otro a través de una escala por intervalos. Esta variable se utilizó en otros trabajos de investigación de autores como López-Gracia y Sánchez-Andújar (2007) y Esparza et al. (2010).

Las empresas investigadas están constituidas por 14 personas físicas, que representan el $58.3 \%$ y por 10 personas morales, el $41.7 \%$.

\section{Análisis de resultados}

De acuerdo con las hipótesis de la investigación, los resultados son los siguientes: (H1): Las PyMEs familiares de la industria textil en Yucatán tienen menor crecimiento en ventas que las no familiares.

Análogamente, con relación a $\mathrm{H} 1$ se encontraron diferencias significativas en los niveles de crecimiento en ventas que presentaron las empresas familiares y las no familiares (valor $p=0.051$ en la prueba $U$ de Mann Whitney, valor $p=0.040$ en la prueba exacta de Monte Carlo) como se indica en el cuadro 1. De acuerdo con los valores medios observados, el nivel de crecimiento en ventas de las empresas no familiares es mayor, corroborándose así la hipótesis de investigación. 


\begin{tabular}{|c|c|c|c|}
\hline \multicolumn{3}{|c|}{ 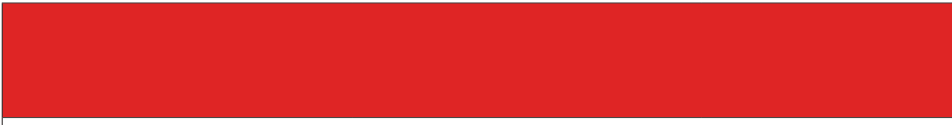 } & $\begin{array}{c}\text { Crecimiento } \\
\text { en ventas }\end{array}$ \\
\hline \multicolumn{3}{|c|}{ U de Mann-Whitney } & 4.500 \\
\hline \multicolumn{3}{|l|}{ W de Wilcoxon } & 257.500 \\
\hline \multicolumn{3}{|l|}{ Z } & -1.949 \\
\hline \multicolumn{3}{|c|}{ Sig. asintót. (bilateral) } & .051 \\
\hline \multicolumn{3}{|c|}{ Sig. exacta [2*(Sig. unilateral)] } & $.065(a)$ \\
\hline \multirow{3}{*}{$\begin{array}{l}\text { Sig. Monte Carlo } \\
\text { (bilateral) }\end{array}$} & Sig. & & $.040(b)$ \\
\hline & \multirow{2}{*}{$\begin{array}{l}\text { Intervalo de } \\
\text { confianza de 95\% }\end{array}$} & Límite Inferior & .036 \\
\hline & & Límite superior & .044 \\
\hline \multirow{3}{*}{$\begin{array}{l}\text { Sig. Monte Carlo } \\
\text { (unilateral) }\end{array}$} & Sig. & & $.040(b)$ \\
\hline & \multirow{2}{*}{$\begin{array}{l}\text { Intervalo de } \\
\text { confianza de 95\% }\end{array}$} & Límite Inferior & .036 \\
\hline & & Límite superior & .044 \\
\hline
\end{tabular}

a No corregidos para los empates.

b Basado en 10,000 tablas muestrales con semilla de inicio 1,573,343,031.

c Variable de agrupación: Control mayoritario familiar.

Tabla 1. Prueba U de Mann Whitney y prueba exacta de Monte Carlo para crecimiento en ventas de las PyMES familiares y no familiares. Fuente: Elaboración propia con base en los datos de la encuesta (2012).

$\left(\mathrm{H}_{2}\right)$ : Existe una relación positiva entre la utilización de la información contable y financiera de las PyMES familiares de la industria textil en Yucatán y su rendimiento.

Con relación a $\mathrm{H}_{2}$, puede afirmarse que existe una relación positiva, es decir, directa entre la utilización de la información contable y financiera de las PyMES familiares de la industria textil en Yucatán y su rendimiento, ya que se obtuvo un valor de 0.748 (valor $p=0.000$ ), para el coeficiente de correlación Tau-b de Kendall y 0.853 para el coeficiente de correlación de Pearson (valor $p=0.000$ ). Esto puede ser observado en el Cuadro 2. 


\begin{tabular}{|c|c|c|c|c|}
\hline \multicolumn{3}{|c|}{$\begin{array}{ll}\text { Correlaciones } \\
\end{array}$} & \multirow[b]{2}{*}{$\begin{array}{l}\text { Empleo de } \\
\text { información } \\
\text { contable y } \\
\text { financiera }\end{array}$} & \multirow[b]{2}{*}{ Rendimiento } \\
\hline & & & & \\
\hline \multirow{3}{*}{\multicolumn{2}{|c|}{$\begin{array}{l}\text { Empleo de información } \\
\text { contable y financiera }\end{array}$}} & Correlación de Pearson & 1 & $.853(* *)$ \\
\hline & & Sig. (bilateral) & & 0 \\
\hline & & N & 22 & 22 \\
\hline \multirow{3}{*}{\multicolumn{2}{|c|}{ Rendimiento }} & Correlación de Pearson & $.853(* *)$ & 1 \\
\hline & & Sig. & 0 & \\
\hline & & $\mathrm{N}$ & 22 & 22 \\
\hline \multirow{6}{*}{$\begin{array}{l}\text { Tau_b de } \\
\text { Kendall }\end{array}$} & \multirow{3}{*}{$\begin{array}{l}\text { Empleo de } \\
\text { información conta- } \\
\text { ble y financiera }\end{array}$} & Coeficiente de correlación & 1 & $.748(* *)$ \\
\hline & & Sig. (bilateral) & . & 0 \\
\hline & & $\mathrm{N}$ & 22 & 22 \\
\hline & \multirow{3}{*}{ Rendimiento } & Coeficiente de correlación & $.748\left(^{* *}\right)$ & 1 \\
\hline & & Sig. (bilateral) & 0 & . \\
\hline & & $\mathrm{N}$ & 22 & 22 \\
\hline \multirow{6}{*}{$\begin{array}{l}\text { Rho de } \\
\text { Spearman }\end{array}$} & \multirow{3}{*}{$\begin{array}{l}\text { Empleo de infor- } \\
\text { mación contable y } \\
\text { financiera }\end{array}$} & Coeficiente de correlación & 1 & $.886\left(^{* *}\right)$ \\
\hline & & Sig. (bilateral) & & 0 \\
\hline & & $\mathrm{N}$ & 22 & 22 \\
\hline & \multirow{3}{*}{ Rendimiento } & Coeficiente de correlación & $.886(* *)$ & 1 \\
\hline & & Sig. (bilateral) & 0 & . \\
\hline & & $\mathrm{N}$ & 22 & 22 \\
\hline
\end{tabular}

**La correlación es significativa al nivel 0.01 (bilateral).

Tabla 2. Coeficiente de correlación de Pearson y Tau-b de Kendall para la relación entre información contable y financiera y rendimiento de las PyMES familiares.

Fuente: Elaboración propia con base en los datos de la encuesta (2012). 
$\left(H_{3}\right)$ : Las PyMES familiares de la industria textil en Yucatán tienden a implementar en menor medida los sistemas de control de gestión (SCG) que las no familiares.

Con respecto a $\mathrm{H}_{3^{\prime}}$ considerando que en este caso se corroboró el cumplimento del supuesto de normalidad de las variables objeto de estudio, como se muestra en el cuadro 3, los resultados de las Pruebas t para muestras independientes aplicadas señalan que no se presentan diferencias significativas en la amplitud (valor $p=0.559$ ), oportunidad (valor $p=$ 0.388 ), agregación (valor $p=0.332$ ) o integración (valor $p=0.334$ ) del SCG de las empresas familiares y las no familiares que declararon contar con él, incluso con relación al resultado global que registra el acumulado de estos aspectos (valor $p=0.784$ ).

\begin{tabular}{|c|c|c|}
\hline \multicolumn{2}{|c|}{ Prueba de muestras independientes } & \multirow{3}{*}{$\begin{array}{c}\text { Prueba T para la } \\
\text { igualdad de medias } \\
\text { Sig. (bilateral) }\end{array}$} \\
\hline & & \\
\hline & & \\
\hline \multirow{2}{*}{ Amplitud } & Se han asumido varianzas iguales & 0.559 \\
\hline & No se han asumido varianzas iguales & 0.377 \\
\hline \multirow{2}{*}{ Oportunidad } & Se han asumido varianzas iguales & 0.388 \\
\hline & No se han asumido varianzas iguales & 0.46 \\
\hline \multirow{2}{*}{ Agregación } & Se han asumido varianzas iguales & 0.332 \\
\hline & No se han asumido varianzas iguales & 0.167 \\
\hline \multirow{2}{*}{ Integración } & Se han asumido varianzas iguales & 0.334 \\
\hline & No se han asumido varianzas iguales & 0.547 \\
\hline \multirow{2}{*}{$\begin{array}{l}\text { Resultado } \\
\text { Global Acumulado }\end{array}$} & Se han asumido varianzas iguales & 0.784 \\
\hline & No se han asumido varianzas iguales & 0.683 \\
\hline
\end{tabular}

Tabla 3. Prueba T para la igualdad de medias para distintos aspectos de la implementación del Sistema de Control de Gestión de PyMES familiares y no familiares. Fuente: Elaboración propia con base en los datos de la encuesta (2012).

\section{Conclusiones}

Las empresas de la industria textil en Yucatán tienen en su mayoría una antigüedad de diez años y se encuentran bajo la dirección y la propiedad de la primera generación, por lo que es importante en estos momentos encontrar mecanismos que permitan la permanencia de las mismas en el largo plazo y evitar como señala Ward (2004), que estén en el $70 \%$ de las que no sobreviven al primer relevo generacional. 
La personalidad jurídica de las PyMES de la industria textil en Yucatán es mayormente la de personas físicas. Esto posiblemente tenga relación con la simplificación tributaria que se tiene a diferencia de las personas morales, igualmente coincide con lo mencionado por autores como Naldi et al. (2007), que señalaron que una misma persona es el que aparece como dueño y es quien toma decisiones administrativas y operativas del negocio.

El crecimiento en ventas de las empresas familiares se ha mantenido constante a diferencia de las no familiares que sí han obtenido un crecimiento, lo cual está contemplado dentro de la teoría de la agencia que sugiere que los gestores ajenos a la familia persiguen objetivos personales diferentes a los que mantienen los propietarios de la empresa, de tal forma, que los directivos pueden anteponer el objetivo de crecimiento sobre el de rentabilidad (Fama, 1980). Así como con los resultados obtenidos por autores como Cromie et al. (2001) y Gallo et al. (2004). Este nulo crecimiento en ventas en las PyMES familiares se comprueba con la inexistente creación de nuevas fuentes de empleo, de acuerdo a lo observado en la sección de resultados. De esta manera se reproduce incesantemente el círculo vicioso: a menores ingresos, producto del desempleo y la baja remuneración, menor capacidad de compra por parte de la mayoría de la población; a menor demanda, menores posibilidades de generar nuevos empleos mediante la expansión del aparato productivo; a menor de demanda de fuerza laboral mayor desempleo y empeoramiento de las condiciones de vida de la población, dejando la generación de empleos en manos de las grandes empresas.

De acuerdo con los resultados obtenidos con respecto a los sistemas de control de gestión, se desconoce la aplicación para una eficaz y eficiente toma de decisiones de herramientas, tales como el balance general, el estado de resultados, el estado de flujo de efectivo, las conciliaciones bancarias, los presupuestos, el flujo de efectivo pronosticado, análisis de indicadores y de tendencias del sectory el punto de equilibrio. Todo lo anteriormente señalado conllevará a problemas de planeación financiera a corto plazo: (1) carencia de efectivo, (2) exceso en inversión de cuentas por cobrar, (3) exceso de inversión en inventarios, (4) deficiencias en las negociaciones de financiamiento a corto plazo, entre otros; y en el largo plazo: (1) inversiones improductivas u obsoletas, (2) compromisos de amortización de deudas fuera de la capacidad financiera de la empresa, y (3) capital contable inapropiado para el desarrollo del negocio, entre otros.

Dentro de las limitaciones, cabe destacar la dificultad de los empresarios para conceder la información de las empresas, la representatividad geográfica al ser un estudio regional, así como la falta de bases de datos económicos de las empresas estudiadas.

Este estudio realizado en Yucatán sobre las PyMES familiares y no familiares en la industria textil muestra resultados de la gestión financiera que no han sido estudiados 
anteriormente en el medio, bajo el enfoque de competitividad empresarial, razón por la cual lo hace realmente original. La importancia radica en que el sector textil más competitivo llevará a la mejora económica en la región, un desarrollo humano sostenible y una integración social, económica y ambiental, que involucra la creación de valor económico de una manera que también crea un valor para la sociedad.

Se puede sugerir futuras investigaciones relacionadas con este sector que abrirían temas específicos como el crecimiento de las ventas y la aplicación de gestión vinculados a la competitividad y la gestión familiar a través de estudios cuantitativos y cualitativos, los sistemas de control, ya que en México existen pocos estudios sobre estos temas. Este estudio contribuye a mejorar aún más la literatura de investigación relacionadas con las empresas familiares, en general, y las empresas familiares en México, en particular. Con respecto a las instituciones de educación superior, se deben considerar los resultados obtenidos para actualizar los programas de estudio, así como ofrecer cursos de capacitación en gestión financiera. 


\section{Referencias Bibliográficas}

Abdel, M., \& Luther, R. (2008). The impact of firm characteristics on management accounting practices: A UK-based empirical analysis. The British Accounting Review. 40, 2-27.

Administración General de Aduanas (2012). Consultado en www.aduanas.gob.mx

Aguilar, M. (2005). La competitividad de la industria textil en México en un contexto de globalización 1985-2003. Tesis de licenciatura. Benemérita Universidad de Puebla, Puebla.

Aldrich, H., \& Cliff, J. (2003). The pervasive effects of family on entrepreneurship: toward a family embeddedness perspective. Journal of Business Venturing. 18, 573-596.

Alonzo, F. (2011). Evolución de la industria del vestido en Yucatán en el marco de las cadenas globales de valor. Revista de Economía. 76 (28), 1-8.

Amat, J. (2004). La sucesión en la empresa familiar. España: Colección del Instituto de la Empresa Familiar.

Astrachan, J., \& Shanker, M. (2003). Family Businesses' contribution to the U.S. Economy: A closer look. Family Business Review. 16 (3), 211-219.

Belausteguigoitia, I. (2010). Empresas Familiares, su dinámica, equilibrio y consolidación. México: McGraw-Hill.

Bisbe, J., \& Otley, D. (2004). The effects of the interactive use of management control systems on product innovation. Organizations and Society. 29, 709-37.

Brealey, R., \& Myers, S. (2005). Principios de finanzas corporativas. México: McGraw-Hill.

Burk, J., \& Lehman, R. (2004). Financing Your Small Business. From SBA Loans \& Credit Cards to Common Stock \& Partnership Interests. Illinois: Sphinx Publishing.

Castán, J. (2005). Fundamentos y aplicaciones de la gestión financiera de la empresa. España: Pirámide. 
Chenhall, R. (2003). Management control system design within its organizational context: Findings from contingency-based research and directions for the future. Organizations and Society. 2 (2), 127-168.

Cromie, S., Dunn, B., Sproull, A., \& Chalmers, D. (2001). Small Firms with a Family Focus in the Scottish Highlands and Islands. The Irish Journal of Management. 2 (22), 45-66.

Dávila, A. (2000). An empirical study on the drivers of management control systems design in new product development. Organizations and Society. 25, 383-410.

Dávila, A., \& Foster, G. (2005). Management Accounting Systems Adoptions Decisions: Evidence and Performance Implications from Early-Stage/Startup Companies. The Accounting Review. 80 (4), 1039-1068.

Díaz de Rada, V. (2007). Tipos de encuestas considerando la dimensión temporal. Revista de Sociología. 86, 131-145.

Duhan, S. (2007). A capabilities based toolkit for strategic information systems planning in SMEs. International Journal of information Management. 27, 352-367.

Esparza, J., García-Pérez, D., \& Duréndez, G. (2010). Diferencias de gestión familiar entre empresas familiares y no familiares del sector turístico mexicano. Actualidad Contable. 20, 29-48.

Fama, E. (1980). Agency Problems and the Theory of the Firm. Journal of Political Economy. 2 (88), 288-307.

Gallo, M., Tápies, J., \& Cappuyns, K. (2004). Comparison of Family and Nonfamily Business: Financial Logic and Personal Preferents. Family Business Review. 4 (17), 303-318.

García, J. (2008). Mypimes out. Cómo afrontar los principales errores contables yadministrativos del sector. Consultoría. Industria del conocimiento. 11, 46-48.

Hernández, R., Fernández, C., \& Baptista, P. (2006). Metodología de la investigación. México: McGraw-Hill. 
Ibrahim, N., Angelidis, J., \& Parsa, F. (2008). The status of planning in small businesses. American Business Review. 22 (2), 52-60.

Instituto Nacional de Estadística y Geografía (INEGI). (2012). Recuperado de http://www.inegi. org.mx

Kazmier, L. (1998). Estadística aplicada a la Administracióny a la Economía. México: McGraw-Hill.

Klein, S. (2000). Family Businesses in Germany: Significance and Structure. Family Business Review. 13 (3), 157-181.

Lee, J. (2004). The Effects of Family Ownership and Management on Firm Performance. Advanced Management Journal. 69, 4-12.

López-Gracia, J., \& Sánchez-Andújar, S. (2007). Financial Structure of the Family Business: Evidence from a Group of Small Spanish Firms. Family Business Review. 20 (4), 269-287.

Machado, M. (1999). El complejo objeto de estudio de la contabilidad: por la vía constructiva. Revista Contaduría. 36, 17-47.

Macías, S. (2003). La importancia de las PyMES para el mercado mexicano. Recuperado de http://compite.org.mx

Maseda, A., Iturralde, T., \& Arosa, B. (2009). Situación de la empresa familiar en el territorio histórico de Bizkaia. Ponencia presentada al XXIII Congreso Anual y XIX Hispano Francés de la Academia Europea de Dirección y Economía de la Empresa (AEDEM). España: ESIC.

Morck, R., \& Nakamura, M. (2003): The history of corporate ownership in Japan. Finance Working, European Corporate Governance Institute. 20, 1-143.

Naldi, L., Nordqvist, M., Sjöberg, K., \& Wiklund, J. (2007). Entrepreneurial orientation, risk taking, and performance in family firms. Family Business Review, 20 (1), 33-47.

Office of Textiles and Apparel (OTEXA). (2012). Recuperado de http://www.otexa.ita.doc.gov 
Otley, D. (1980). Contingency Theory of Management Accounting: Achievement and Prognosis. Accounting Organizations and Society. 5 (4), 413-428.

Secretaría de Economía (2011). Directorio IMMEX. Disponible en http://www.economia.gob.mx

Schumpeter, J. (1990). Essays on entrepreneurs, innovations, business cycles, and the evolution of capitalism. The Journal of Economic History. 50, 246-247.

Suárez, A. (2003). Decisiones óptimas de inversión y financiación en la empresa. España: Pirámide.

Tiessen, P., \& Waterhouse, J.H. (1983). Towards a descriptive theory of management accounting. Organizations and Society. 8 (2), 251-267.

Ward, J. (2004). Tensión y fracaso empresarial. Iniciativa emprendedora y Empresa Familiar. 26, 38-41.

Widener, S. (2007). An empirical analysis of the levers of control framework. Organizations and Society. 32, 757-788. 
Estudios de Competitividad

ISBN 978-607-96359-3-0

DOI 10.29410/QTP.15.02

Esta publicación digtal se terminó de producir en Noviembre 2015.

Su edición y diseño estuvieron a cargo de:

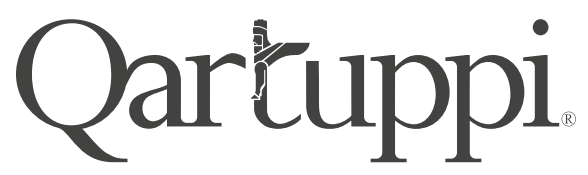

Qartuppi, S. de R.L. de C.V.

http://www.qartuppi.com 


\section{(c) (i) (8)}

BY NC

Esta obra está bajo una Licencia Creative Commons

Reconocimiento-NoComercial 4.0 Internacional.

https://creativecommons.org/licenses/by-nc/4.0/deed.es 


\section{Estudios de Competitividad}

Este libro es el resultado de la participación de investigadores de universidades de México y Colombia, quienes abordan temas referentes al marco contextual de la empresa, vinculadas con la generación de ventajas competitivas. Es un esfuerzo conjunto para asegurar que los capítulos que la componen impacten positivamente, transmitiendo las ideas y análisis de los académicos participantes.

Qartuppi.

ISBN 978-607-96359-3-0

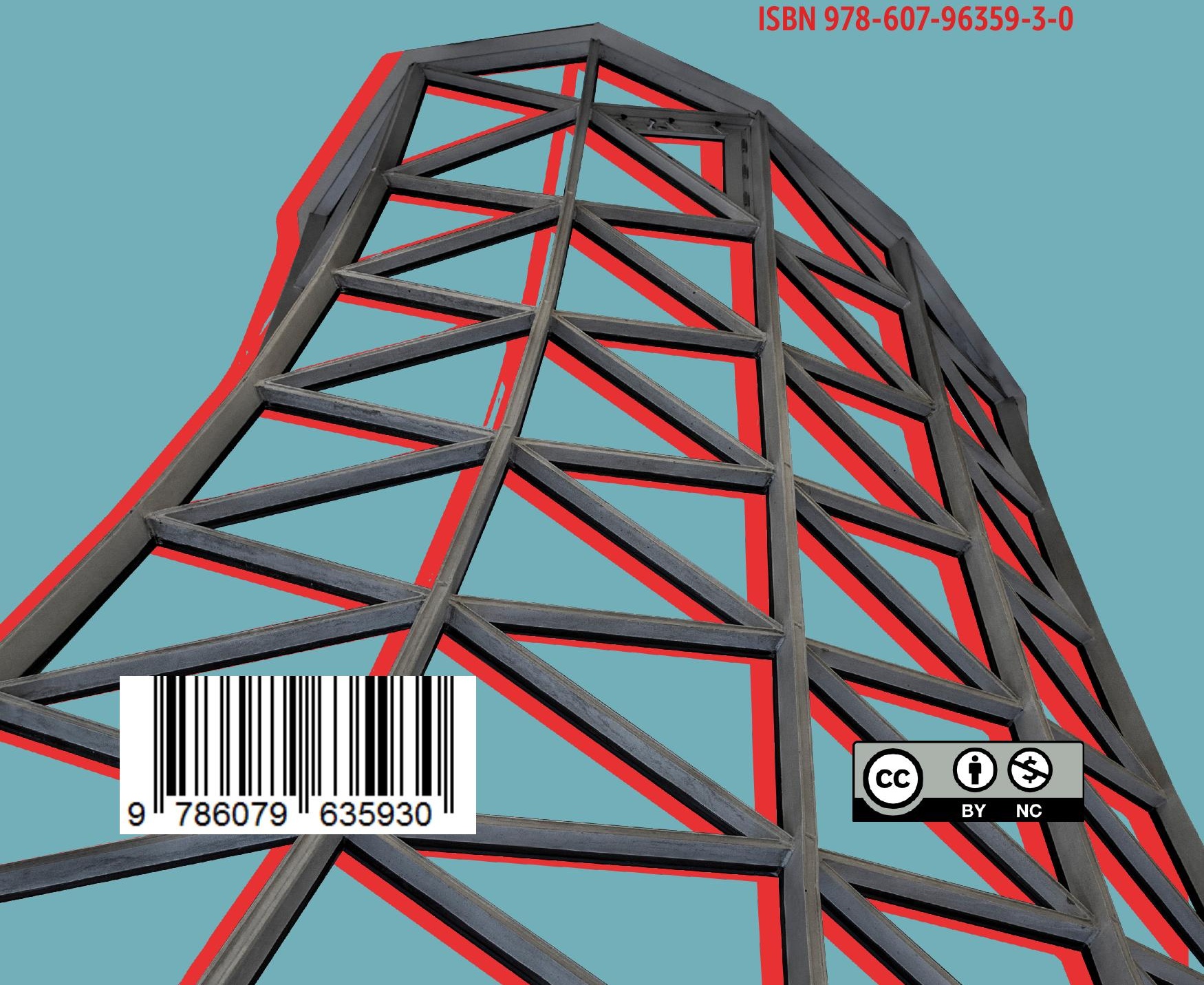

